\title{
Electrokinetically-Enhanced Emplacement of Lactate in a Chlorinated Solvent Contaminated Clay Site to Promote Bioremediation
}

Ainsley M. Inglis, The University of Western Ontario

Supervisor: Gerhard, Jason I., The University of Western Ontario

Joint Supervisor: O'Carroll, Denis M., The University of Western Ontario

A thesis submitted in partial fulfillment of the requirements for the Master of Engineering Science degree in Civil and Environmental Engineering

(C) Ainsley M. Inglis 2018

Follow this and additional works at: https://ir.lib.uwo.ca/etd

Part of the Environmental Engineering Commons

\section{Recommended Citation}

Inglis, Ainsley M., "Electrokinetically-Enhanced Emplacement of Lactate in a Chlorinated Solvent Contaminated Clay Site to Promote Bioremediation" (2018). Electronic Thesis and Dissertation Repository. 5600.

https://ir.lib.uwo.ca/etd/5600

This Dissertation/Thesis is brought to you for free and open access by Scholarship@Western. It has been accepted for inclusion in Electronic Thesis and Dissertation Repository by an authorized administrator of Scholarship@Western. For more information, please contact wlswadmin@uwo.ca. 


\begin{abstract}
Bioremediation through the injection of electron donors and bacterial cultures is effective at treating chlorinated solvent contamination but faces limitations in low permeability zones where the injected amendments cannot be delivered successfully. Using electrokinetics in combination with bioremediation to enhance the delivery of amendments was tested at a chlorinated solvent contaminated field site, where lactate was injected into clay under a direct current. Advection at locations with higher hydraulic conductivities contributed to lactate transport and dilution of aqueous chlorinated solvents. There was evidence of successful delivery of lactate by electromigration (EM) in all monitoring locations with EM lactate transport rates between 1.3 to $3.0 \mathrm{~cm} /$ day. Lactate emplacement resulted in the stimulation of bacterial populations and evidence suggests some biodegradation of chlorinated solvents was observed on site. This research provides evidence that with further field investigation, electrokinetically-enhanced bioremediation has potential as a treatment strategy for contaminated low permeability strata.

\section{Keywords}

Electrokinetics, bioremediation, lactate, clay, chlorinated solvents, field study, bacterial community structure, anaerobic degradation 


\section{Co-Authorship Statement}

This thesis was written by the candidate in accordance with the guidelines and regulations as stipulated by the Faculty of Graduate Studies at the University of Western Ontario. The candidate assisted in field study implementation and conducted sampling, analysis and interpretation of data under co-supervision of Dr. Denis O'Carroll and Dr. Jason Gerhard. The co-authorship of Chapter 3 is as follows:

Chapter 3: Electrokinetically-enhanced emplacement of lactate in a chlorinated solvent contaminated clay site to promote bioremediation.

Authors: Ainsley Inglis, Nicholas Head, Ariel Nunez Garcia, Ahmed Chowdhury, Jason Gerhard, Denis O’Carroll.

A. Inglis Assisted in implementation of field study, performed sampling, data collection and analysis, specifically analysis of cVOCs using GC and analysis of DNA using qPCR and metagenomic sequencing, interpreted field study results, and wrote chapter drafts.

N. Head Assisted in implementation of field study, performed sampling, and analysis of dissolved organic carbon, metals and anions, assisted in interpretation of field study results.

A. N. Garcia Assisted in sampling, provided training on analysis of cVOCs using the GC and provided insight on data.

A. Chowdhury Assisted in sampling and provided insight on data interpretation.

D. O'Carroll Initiated research topic, supervised field study, assisted in data interpretation and reviewed/revised draft chapters.

J. Gerhard Supervised field study, assisted in data interpretation and reviewed/revised draft chapters. 


\section{Acknowledgments}

First, I would like to thank my supervisors, Dr. Jason Gerhard and Dr. Denis O'Carroll for all the support they have provided me with during this time. This research would not have been possible without their guidance.

Thank you to the entire RESTORE research group for making this experience truly enjoyable and for the supportive atmosphere that helped motivate me. Special thanks to Nicholas Head for all his contributions while working by my side on this field trial for the past 2 years. His involvement was key to the completion of this research. Thanks also to Dr. Ahmed Chowdhury and Ariel Núñez García for their assistance in the field and lab as well as the many discussions in regards to the project.

I also want to thank Dr. Elizabeth Edwards and members of her research group at the University of Toronto who welcomed me into their labs, in particular Line Lomheim for providing guidance and training while I was there. Also, thanks to Dr. Kela Weber for providing access to an Illumina MiSeq at RMCC and to Sarah Wallace for training and assisting me on this.

Thank you to our industry partners Geosyntec Consultants, Jacobs, and the Dow Chemical Company for their support on this project. I am grateful for the opportunity to work with these amazing partners. I would specifically like to thank Dr. David Reynolds, Dave Hogberg, and Marlaina Auger (Geosyntec Consultants), Jennifer Hayman and Jake Eimers (Jacobs), Audrey Sidebottom (The Dow Chemical Company), and Leanne Austrins (Arcadis). The pilot field test would not have been possible without their contributions.

Finally, I want to thank my wonderful family and friends for their support during this journey. 


\section{Table of Contents}

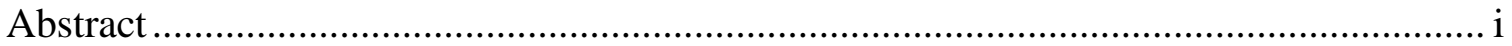

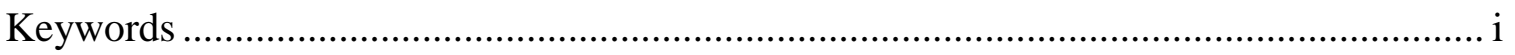

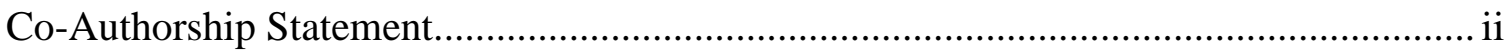

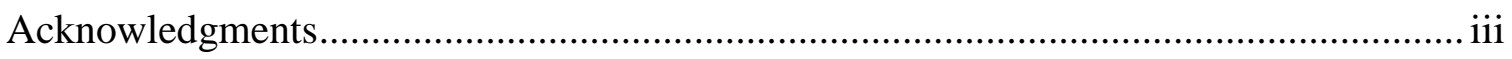

List of Tables .................................................................................................. vii

List of Figures ................................................................................................ vii

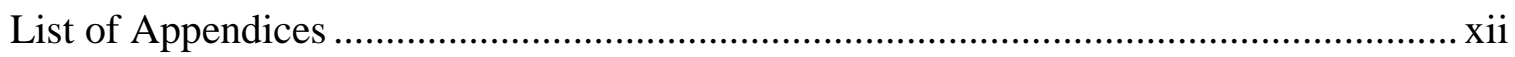

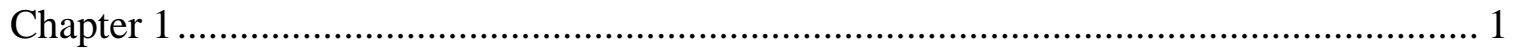

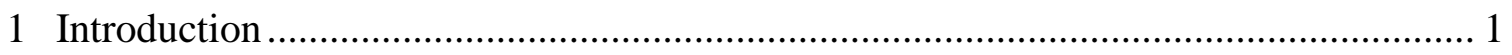

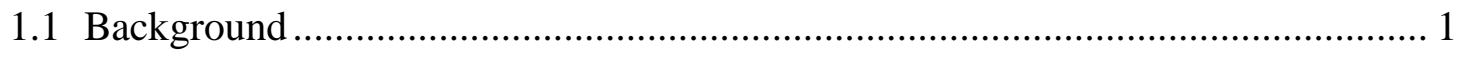

1.2 Research Objectives ................................................................................... 2

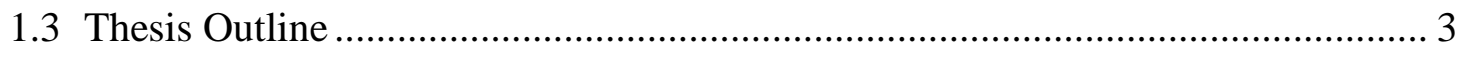

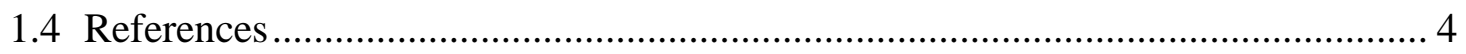

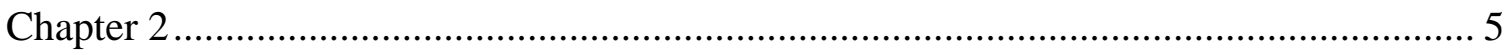

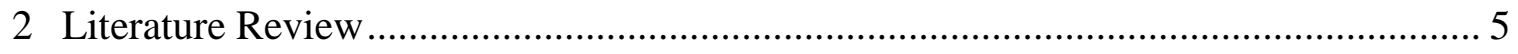

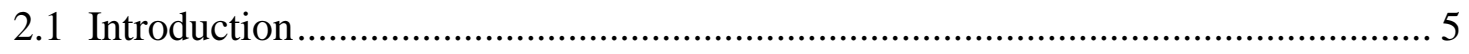

2.2 Chlorinated Solvent Sites with Low Permeability Media................................. 6

2.2.1 Chlorinated Solvent Behaviour in the Subsurface ............................... 6

2.2.2 Microbial Populations in Chlorinated Solvent Contaminated Sites .......... 7

2.3 Anaerobic Bioremediation of Chlorinated Solvents .................................... 8

2.3.1 Biostimulation with Lactate for Chlorinated Solvent Reduction............... 9

2.3.2 Bioaugmentation with KB-1 for Chlorinated Solvent Reduction............. 10

2.3.3 Combined Bioaugmentation and Biostimulation................................. 12

2.3.4 Evaluating Bioremediation Success using DNA Analysis ..................... 12 
2.3.5 Limitations of In-Situ Bioremediation............................................. 13

2.4 Electrokinetics (EK) for Chlorinated Solvent Remediation ............................ 15

2.4.1 Electrokinetic Processes and Transport Mechanisms ............................. 15

2.4.2 Electrokinetics as a Remediation Strategy ......................................... 19

2.4.3 Electrokinetically-Enhanced Bioremediation ................................. 20

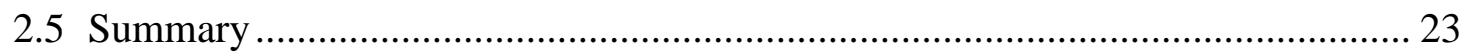

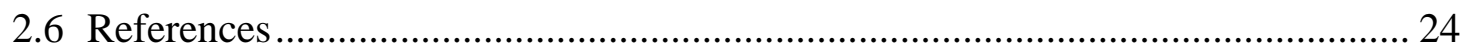

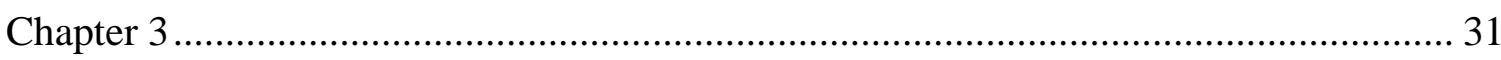

3 Electrokinetically-enhanced emplacement of lactate in a chlorinated solvent contaminated clay site to promote bioremediation ........................................... 31

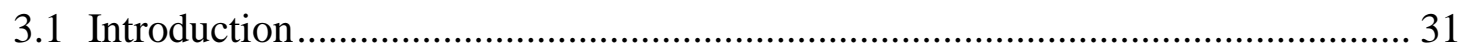

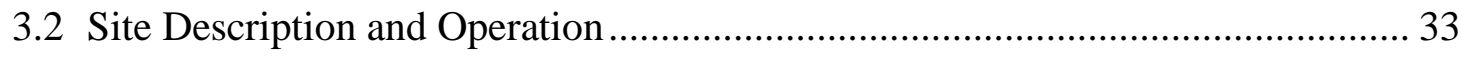

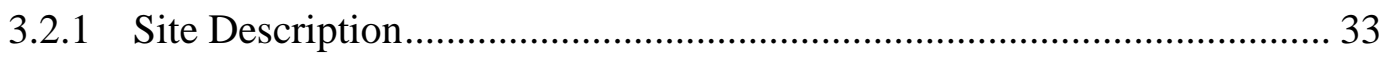

3.2.2 EK Operation and Lactate Injection .............................................. 34

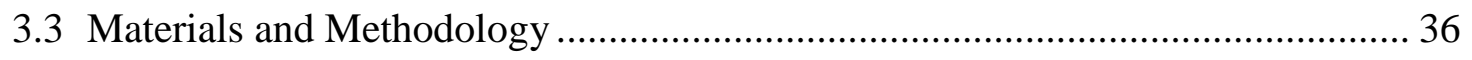

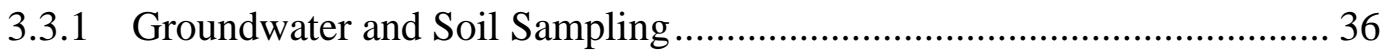

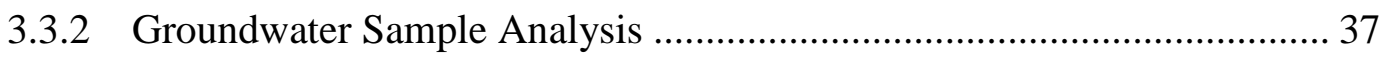

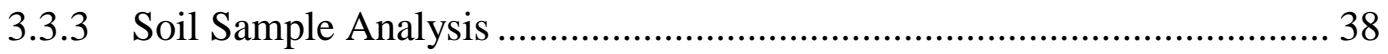

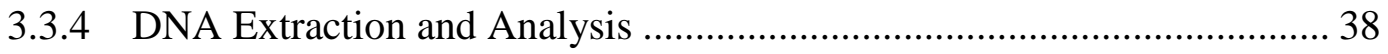

3.3.5 Determining Local Hydraulic Conductivity ...................................... 39

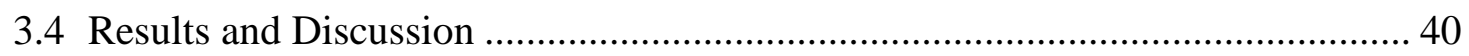

3.4.1 Lactate Transport under EK........................................................... 40

3.4.2 Bacterial Abundance and Community Structure ................................. 45

3.4.3 Changes in Chlorinated Solvent Concentrations .................................. 51

3.4.4 Combined Discussion of All Results ................................................. 56

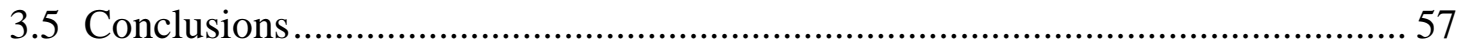




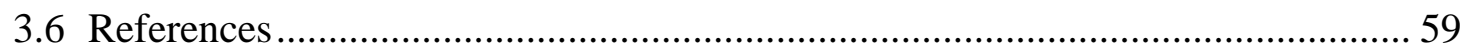

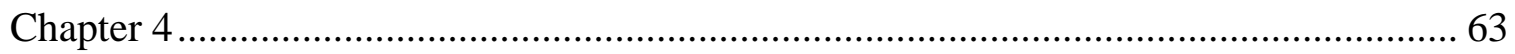

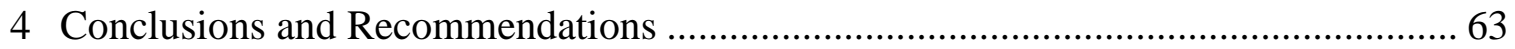

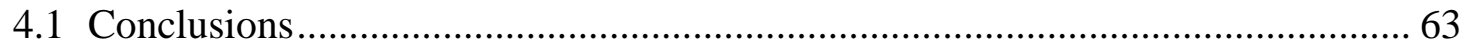

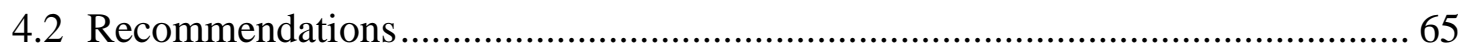

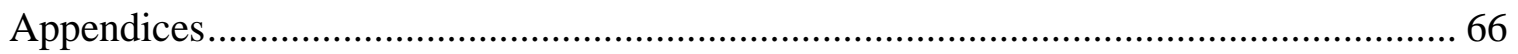

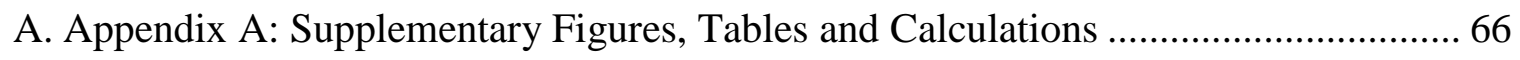

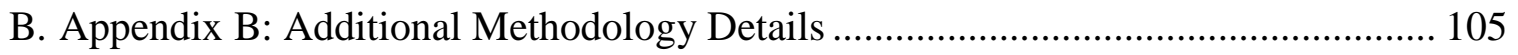

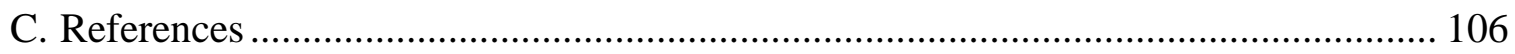

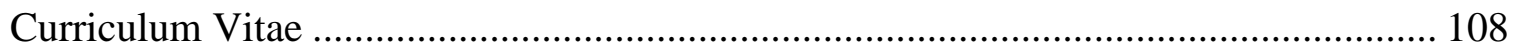




\section{List of Tables}

Table A.1 Average voltage gradients for entire duration of EK measured in-situ for various depths and sections of the EK-Bio cell (using a time-weighted average) ......

Table A.2 Average voltage gradients measured in-situ at each well before lactate breakthrough (using a time-weighted average)

Table A.3 Observed lactate transport rates into each well assuming first arrival is only due to electromigration. 73

Table A.4 General bacteria qPCR results for all DNA samples analyzed. 88

Table A.5 Dehalococcoides qPCR data for all DNA samples analyzed............................ 92

Table A.6 Percentages of bacterial population made up by each genus in Control samples over time.

Table A.7 Percentages of bacterial population made up by each genus in EK-Bio MW1 samples over time.

Table A.8 Percentages of bacterial population made up by each genus in EK-Bio MW2 samples over time. 


\section{List of Figures}

Figure 2.1 (a) EK transport processes and (b) Contaminant phase partitioning 17

Figure 3.1 Plan view and cross section of EK-Bio, where red indicates the electrodes and grey indicates the screened intervals

Figure 3.2 Applied current to each electrode (a) and resulting voltage gradient (b) over days of EK application (i.e. power on)

Figure 3.3 Fraction of lactate breakthrough determined from DOC concentrations over time in the EK-Bio cell.

Figure 3.4 Fraction of sodium breakthrough in EK-Bio from injected concentration of 357 $\mathrm{mM}$ in the sodium lactate solution.

Figure 3.5 General bacteria concentration in Control and EK-Bio aqueous samples determined via qPCR.

Figure 3.6 Principle Coordinates Analysis of axes 1 and axes 2 showing dissimilarities between Control and EK-Bio samples, created through Illumina sequencing and MetaAmp analysis.

Figure 3.7 EK-Bio temporal changes in relative abundance of Phyla and Firmicutes genera determined from Illumina sequencing and MetaAmp analysis

Figure 3.9 Normalized breakthrough of sodium and lactate, concentration decreases of cVOCs, and estimates of contribution of dilution to cVOC decreases in MW1A (a) and MW2B (b) in EK-Bio cell.

Figure 3.10 EK-Bio total soil molar concentration of cVOCs for sampling rounds post-EK application and sample location outside EK-application. 
Figure 3.11 Monitored groundwater parameters for MW1A (a) and MW1B (b) normalized to the maximum value of each parameter measured on site. 57

Figure A.1 Plan views of field site provided by Jacobs (previously CH2M Hill)............... 66

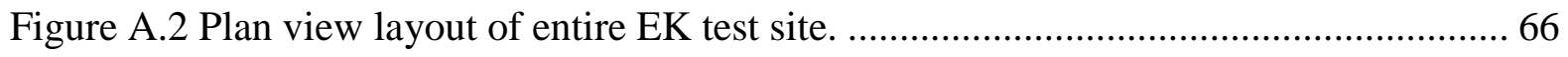

Figure A.3 Total applied current across all EK cells (a) and resulting voltage gradient (b) over total time since initial EK application.

Figure A.4 Process Symbols for Process Flow Diagrams provided by Geosyntec Consultants

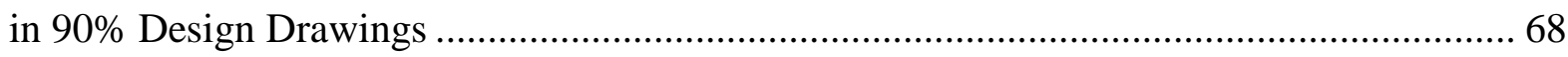

Figure A.5 Process and Instrumentation Diagram- Water Balancing System - Well Network (Provided by Geosyntec)

Figure A.6 Process and Instrumentation Diagram- Water Balancing System - Tank System

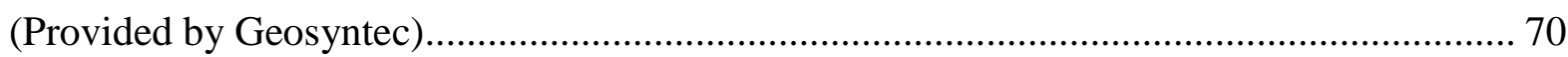

Figure A.7 Process and Instrumentation Diagram- Amendment System (Provided by Geosyntec) 71

Figure A.8 Control DOC concentrations over time 72

Figure A.9 Measured in-situ voltage gradient at various intervals and depths of the site while EK was applied. 73

Figure A.10 Hypothetical electric field and overlap between upper and lower electrodes. ... 74

Figure A.11 EK-Bio MW1 location core from $2.44 \mathrm{~m}$ to $3.66 \mathrm{~m}$ showing distinct visual differences from the low plasticity brown clay seen at other EK-Bio monitoring locations.. 76

Figure A.12 EK-Bio MW1 location core from $3.66 \mathrm{~m}$ to $4.27 \mathrm{~m}$ showing homogenous low plasticity brown clay. MW1B screened interval is $3.66 \mathrm{~m}$ to $4.27 \mathrm{~m} \mathrm{bgs}$ 76

Figure A.13 EK-Bio MW2 location cores showing homogenous low plasticity brown clay in $2.44 \mathrm{~m}$ to $3.66 \mathrm{~m}$ interval (bottom) and $3.66 \mathrm{~m}$ to $4.27 \mathrm{~m}$ interval (top). 77 
Figure A.14 Advective transport rates due to the hydraulic gradient between SW1 and MW1A for various hydraulic conductivities.

Figure A.15 Advective transport rates due to the hydraulic gradient between SW1 and MW1B for various hydraulic conductivities. 80

Figure A.16 Advective transport rates due to the hydraulic gradient between SW2 and MW2A for various hydraulic conductivities. 81

Figure A.17 Advective transport rates due to the hydraulic gradient between SW2 and MW2B for various hydraulic conductivities. 83

Figure A.18 h/ho vs time plot for EK-Bio MW1A ….................................................... 85

Figure A.19 h/ho vs time plot for EK-Bio MW1B ........................................................ 85

Figure A.20 h/ho vs time plot for EK-Bio MW2A ........................................................ 86

Figure A.21 h/ho vs time plot for EK-Bio MW2B .......................................................... 86

Figure A.22 Water levels in each EK-Bio well on sampling events. ................................ 87

Figure A.23 Differences in water levels between EK-Bio and Control wells with 7 days recovery time.

Figure A.24 Differences in water levels between EK-Bio and Control wells with greater than 30 days of recovery time. 88

Figure A.25 Dehalococcoides concentrations in EK-Bio and Control cell determined through qPCR. .

Figure A.26 Changes in volatile fatty acids (VFA) from EK and lactate injection phase to post-injection period in EK-Bio B depth wells.

Figure A.27 Relative Abundance of Phyla and Firmicutes Genera in Control Cell determined from Illumina Sequencing and MetaAmp Analysis. 100 
Figure A.28 Principle Coordinates Analysis of axes 1 and axes 3 showing dissimilarities between Control and EK-Bio samples, created through Illumina sequencing and MetaAmp analysis.

Figure A.29 Hierarchical clustering of Control and EK-Bio samples in a Dendrogram from Illumina Sequencing and performing MetaAmp analysis. 101

Figure A.30 Control cell aqueous cVOC concentrations over time showing no trend......... 102

Figure A.31 Total soil cVOC concentration cross section in the EK-Bio cell before treatment showing heterogeneities in background contaminant distribution. 102

Figure A.32 Cross section of EK-Bio soil layers at each well location roughly inferred from borehole logs and soil core photographs. 103

Figure A.33 EK-Bio 1,2-DCA soil concentration profile for each sampling time and location within the supply well screened interval. 103

Figure A.34 Relative abundance of various cVOCs from each soil coring round as a fraction of total cVOCs. 104

Figure A.35 Monitored parameters for all wells normalized to the maximum value measured on site so each well is directly comparable. 104 


\section{List of Appendices}

Appendix A: Supplementary Figures, Tables and Calculations ......................................... 66

Appendix B: Additional Methodology Details ............................................................. 105 


\section{Chapter 1}

\section{Introduction}

\subsection{Background}

The use of chlorinated solvents in industrial practices became significant during World War II and persisted for several decades. They are used in a wide range of industries, therefore their production, transport, and disposal has been extensive. Due to having a higher density than water they are classified as "dense non-aqueous phase liquids" (DNAPLs). Their chemical and physical properties led to the high likelihood of widespread groundwater and soil contamination when released into the environment (Pankow \& Cherry, 1996). Contaminated sites typically contain heterogeneities and therefore the distribution of chlorinated solvents in the subsurface after a release can be complex. Contaminant plumes can move quickly through high permeability media by advection, while contaminants slowly enter low permeability media such as underlying silt and clay layers or lenses by diffusion (Mackay \& Cherry, 1989). After concern around chlorinated solvent contamination in groundwater arose in the 1970's, remediation strategies began to be developed to treat chlorinated solvents in groundwater (Pankow \& Cherry, 1996). Typically these techniques only effectively target contamination in the higher permeability regions, leaving contamination behind in these low permeability zones. In this situation the direction of diffusion is reversed and contaminants can slowly diffuse from the low permeability zone back into the treated aquifer, hindering the longevity of the remediation solution (Mackay \& Cherry, 1989). Contaminant persistence due to this back diffusion has been proven to hinder the achievement of chlorinated solvent concentrations beneath regulatory levels, even after appropriate measures have been taken to reduce contaminant concentrations in the aquifer (Parker et al., 2008).

In-situ bioremediation is a remediation strategy that has been used for over 50 years and more recently the use of bioremediation has expanded for various contaminants and environments (Hazen, 2010). In-situ bioremediation practices are typically identified as 
biostimulation, bioaugmentation or a combination of the two. Biostimulation is the addition of nutrients or electron donors to enhance the biodegradation process, while bioaugmentation is the addition of microbial cultures that have the ability to degrade the contaminants (Hazen, 2010).

In-situ bioremediation is considered to be a cost-effective and environmentally acceptable remediation strategy in the proper situation, though limitations do exist (Sims et al., 1992). One major limitation of in-situ bioremediation is the inability to successfully apply the technology to low permeability media (Sims et al., 1992). The success of bioremediation is dependent on the ability for nutrients, electron donors, and/or bacterial cultures to be delivered throughout the contaminant zone. This delivery is hindered in low permeability media, limiting microbial activity and thus the potential for biodegradation (Thomas \& Ward, 1992). Electrokinetics is a proposed technology, involving the application of a low voltage direct current across electrodes installed in the subsurface, to enhance the delivery of amendments required for many remediation technologies (Acar \& Alshawabkeh, 1993). Electrokinetics therefore has the potential to be paired with bioremediation, possibly allowing it to be successfully applied in low permeability media.

Electrokinetics in combination with bioremediation has been studied at the laboratory scale with success in the delivery of lactate and bacterial cultures in clay (Mao et al., 2012; X. Wu et al., 2007, 2012). Delivery of the electron donor and bacteria has proven to have the ability to cause the transformation of chlorinated solvent contamination in the clay (Mao et al., 2012; X. Wu et al., 2012). Although this novel remediation strategy has shown promise at the laboratory scale, there has been no peer-reviewed journal publications investigating electrokinetically-enhanced bioremediation for the treatment of organic contaminants in clay at a field site.

\subsection{Research Objectives}

The overall scope of this project was to evaluate the potential for electrokinetics to be combined with bioremediation at the field scale to enhance the delivery of lactate in clay and in turn result in biodegradation of chlorinated solvents. This is investigated through 
the implementation and monitoring of a pilot field test. The first objective was to determine if electrokinetics successfully enhanced the delivery of lactate. Dissolved organic carbon samples were collected and analyzed weekly as an indicator for lactate breakthrough into each well. The corresponding observed field transport rates were determined using this data. Additional objectives were to evaluate the effect of the lactate emplacement in the clay on the bacterial populations and determine if this would result in decreases in chlorinated solvent concentrations. The bacterial abundance and bacterial community structure were compared over time in each monitoring well to look for evidence of biostimulation by the lactate. This analysis was performed on DNA that was extracted from field-collected groundwater filters. In addition, the chlorinated solvent concentrations were monitored weekly in groundwater samples and analyzed twice postlactate injection in two sets of soil cores. The effect of enhanced lactate delivery on the chlorinated solvent concentrations was investigated using these results. Monitoring of the chlorinated solvents concentrations over time was important since the ultimate goal of electrokinetically-enhanced bioremediation is the reduction of contaminant concentrations in clay.

\subsection{Thesis Outline}

This thesis is presented as an "Integrated Article Format". The following is an outline of the content found in each chapter:

Chapter 1: Introduction of chlorinated solvent contamination, bioremediation, electrokinetics and presentation of research objectives

Chapter 2: Reviews the relevant literature. Topics include chlorinated solvent contaminated sites, bioremediation strategies, electrokinetics and its combined application with bioremediation strategies.

Chapter 3: Provides a concise, complete description of the research, including key literature and background, site description, field trial materials and methods. It further presents results of each objective, discussion of these results, and main conclusions of the research. 
Chapter 4: Summarizes conclusions for each objective and provides recommendations for future research.

Appendices contain information supplementary to chapter 3.

Appendix A: Contains supporting figures, table and calculations for results

Appendix B: Contains additional methodology information

\subsection{References}

Acar, Y. B., \& Alshawabkeh, A. N. (1993). Principles of Electrokinetic Remediation. Environmental Science and Technology, 27(13), 2638-2647.

Hazen, T. C. (2010). In Situ: Groundwater Bioremediation. Handbook of Hydrocarbon and Lipid Microbiology, 2583-2596.

Mackay, D. M., \& Cherry, J. A. (1989). Groundwater contamination: Pump-and-treat remediation. Environmental Science and Technology, 23(6), 630-636.

Mao, X., Wang, J., Ciblak, A., Cox, E. E., Riis, C., Terkelsen, M., ... Alshawabkeh, A. N. (2012). Electrokinetic-enhanced bioaugmentation for remediation of chlorinated solvents contaminated clay. Journal of Hazardous Materials, 213-214, 311-317.

Pankow, J. F., \& Cherry, J. A. (1996). Dense Chlorinated Solvents and other DNAPLs in Groundwater: History, Behavior, and Remediation. Waterloo Press.

Parker, B. L., Chapman, S. W., \& Guilbeault, M. A. (2008). Plume persistence caused by back diffusion from thin clay layers in a sand aquifer following TCE source-zone hydraulic isolation. Journal of Contaminant Hydrology, 102(1-2), 86-104.

Sims, J. L., Suflita, J. M., \& Russell, H. H. (1992). In-Situ Bioremediation of Contaminated Ground Water. United States Environmental Protection Agency.

Thomas, J. M., \& Ward, C. H. (1992). Subsurface microbial ecology and bioremediation. Journal of Hazardous Materials, 32(2-3), 179-194.

Wu, X., Alshawabkeh, A. N., Gent, D. B., Larson, S. L., \& Davis, J. L. (2007). Lactate Transport in Soil by DC Fields. Journal of Geotechnical and Geoenvironmental Engineering, 133(12), 1587-1596.

Wu, X., Gent, D. B., Davis, J. L., \& Alshawabkeh, A. N. (2012). Lactate injection by electric currents for bioremediation of tetrachloroethylene in clay. Electrochimica Acta, 86, 157-163. 


\section{Chapter 2}

\section{Literature Review}

\subsection{Introduction}

Chlorinated solvents are common soil and groundwater contaminants. World War II signaled the beginning of the widespread use of chlorinated solvents in industrial applications and this use continued to increase over the next few decades (Pankow \& Cherry, 1996). Contamination of groundwater by chlorinated solvents was inevitable with this vast production, transport and disposal while the negative impacts were not fully understood or made public (Pankow \& Cherry, 1996). Between 1985 and 2002, the U.S. Geological Survey sampled more than 5000 wells in the United States and found that chlorinated solvents were among the most commonly detected volatile organic compound (Moran et al., 2007). Chlorinated solvents are known to have serious negative human health effects. These include effects on the kidney and liver, central nervous system, reproductive system, and endocrine system. Many of these solvents are listed as known or probable carcinogens by Health Canada (Health Canada, 2017). The Ontario drinking water quality standards (O. Reg. 169/03) of some of the common chlorinated solvents encountered are found in Table 2.1.

Table 2.1 Ontario Drinking Water Quality Standards for Common Chlorinated Solvents (O. Reg. 169/03)

\begin{tabular}{|l|r|}
\hline \multicolumn{1}{|c|}{ Contaminant of Concern } & Drinking Water Standard (mg/L) \\
\hline Tetrachloroethene (PCE) & 0.01 \\
\hline Trichloroethene (TCE) & 0.005 \\
\hline 1,1- Dichloroethene (1,1-DCE) & 0.014 \\
\hline 1,2-Dichloroethane (1,2-DCA) & 0.005 \\
\hline Vinyl Chloride (VC) & 0.001 \\
\hline
\end{tabular}

This review looks at the behaviour of these chlorinated solvents once released to the environment, in particular in a subsurface with low permeability zones. The important bacterial communities in chlorinated solvent contaminated sites as well as the effects of low permeability media and contamination on these bacterial populations will be discussed. Bioremediation as a strategy for the treatment of these contaminated sites and 
its limitations will be reviewed. Finally, electrokinetics technology is explored and its potential to help overcome the limitations associated with bioremediation in low permeability media is examined.

\subsection{Chlorinated Solvent Sites with Low Permeability Media}

\subsubsection{Chlorinated Solvent Behaviour in the Subsurface}

Chlorinated solvents are denser than water and are therefore classified as "dense nonaqueous phase liquids" (DNAPLs) (Pankow \& Cherry, 1996). When DNAPLs are released into the environment they penetrate down beneath the water table, leaving behind residual DNAPL and pooling on low permeability layers and lenses until the distribution of DNAPL becomes static (Kueper et al., 2014). The free phase DNAPL continues to dissolve over time contributing to the development of down-gradient dissolved phase plumes. This dissolved phase mass can diffuse into low permeability zones, such as clays and silts, and diffusion from the pooled DNAPL into the underlying low permeability lenses can occur (Kueper et al., 2014). Following the complete depletion of DNAPL due to long term dissolution, diffusion and sorption or due to treatment strategies, dissolved phase concentrations are reduced in the permeable zones as clean groundwater flows from upgradient (Kueper et al., 2014). This leads to a reversed concentration gradient that results in back diffusion from the contaminated low permeability zones back into the permeable zones. Back diffusion out of the low permeability zones will occur for a longer duration than the original forward diffusion. This process is expected to contribute as a long term source of contamination that prevents the plume from meeting cleanup standards on sites with a high proportion of low permeability zones, such as fractured clay or highly heterogeneous sites (Kueper et al., 2014).

Post remediation concentration rebound from low permeability zones has been demonstrated to occur through numerical modelling of a common remediation strategy, in-situ chemical oxidation, in fractured clay (Mundle et al., 2007). This same effect has been observed in a field site studied by Chapman and Parker in 2005.10 years prior to their study, a trichloroethene source zone that sat on top of a clayey aquitard was isolated 
in the above sandy aquifer using a steel sheet piling enclosure. After a 2 to 3 year decline in groundwater concentrations, evidence of long term plume tailing was observed. Field samples from the aquitard-aquifer interface were used to develop a numerical model that predicted groundwater concentrations remaining above regulatory limits for hundreds of years due to back diffusion from the aquitard (Chapman \& Parker, 2005). Another study, looking at a site in which the trichloroethene source zone was successfully hydraulically isolated, found that even a few thin clay beds located throughout a sandy aquifer can result in contaminant persistence due to back diffusion. Through numerical modelling this back diffusion was again predicted to result in groundwater concentrations that remain above regulatory limits long after the source zone is removed from the aquifer (Parker et al., 2008).

\subsubsection{Microbial Populations in Chlorinated Solvent Contaminated Sites}

Organohalide respiring bacteria (OHRB) are often a small but important component of natural microbial populations in the subsurface. There is a widespread distribution of OHRB, which is likely due to the natural occurrence of organohalides in low concentrations in the environment (Adrian \& Loffler, 2016). The coexistence of microorganisms with a variety of organic compounds for billions of years has led to the evolution of enzymes that have the ability to result in the transformation of organic compounds (Antizar-Ladislao, 2014). In anaerobic conditions, bacteria such as OHRB can use a range of terminal electron acceptors for respiration, depending on the redox conditions and their availability. These include nitrate, iron, manganese, sulfate, carbon dioxide and, for OHRB, includes organohalides (Boopathy, 2000). Therefore OHRB are able to continue to live in environments where significant anthropogenic releases of organohalides, such as chlorinated solvents, has left the soil and groundwater contaminated (Adrian \& Loffler, 2016).

For OHRB to thrive there needs to be adequate bioavailability of the electron acceptors, electron donors, and nutrients, while environmental conditions such as $\mathrm{pH}$ and temperature need to be within a suitable range for the specific type of bacteria present (Boopathy, 2000). Microbial abundance, activity and subsequent potential for 
biodegradation is typically lower in zones with high clay content and low transmissivities (Thomas \& Ward, 1992). In low permeability media such as clay, biotransformation of contaminants is limited due to low groundwater flow velocities and thus ineffective advective transport which results in limited contact between bacteria, contaminants and electron donors (Sturman et al., 1995). In addition the properties of the specific organic contaminants can vary, including aqueous solubility, volatility and reactivity, which could influence their bioavailability in water and soils (Megharaj et al., 2011).

The release of high concentrations of certain chlorinated solvents can have toxic effects on certain microbial populations. Fat soluble chlorinated solvents partition to microbial membranes and can cause damage to the cells if concentrations are above a certain limit (Koenig et al., 2014). These organic contaminants can bioaccumulate within the bacteria to levels above their toxicity limit. Generally, solvents with higher octanol-water partition coefficients have increased toxic effects on bacteria (Koenig et al., 2014). It has been observed that fermentative bacteria are more resistant to high contaminant concentrations than respiring bacteria (Bowman et al., 2009; Koenig et al., 2014). Fermentative bacteria can provide hydrogen as an electron donor to OHRB. Due to this and their high tolerance to organic contaminants, co-existence of these fermenters with OHRB could provide an advantage for bioremediation strategies instead of focusing on adequate stimulation of OHRB alone (Koenig et al., 2014). The ability for specific bacteria to thrive in chlorinated solvent contaminated sites is clearly highly dependent on site specific conditions. These include site permeability and heterogeneity, site geochemical properties, and contaminant properties, concentrations and distribution.

\subsection{Anaerobic Bioremediation of Chlorinated Solvents}

In-situ bioremediation is the process where organic contaminants are biologically degraded either aerobically to carbon dioxide and water, or anaerobically to a reduced transformation product typically of lesser concern. This remediation strategy is considered cost effective, requires low maintenance, and is therefore a sustainable method for treatment of organic contaminated sites (Megharaj et al., 2011). The following will focus specifically on anaerobic bioremediation strategies for the treatment of chlorinated solvents. 


\subsubsection{Biostimulation with Lactate for Chlorinated Solvent Reduction}

Degradation of contaminants can be stimulated through the injection of nutrients, electron donors and electron acceptors in a process called biostimulation (Megharaj et al., 2011). The biotic degradation mechanisms for chlorinated solvents involves redox reactions that require the input of electrons and result in reductive dechlorination. With the addition of an electron donor, hydrogenolysis results in the release of one chloride ion while dichloroelimination results in the release of 2 chloride ions from the chlorinated compound which acts as the electron acceptor (Aulenta et al., 2006). It has been observed that if no electron donors are supplied, biotic dechlorination cannot occur. Aulenta et al. (2006) demonstrated this in a microcosm study in which all controls with no electron donor added saw no evidence of biotic degradation mechanisms. Reduced conditions that are required for reductive dechlorination were observed within a few days only in microcosms that had electron donor addition. Biostimulation through the addition of electron donors therefore allows the biotic degradation mechanisms to occur (Aulenta et al., 2006).

Though several electron donors can be used to support anaerobic degradation in this way, the added biostimulants are often fermented resulting in the production of hydrogen. Hydrogen has been established to have an important role in the reductive dechlorination of chlorinated solvents. Often it is the produced hydrogen that is used as the electron donor by OHRB, and therefore fermentation of the chosen amendment is also important to allow for anaerobic biodegradation (Ballapragada et al., 1997).

Exploration has gone into determining the best electron donor to obtain complete degradation and to be used in various site conditions. Lactate can be used for complete dechlorination of PCE to ethene or ethane if added in sufficient quantities (De Bruin et al., 1992). Lactate has been found to have fast fermentation kinetics providing a rapid source of hydrogen (Ballapragada et al., 1997). As a result, lactate was identified as an electron donor source that can result in rapid initial dechlorination (Aulenta et al., 2006). Lactate is therefore commonly used as an electron donor. A reaction for the fermentation of lactate to produce hydrogen is as follows (Ballapragada et al., 1997): 


$$
\mathrm{C}_{3} \mathrm{H}_{5} \mathrm{O}_{3}+\mathrm{H}_{2} \mathrm{O} \rightarrow \mathrm{CH}_{3} \mathrm{COOH}+\mathrm{CO}_{2}+2 \mathrm{H}_{2} \text { (Equation 2.1) }
$$

As an example, the half reactions using this produced hydrogen as an electron donor to allow for dichloroelimination of 1,2-dichloroethane (1,2-DCA) to ethene are shown as follows (Aulenta et al., 2006):

$$
\begin{gathered}
2 \mathrm{H}_{2} \rightarrow 4 H^{+}+4 e^{-} \text {(Equation 2.2) } \\
2 \mathrm{C}_{2} \mathrm{H}_{4} \mathrm{Cl}_{2}+4 \mathrm{H}^{+}+4 e^{-} \rightarrow 4 \mathrm{HCl}+2 \mathrm{C}_{2} \mathrm{H}_{4} \quad \text { (Equation 2.3) }
\end{gathered}
$$

Biostimulation with lactate by Aulenta et al. (2007) was successful in resulting in biodegradation of chlorinated solvents at a field site. This was done by mixing the lactate amendment with extracted contaminated groundwater and then reinjecting it into the subsurface. When lactate was metabolized by the microorganisms the main products were acetate and propionate, and the concentrations of these volatile fatty acids were monitored to ensure sufficient donation of electrons. Lactate concentrations increased rapidly when continuous injection began, then fell as acetate and propionate were formed. This resulted in an increased electron donor availability for the system, which stimulated microorganisms to use electron acceptors naturally occurring in the groundwater. The chlorinated solvents acted as an electron acceptor and with this high electron donor availability, the chlorinated solvents were able to be reduced by biostimulation (Aulenta et al., 2007).

\subsubsection{Bioaugmentation with KB-1 for Chlorinated Solvent Reduction}

Another in-situ bioremediation strategy is bioaugmentation, which involves the addition of microbial communities with proven abilities to degrade the target contaminant (Megharaj et al., 2011). When specific contaminant degrading bacteria are not present in the subsurface in sufficient quantities, the addition of these microorganisms can be required. For successful biodegradation due to the addition of these microorganisms, the bacteria must be transported throughout the zone of contamination, have the ability to grow in the prevailing subsurface conditions, have sufficient access to nutrients, and maintain their ability to metabolize the target contaminants. Subsurface soil properties 
including large grain size, high hydraulic conductivities and the presence of preferential pathways favor the transport of microorganisms (Thomas \& Ward, 1992).

Bioaugmentation with the correct bacteria to target the contamination present is necessary. Dehalococcoides is known to result in the complete reduction of chlorinated ethenes and is therefore accepted as the OHRB of choice for chlorinated solvents (Adrian \& Loffler, 2016; Maymó-Gatell et al., 1999). Specifically, Dehalococcoides ethenogenes strain 195 is able to completely reduce tetrachloroethene to ethene (Maymó-Gatell et al., 1999). Several bioremediation studies have had success with Dehalococcoides as the present OHRB (Aulenta et al., 2006; Aulenta et al., 2007; McCarty et al., 2007). Therefore, bioaugmentation with Dehalococcoides is a viable option for enhancing insitu bioremediation of chlorinated solvents. Major et al. (2002) determined that KB-1 culture (SiREM, Canada), a natural microbial consortium containing Dehalococcoides, can be used for successful bioaugmentation when this bacteria is not naturally present in sufficient quantities. Bioaugmentation with the KB-1 dechlorinating enrichment culture stimulated the complete reduction of tetrachloroethene (PCE), trichloroethene (TCE) and cis-1,2-dichloroethene (cDCE). The KB-1 culture was enriched from natural groundwater and soil from a chlorinated solvent contaminated site and was grown under strict anaerobic conditions (Major et al., 2002). Using a microbial consortium provides an advantage over a pure bacterial culture since it provides the required microbial diversity that may not naturally be present in the field (Tyagi et al., 2011). Although Dehalococcoides is the dominant bacteria in KB-1 cultures, other bacteria have been identified by Duhamel and Edwards (2006) in KB-1 cultures enriched on various chlorinated ethenes. Other dechlorinating bacteria such as Geobacter can be present in TCE and PCE cultures. In addition, non-dechlorinating organisms including those considered to be fermenters, acetogens and methanogens have been detected (Duhamel \& Edwards, 2006). Specifically Firmicutes, methanogenic Archaea, and Deltaproteobacteria were identified as key organisms in KB-1 to potentially facilitate Dehalococcoides growth (Hug et al., 2012). The KB-1 culture therefore has functional redundancy that can help support robust growth and sustainable chlorinated ethene degradation (Duhamel \& Edwards, 2006; Hug et al., 2012). 


\subsubsection{Combined Bioaugmentation and Biostimulation}

Bioaugmentation and biostimulation can be used as complementary bioremediation strategies to maximize their benefits and target specific contaminants under specific site conditions (Tyagi et al., 2011). The pilot field study by Major et al. (2002) found that biostimulation through the injection of electron donors did not result in the complete reduction of chlorinated solvents alone. The electron donor methanol was used because it was the enrichment substrate for KB-1 and acetate promoted rapid anaerobic conditions, both of which enhance the ability for the subsequent injection of KB-1 culture to succeed. With the addition of KB-1 culture after the delivery of the electron donors, complete reduction was achievable (Major et al., 2002). Another study by Scheutz et al. (2008) involved the delivery of lactate and bioaugmentation with KB-1 in a chlorinated solvent contaminated field site. Increases in ethene concentrations that were concurrent with increases in Dehalococcoides provided validation that this technique was successful in the biotransformation of cDCE in the field (Scheutz et al., 2008). These studies validate that the combination of biostimulation and bioaugmentation strategies can increase the potential for success of in-situ bioremediation.

\subsubsection{Evaluating Bioremediation Success using DNA Analysis}

Various types of analysis can be performed on DNA extracted from soil and groundwater and this analysis can assist in validating the success of bioremediation. One of these tools that is frequently used is quantitative Polymerase Chain Reaction (qPCR) which can quantify the abundance of a targeted bacteria in the sample. Many bioremediation studies have used qPCR to quantify changes in dechlorinating bacteria, commonly targeting Dehalococcoides 16S rRNA gene, such that the influence of biostimulation and/or bioaugmentation strategies on these populations can be observed and the success in stimulating and/or delivering these dechlorinating bacteria can be evaluated (Adetutu et al., 2015; Lee et al., 2008; Lendvay et al., 2003; Ritalahti et al., 2006; Schaefer et al., 2010).

Another tool that can be used is metagenomic sequencing, where the relative abundance of microorganisms at various taxonomic levels in a sample can be determined. Results 
from qPCR have the potential to be biased when used alone since it targets specific groups, but the use of metagenomic sequencing can reduce this by providing information on the present microbial populations and their possible function (Riesenfeld et al., 2004). Some studies have used metagenomic sequencing to investigate and gain a better understanding of dechlorinating microbial communities by providing insight on the potential capabilities of the microbial community members (Brisson et al., 2012; Hug et al., 2012). Metagenomic sequencing has also been used to evaluate shifts in the microbial community structure during the application of in-situ bioremediation including both biostimulation and bioaugmentation approaches (Adetutu et al., 2015; Dugat-Bony et al., 2012).

\subsubsection{Limitations of In-Situ Bioremediation}

The success of bioremediation processes on site requires the right type of bacteria and environmental conditions to be present in the subsurface (Boopathy, 2000). The metabolism of environmental bacteria required for biodegradation is dependent on the availability of electron donors and acceptors, and essential nutrients (Antizar-Ladislao, 2014). In some cases microbial metabolism of contaminants can produce more toxic daughter products such as VC from the incomplete degradation of PCE (Boopathy, 2000). Therefore, if natural site conditions do not support complete reduction to ethene, it needs to be ensured through the proper combination of bioaugmentation and biostimulation.

Failures in bioremediation often occur when introduced microorganisms cannot thrive in that specific subsurface environment or when they cannot access the contamination. This can be due to lack of nutrients, competition, immobility of the introduced culture, not enough contamination to supply the metabolic activities of the microorganism, and microorganisms using other substrates instead of the desired contamination (AntizarLadislao, 2014). The transport of nutrients, electron acceptors and electron donors to the microorganism as well as the transport of microorganisms themselves are all highly dependent on the permeability of the subsurface material (Thomas \& Ward, 1992). Therefore, the presence low permeability strata can limit the ability for bioremediation techniques to be applied successfully on a field site. The rate of biodegradation is 
dependent on bioavailability which is controlled by mass transfer of required substrates to the degrading bacteria. Decreases in bioavailability over time can result from slow diffusion into small pores and adsorption, and is therefore affected by soil properties (Boopathy, 2000). Although the presence of low-permeability media leads to difficulties in the application of in-situ bioremediation, bacteria still have the ability to enable biodegradation in clay under the proper conditions. Microcosm studies using clay soil samples have shown enhancement of microbial activity and successful biodegradation of a variety of hydrocarbons with the addition of biostimulants (Gouda et al., 2008; Nales et al., 1998; Silva-Castro et al., 2012). One microcosm study in particular validated the survival and growth of Dehalococcoides and complete reduction of TCE in a clay till by native dechlorinating bacteria in the clay and bioaugmentation with KB-1 (Bælum et al., 2014). A numerical model simulation of a site historically contaminated with methyl tertbutyl ether (MTBE), provided evidence that MTBE that had diffused into the low permeability silt layers was transformed anaerobically to tert-butyl alcohol (TBA). TBA was then the dominant solute that back-diffused out of the silt layers and into the aquifer, resulting in long-term plume persistence (Rasa et al., 2011). These studies suggest that biodegradation of various contaminants can occur in low permeability media if proper conditions and bacteria are present.

Although lab scale tests are an important step in the investigation of new remediation technologies, it is important to be aware that bioremediation strategies that work at the lab scale may not be successful in the field since every contaminated site contains different environmental and geochemical conditions. This makes it difficult to obtain optimal conditions at a field site that are typically controllable in the lab (AntizarLadislao, 2014). Because field sites are harder to control and often contain significant spatial heterogeneities, it can be more difficult to identify microbial contributions to contaminant losses and therefore there can be challenges in definitively identifying the success of in-situ bioremediation in the field (Madsen, 1991). 


\subsection{Electrokinetics (EK) for Chlorinated Solvent Remediation}

\subsubsection{Electrokinetic Processes and Transport Mechanisms}

Electrokinetics involves the application of a low level direct current across 2 electrodes installed in the ground. This current is typically on the order of $\mathrm{mA} / \mathrm{cm}^{2}$ of crosssectional soil area or a few V/cm of lateral distance between the electrodes (Acar \& Alshawabkeh, 1993). The mobilization and transport of contaminants and other species through the porous media results when this electric field is applied (Cameselle et al., 2013). Under electrokinetic application, species transport occurs through a combination of electromigration, electrophoresis, electroosmosis, and diffusion. The contribution of each of these transport mechanisms to the overall mass flux of a particular species depends on several factors including soil mineralogy, electrochemical properties of the species, composition and conductivity of the pore fluid, and the porosity and tortuosity of the porous media (Acar \& Alshawabkeh, 1993).

Electromigration (EM) is the movement of ions towards the oppositely charged electrode and the estimated EM flux of a particular species is represented in the following equation (Acar \& Alshawabkeh, 1993):

$$
J_{E M}=u_{i}^{*} c_{i} i_{e}=\frac{D_{o} \tau n z_{i} F}{R T} c_{i} i_{e} \quad \text { (Equation 2.4) }
$$

where, $u_{i}{ }^{*}$ is effective ionic mobility of the species $\left(\mathrm{m}^{2} / \mathrm{V}-\mathrm{s}\right), c_{i}$ is concentration $\left(\mathrm{g} / \mathrm{m}^{3}\right), i_{e}$ is voltage gradient $(\mathrm{V} / \mathrm{m}), D_{o}$ is the diffusion coefficient at infinite dilution, $\left(\mathrm{m}^{2} / \mathrm{s}\right), \tau$ is soil tortuosity factor (-) which could be between 0.01 and 0.84 (Shackelford \& Daniel, 1991), $n$ is soil porosity (-), $\mathrm{Z}_{\mathrm{i}}$ is charge of the species, $\mathrm{F}$ is Faraday's constant $(96485$ $\mathrm{C} / \mathrm{mol}$ ), $\mathrm{R}$ is the universal gas constant, $8.314 \mathrm{~J} / \mathrm{mol}-\mathrm{K}$, and $\mathrm{T}$ is temperature $(\mathrm{K})$. Many factors affect the transport of a specific ion by electromigration including conductivity of the soil, soil porosity, $\mathrm{pH}$ gradient, applied voltage gradient, initial concentration of the ion and the presence of competitive ions (Cameselle et al., 2013). Electromigration rates are theoretically related to the effective ionic mobility and the applied voltage gradient. The effective ionic mobility is estimated using the Nernst-Townsend-Einstein relation between effective ionic mobility and molecular diffusion coefficient. This expresses 
effective ionic mobility of a species as a function of its molecular diffusion coefficient and valence of the species as well as the soil porosity and tortuosity factor (Acar \& Alshawabkeh, 1993). Therefore, the effective ionic mobility, and in turn electromigration transport rates can be quite variable depending on the ion of interest and variations in soil properties. Electrophoresis is similar to electromigration but involves the movement of charged nanoparticles or colloids under an electric field towards the oppositely charged electrode (Cameselle et al., 2013). Contaminants that are bound to free particulate matter can also be transported this way (Virkutyte et al., 2002).

Another mechanism that can result is the transport of dissolved species is electroosmosis (EO), which is the overall flux of water in the porous media due to the applied electric field. In low permeability soils, the porous media typically has a negative surface charge so there is a clustering of cations near the negatively charged soil surface creating a diffuse double layer. When an electric field is applied, the excess positive ions in this diffuse double layer move towards the cathode, applying a strain on the surrounding pore fluid and resulting in EO flow towards the cathode (Acar et al., 1995). Electroosmotic flow is typically much greater in low permeability media than flow due to the hydraulic gradient (Cameselle et al., 2013). Electroosmotic flow rate is theoretically estimated using the following relationship developed from the Helmholtz-Smoluchowski relation (Acar \& Alshawabkeh, 1993; Mitchell \& Soga, 2005):

$$
Q_{E O}=k_{E O} i_{e} A=\frac{\epsilon \zeta}{\eta} n i_{e} A
$$

(Equation 2.5)

Where $k_{E O}$ is electroosmotic permeability ( $\left.\mathrm{m}^{2} / \mathrm{V}-\mathrm{s}\right), A$ is the cross-sectional area of fluid flow $\left(\mathrm{m}^{2}\right), i_{e}$ is applied voltage gradient $(\mathrm{V} / \mathrm{m}), \epsilon$ is the dielectric permittivity of the medium $\left(\mathrm{C}^{2} / \mathrm{N}-\mathrm{m}^{2}\right), \zeta$ is the zeta potential of the porous media $(\mathrm{V}), \eta$ is fluid viscosity $(\mathrm{Pa} \cdot \mathrm{s})$, and $n$ is porosity (-). EO transport is a function of electroosmotic permeability which is the volume of water flowing per unit cross-sectional area due to a unit change in electric potential (Acar \& Alshawabkeh, 1993). Electroosmotic flow is mainly dependent on the dielectric constant and viscosity of the pore fluid, porosity and the surface charge of the soil as zeta potential (Cameselle et al., 2013). It is independent of pore size distribution, therefore in fine grained material, electroosmosis is ideal to 
generate a relatively constant flow rate under an applied voltage gradient (Acar \& Alshawabkeh, 1993).

Diffusion is another method of transport but it is induced by a concentration gradient, not the applied electric current, and it can be neglected due to very slow rates in comparison to voltage gradient induced transport (Cameselle et al., 2013). This is because the ionic mobility of a species is at least an order of magnitude larger than the diffusion coefficient and therefore under an electric current, electrokinetic transport mechanisms will dominate (Acar \& Alshawabkeh, 1993).

The dominant transport mechanisms expected due to the application of EK are shown in Figure 2.1a (Saichek \& Reddy, 2005). Phase partitioning is also shown (Figure 2.1b) since these mass transfer processes would also be occurring in addition to EK processes when EK is implemented on a chlorinated solvent contaminated site where contamination exists in several phases (Gerhard, 2017).

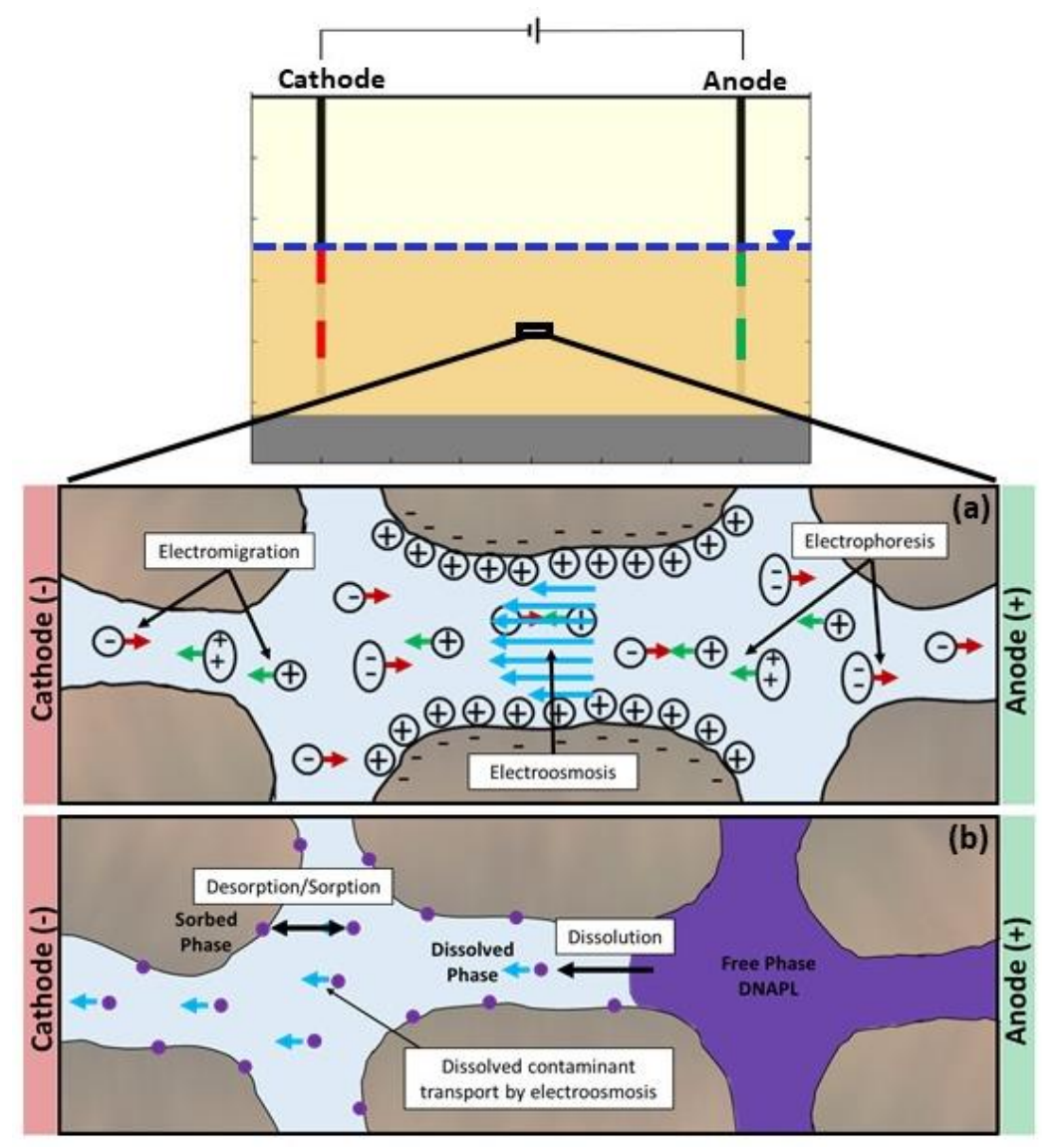

Figure 2.1 (a) EK transport processes and (b) Contaminant phase partitioning and dissolved phase EK transport. 
Electrolysis at each of the electrodes is the main electrochemical reaction to result from the application of an electric current through the subsurface, and will control the chemistry at the boundaries through the following reactions (Acar \& Alshawabkeh, 1993; Cameselle et al., 2013):

$$
\begin{aligned}
& \text { At Anode (Oxidation): } 2 \mathrm{H}_{2} \mathrm{O} \rightarrow 4 e^{-}+4 \mathrm{H}^{+}{ }_{(a q)}+\mathrm{O}_{2(\text { gas })} \quad E^{o}=-1.229 \mathrm{~V} \\
& \text { At Cathode (Reduction): } 4 \mathrm{H}_{2} \mathrm{O}+4 e^{-} \rightarrow 2 \mathrm{H}_{2(\text { gas })}+4 \mathrm{OH}_{(\text {(aq })} \quad E^{o}=-0.828 \mathrm{~V}
\end{aligned}
$$

Hydrogen ions are produced at the anode and hydroxide ions are produced at the cathode, resulting in the production of acid at the anode and an alkaline solution at the cathode. The effective ionic mobility of hydrogen and hydroxide ions are relatively high in comparison to other ion species and therefore their transport will dominate without buffering (Acar \& Alshawabkeh, 1993). Since the mobility of hydrogen ions under the electric field is still about twice that of hydroxide ion, an acid front will propagate from the anode as the hydrogen ions migrate toward the cathode. This occurs until the acid front meets the slower moving base front close to the cathode (Cameselle et al., 2013). Unless this acid front is controlled through the buffering capacity of the soil or buffering at the electrodes, the movement of hydrogen ions will dominate the chemistry across the treatment zone (Acar \& Alshawabkeh, 1993). These electrolysis reactions therefore impact the fundamental processes in a contaminated subsurface and can have serious implications on the success of using electrokinetics for remediation processes. The resulting chemistry changes affect the sorption and desorption, dissolution and precipitation, and chemical speciation relationships as well as the degradation of contaminants (Cameselle et al., 2013). It is therefore important to control these reactions at the electrodes to avoid these affects which is possible by controlling the $\mathrm{pH}$ of the soil. This can be done through $\mathrm{pH}$ conditioning at the electrodes, specifically at the anode, through the circulation of a flushing solution that can neutralize the $\mathrm{pH}$ at these boundaries (Vizcaíno et al., 2018). 


\subsubsection{Electrokinetics as a Remediation Strategy}

Electrokinetics has potential as a remediation strategy since it may be relatively safe, effective, easy to implement and economical compared to traditional in-situ remediation technologies, however a better understanding is required before it can be widely and successfully implemented on contaminated sites (Saichek \& Reddy, 2005). Electrokinetics is well suited to target fine-grained, low permeability media that would result in limitations with existing technologies (Saichek \& Reddy, 2005). Often electrokinetic remediation involves the enhanced removal of contaminants from the subsurface, which has seen success in the extraction of heavy metals, inorganic and some organic contaminants (Acar et al., 1995; Chang et al., 2006; Gent et al., 2004; Maini et al., 2000; Virkutyte et al., 2002). A major limitation of this is that the contaminant must be able to be solubilized to be successfully removed using electrokinetics (Acar et al., 1995). The addition of a surfactant is therefore typically required for removal of hydrophobic organic contaminants due to the strong adsorption to soil and low water solubility (Gomes et al., 2012; Maturi et al., 2009; Pazos et al., 2010; Reddy \& Saichek, 2003). Another option that may be more suitable for these organic contaminants, like chlorinated solvents, is therefore to degrade them in situ. In low permeability media electrokinetics can be coupled with traditional in-situ technologies to enhance amendment transport rates and improve performance where natural groundwater flow is not sufficient (Cameselle et al., 2013; Lima et al., 2017). Several in-situ technologies combined with electrokinetics, including in-situ oxidation, reduction and bioremediation, have been investigated in laboratory scale experiments and shown promising results as a potential remediation strategy for low permeability media (Chowdhury et al., 2012, 2017; $\mathrm{X}$. Wu et al., 2012). Treating contaminants in-situ could also be a superior use of electrokinetics since it does not result in the exposure to toxic contaminants through the generation of an extracted waste stream (Cameselle et al., 2013). 


\subsubsection{Electrokinetically-Enhanced Bioremediation}

\subsubsection{EK Bioremediation Overview}

Electrokinetics in combination with bioremediation has shown promise for future application in low permeability media. EK can help overcome some of the limitations associated with bioremediation alone. This includes controlling geochemical parameters, reducing mass transfer limitations to allow for more effective biostimulation, and improved control of necessary bacterial communities (Lima et al., 2017). Electroosmosis results in mobilization of contaminants which increases their bioavailability to bacteria. In addition the transport of bacteria using EK could help result in their increased interaction with the contaminants (Cameselle et al., 2013). The application of an electric field can also be used to enhance the transport of chemical species introduced into the soil such as nutrients and electron donors/acceptors. The addition and successful electrokinetic delivery of these can assist in the metabolic activity of the bacteria, allowing them to grow and degrade the contaminants more efficiently (Cameselle et al., 2013). The success of EK phenomena to assist bioremediation strategies are highly dependent on specific environmental properties, so using specialized treatment depending on the environment in which it is to be applied is important. Specifically the groundwater chemistry, subsurface composition, the potential for the introduction of advection as an additional transport mechanism, site heterogeneities and the nature of the contamination on site can all strongly influence the success of electrokinetic bioremediation as a treatment strategy (Gill et al., 2014). The following sections outline the limited existing literature on electrokinetic bioremediation. Focus is specifically given on the use of electrokinetics to enhance lactate and KB-1 delivery for the treatment of chlorinated solvents in clay, in which there are only 3 published laboratory studies and no field scale peer-reviewed journal publications to date.

\subsubsection{Laboratory Scale Studies on Electrokinetic Bioremediation}

Several laboratory scale studies have shown that EK combined with bioremediation can be successful in delivering nutrients to the natural bacteria in low permeability soils 
(Hassan et al., 2016). Using electrokinetics to help deliver bacteria during bioaugmentation has also been investigated with results showing promise for bacteria transport via electroosmosis and/or electrophoresis (Hassan et al., 2016). For example, one such lab investigation demonstrated that negatively charged bacteria could be transported by electrophoresis and result in degradation of TCE. However transport by electrophoresis was not suitable for dense low permeability soils due to reduced pore sizes and volume retarding the transport of bacteria and resulting in lower induced transport rates (DeFlaun \& Condee, 1997). Another study tested the potential for transport of polycyclic aromatic hydrocarbon degrading bacteria by either electrophoresis and/or electroosmosis. It was found that both EK transport mechanisms contributed to the transport, yet the most useful mechanism to enhance the transport of bacteria under an electric field was electroosmosis (Wick et al., 2004). These studies validated that the application of an electric current had no adverse effects on the ability of the EK-delivered bacteria to result in degradation of the organic contaminant. Recently the potential influence of an electric current on the survival of microorganisms during electrokinetic bioremediation has been studied, and the results from these studies were highly dependent on a number of factors including $\mathrm{pH}$ changes, the strength of the applied electric field, and the microorganisms of interest (Hassan et al., 2016). A study by Lear et al. (2004) specifically tested the application of an electric current on microbial communities in clay. It was found that the only location with effects on the microbial population was near the anode where the $\mathrm{pH}$ dropped, while all other sampling locations throughout the cell showed no change in microbial structure and diversity (Lear et al., 2004). This study supports that there are no serious detrimental effects on soil microbial health during electrokinetic remediation, and these results in combination with other studies suggest that $\mathrm{pH}$ control could prevent potential effects of electrokinetics on the microbial communities.

\subsubsection{Electrokinetic Biostimulation with Lactate and Bioaugmentation with KB-1}

The delivery of lactate as the electron donor required for anaerobic biodegradation can be enhanced using electrokinetics. This electrokinetic biostimulation using lactate has been 
demonstrated in several lab studies. In a bench scale experiment, lactate was successfully transported by electromigration in a clay soil cell with a cross-section of $5 \mathrm{~cm}$ by $15 \mathrm{~cm}$ and a length of $40 \mathrm{~cm}$ (X. Wu et al., 2007). X. Wu et al. (2012) and Mao et al. (2012) both successfully delivered lactate through clay under EK in bench scale tests, with the intent of evaluating the influence of enhanced lactate delivery on the degradation of organic contaminants in the clay. These tests both validated the ability for the EK enhanced delivery of lactate to result in the transformation of chlorinated solvents when the necessary microbial communities were ensured through the addition of KB-1 culture (Mao et al., 2012; X. Wu et al., 2012). However, X. Wu et al. (2012) noted that PCE was degraded at a slower rate in the clay than expected in a sand under the same conditions. This could suggest that more time may be required to achieve the same extent of anaerobic degradation of chlorinated solvents when using electrokinetic enhanced treatment in clay. Net effective ionic migration rates of lactate achieved in the clay were in the range of 3 to $4.0 \mathrm{~cm}^{2} \mathrm{~d}^{-1} \mathrm{~V}^{-1}$, which corresponded with lactate transport rates of 3 to $3.7 \mathrm{~cm} / \mathrm{d}$ depending on the voltage gradient applied (Mao et al., 2012; X. Wu et al., 2007, 2012). These rates were much higher than any transport due to hydraulic advection observed in the clay cells in these bench scale studies. To ensure the required microbial communities for anaerobic degradation were present, Mao et al. (2012) used electrokinetics for bioaugmentation through the enhanced delivery of injected KB-1 culture. Evidence suggests that KB-1 culture was delivered effectively via electroosmosis and that this injected bacteria had the ability to thrive and successfully support anaerobic degradation of the chlorinated solvents in the clay, after being subject to electrokinetics (Mao et al., 2012).

\subsubsection{Field Scale Electrokinetic Bioremediation}

Research into the field application of electrokinetic bioremediation for enhanced treatment in low permeability media is limited. There has been a published investigation on electrokinetic bioremediation for creosote contaminated soil by Suni et al. (2007) in Finland, however this study was performed in coarse grained, high permeability soil so the potential for enhancing bioremediation in low permeability media was not the focus of this research. In this study, hydraulic and electrokinetic pumping was used to deliver 
nutrients, microorganisms and oxygen in contaminated sand for aerobic biodegradation. Site heterogeneities made interpretation difficult but it was suggested that the application of the electric current had the added benefit of ion migration, resulted in heating to temperatures desirable for bacteria, and could have possibly enhanced the mobility and bioavailability of the contaminant (Suni et al., 2007).

The first known application of electrokinetic bioremediation for the treatment of chlorinated solvents in clay at a field scale was performed in Denmark in 2012, however there have been no peer-reviewed journal publications on this study. There are in fact no peer-reviewed journal publications on field scale electrokinetic bioremediation in clay, although it has been investigated through consultant-led pilot tests such as that in Denmark in 2012. The Denmark pilot test was established after proving the validity of using electrokinetic bioremediation to degrade PCE in soil from this site in the lab scale treatability study by Mao et al. (2012). A conference paper on this pilot test stated that lactate transport rates between 2.5 to $5 \mathrm{~cm} /$ day were achieved and increases in Dehalococcoides were observed supporting successful delivery of KB-1. Contaminant composition was found to shift from PCE to cDCE during the 74 days of system operation, and $\mathrm{VC}$ and ethene began to be detectable over the following 6 months while PCE also increased supporting both reductive dechlorination and dissolution/desorption of PCE (Riis et al., 2012).

\subsection{Summary}

Chlorinated solvent contamination in low permeability zones has negative impacts on the longevity of remediation efforts since back diffusion results in a long-term source of contamination. In-situ bioremediation through the combination of biostimulation and bioaugmentation is established as a successful and sustainable remediation strategy for chlorinated solvent contaminated sites. However, bioremediation faces several limitations in low permeability media. The success of biodegradation is highly dependent on the bioavailability of contaminants, nutrients and electron donors to the microorganisms which becomes reduced in low permeability media. Biostimulation and bioaugmentation strategies require sufficient transport of the injected nutrients, electron donors and the 
organohalide respiring bacterial cultures or consortium. In low permeability media the transport of these amendments is significantly limited and therefore bioremediation alone is not an ideal strategy for low permeability zones. Electrokinetics can result in the enhanced transport of ionic species such as electron donors through electromigration and bacteria through electrophoresis and/or electroosmosis. Therefore, the coupled technology applying electrokinetics with bioremediation has the potential to help overcome the limitations of bioremediation in low permeability media and reduce the concerns associated with back diffusion from these difficult zones. Electrokineticallyenhanced bioremediation has shown promise in laboratory studies, but no peer-reviewed publications exist on its viability to treat chlorinated solvent contaminated clay at the field scale, impairing the ability to understand and overcome the challenges of field implementation.

\subsection{References}

Acar, Y. B., \& Alshawabkeh, A. N. (1993). Principles of Electrokinetic Remediation. Environmental Science and Technology, 27(13), 2638-2647.

Acar, Y. B., Gale, R. J., Alshawabkeh, A. N., Marks, R. E., Puppala, S., Bricka, M., \& Parker, R. (1995). Electrokinetic remediation: Basics and technology status. Journal of Hazardous Materials, 40(2), 117-137.

Adetutu, E. M., Gundry, T. D., Patil, S. S., Golneshin, A., Adigun, J., Bhaskarla, V., ... Ball, A. S. (2015). Exploiting the intrinsic microbial degradative potential for fieldbased in situ dechlorination of trichloroethene contaminated groundwater. Journal of Hazardous Materials, 300, 48-57.

Adrian, L., \& Loffler, F. E. (2016). Organohalide-Respiring Bacteria. Berlin: Springer.

Antizar-Ladislao, B. (2014). Sustainable soil health. Plant Biotechnology: Experience and Future Prospects, 6(6), 389-394.

Aulenta, F., Canosa, A., Leccese, M., Papini, M. P., Majone, M., \& Viotti, P. (2007). Field study of in situ anaerobic bioremediation of a chlorinated solvent source zone. Industrial and Engineering Chemistry Research, 46(21), 6812-6819.

Aulenta, F., Potalivo, M., Majone, M., Papini, M. P., \& Tandoi, V. (2006). Anaerobic bioremediation of groundwater containing a mixture of 1,1,2,2-tetrachloroethane and chloroethenes. Biodegradation, 17(3), 193-206. 
Bælum, J., Scheutz, C., Chambon, J. C., Jensen, C. M., Brochmann, R. P., Dennis, P., ... Jacobsen, C. S. (2014). The impact of bioaugmentation on dechlorination kinetics and on microbial dechlorinating communities in subsurface clay till. Environmental Pollution, 186, 149-157.

Ballapragada, B. S., Stensel, H. D., Puhakka, J. A., \& Ferguson, J. F. (1997). Effect of hydrogen on reductive dechlorination of chlorinated ethenes. Environmental Science and Technology, 31(6), 1728-1734.

Boopathy, R. (2000). Factors limiting bioremediation technologies. Bioresource Technology, 74(1), 63-67.

Bowman, K. S., Rainey, F. A., \& Moe, W. M. (2009). Production of hydrogen by clostridium species in the presence of chlorinated solvents. FEMS Microbiology Letters, 290(2), 188-194.

Brisson, V. L., West, K. A., Lee, P. K., Tringe, S. G., Brodie, E. L., \& Alvarez-Cohen, L. (2012). Metagenomic analysis of a stable trichloroethene-degrading microbial community. The ISME Journal, 6, 1702-1714.

Cameselle, C., Gouveia, S., Akretche, D. E., \& Belhadj, B. (2013). Advances in Electrokinetic Remediation for the Removal of Organic Contaminants in Soils. In Organic Pollutants- Monitoring, Risk and Treatment.

Chang, J. H., Qiang, Z., \& Huang, C. P. (2006). Remediation and stimulation of selected chlorinated organic solvents in unsaturated soil by a specific enhanced electrokinetics. Colloids and Surfaces A: Physicochemical and Engineering Aspects, 287(1-3), 86-93.

Chapman, S. W., \& Parker, B. L. (2005). Plume persistence due to aquitard back diffusion following dense nonaqueous phase liquid source removal or isolation. Water Resources Research, 41(12), 1-16.

Chowdhury, A. I. A., Gerhard, J. I., Reynolds, D., Sleep, B. E., \& O’Carroll, D. M. (2017). Electrokinetic-enhanced permanganate delivery and remediation of contaminated low permeability porous media. Water Research, 113, 215-222.

Chowdhury, A. I. A., O’Carroll, D. M., Xu, Y., \& Sleep, B. E. (2012). Electrophoresis enhanced transport of nano-scale zero valent iron. Advances in Water Resources, 40, 71-82.

De Bruin, W. P., Kotterman, M. J. J., Posthumus, M. A., Schraa, G., \& Zehnder, A. J. B. (1992). Complete biological reductive transformation of tetrachloroethene to ethane. Applied and Environmental Microbiology, 58(6), 1996-2000.

DeFlaun, M. F., \& Condee, W. (1997). Electrokinetic transport of bacteria. Journal of Hazardous Materials, 55, 263-277. 
Dugat-Bony, E., Biderre-Petit, C., Jaziri, F., David, M. M., Denonfoux, J., Lyon, D. Y., ... Peyret, P. (2012). In situ TCE degradation mediated by complex dehalorespiring communities during biostimulation processes. Microbial Biotechnology, 5(5), 642653.

Duhamel, M., \& Edwards, E. A. (2006). Microbial composition of chlorinated ethenedegrading cultures dominated by Dehalococcoides. Federation of European Microbiological Societies, 58, 538-549.

Gent, D. B., Bricka, R. M., Alshawabkeh, A. N., Larson, S. L., Fabian, G., \& Granade, S. (2004). Bench-and field-scale evaluation of chromium and cadmium extraction by electrokinetics. Journal of Hazardous Materials, 110, 53-62.

Gerhard, J. (2017). Subsurface Contamination by Hazardous Industrial Chemicals: Phase Partitioning.[PowerPoint slides]. Civil and Environmental Engineering, University of Western Ontario.

Gill, R. T., Harbottle, M. J., Smith, J. W. N., \& Thornton, S. F. (2014). Electrokineticenhanced bioremediation of organic contaminants: A review of processes and environmental applications. Chemosphere, 107, 31-42.

Gomes, H. I., Dias-Ferreira, C., \& Ribeiro, A. B. (2012). Electrokinetic remediation of organochlorines in soil: Enhancement techniques and integration with other remediation technologies. Chemosphere, 87(10), 1077-1090.

Gouda, M. K., Omar, S. H., Nour Eldin, H. M., \& Chekroud, Z. A. (2008). Bioremediation of kerosene II: a case study in contaminated clay (Laboratory and field: scale microcosms). World Journal of Microbiology and Biotechnology, 24(8), $1451-1460$.

Hassan, I., Mohamedelhassan, E., Yanful, E. K., \& Yuan, Z.-C. (2016). A Review Article: Electrokinetic Bioremediation Current Knowledge and New Prospects. Advances in Microbiology, 06(01), 57-72.

Health Canada. (2017). Guidelines for Canadian Drinking Water Quality-Summary Table. Ottawa, Ontario: Water and Air Quality Bureau, Healthy Environments and Consumer Safety Branch, Health Canada.

Hug, L. A., Beiko, R. G., Rowe, A. R., Richardson, R. E., \& Edwards, E. A. (2012). Comparative metagenomics of three Dehalococcoides-containing enrichment cultures: the role of the non-dechlorinating community. BMC Genomics, 13.

Koenig, J. C., Groissmeier, K. D., \& Manefield, M. J. (2014). Tolerance of Anaerobic Bacteria to Chlorinated Solvents. Microbes and Environments, 29(1), 23-30.

Kueper, B. H., Stroo, H. F., Vogel, C. M., \& Ward, C. H. (2014). Chlorinated Solvent Source Zone Remediation (Vol. 1971). New York: Springer Science+Business Media. 
Lear, G., Harbottle, M. J., Van Der Gast, C. J., Jackman, S. A., Knowles, C. J., Sills, G., $\&$ Thompson, I. P. (2004). The effect of electrokinetics on soil microbial communities. Soil Biology and Biochemistry, 36(11), 1751-1760.

Lee, P. K. H., Macbeth, T. W., Sorenson, K. S., Deeb, R. A., \& Alvarez-Cohen, L. (2008). Quantifying Genes and Transcripts To Assess the In Situ Physiology of "Dehalococcoides" spp. in a Trichloroethene-Contaminated Groundwater Site. Applied and Environmental Microbiology, 74(9), 2728-2739.

Lendvay, J. M., Loffler, F. E., Dollhopf, M., Aiello, M. R., Daniels, G., Fathepur, B. Z., ... Adriaens, P. (2003). Bioreactive Barriers: A Comparison of Bioaugmentation and Biostimulation for Chlorinated Solvent Remediation. Environmental Science \& Technology, 37(7), 1422-1431.

Lima, A. T., Hofmann, A., Reynolds, D., Ptacek, C. J., Van Cappellen, P., Ottosen, L. M., ... Sanchez-Hachair, A. (2017). Environmental Electrokinetics for a sustainable subsurface. Chemosphere, 181, 122-133.

Madsen, E. L. (1991). Determining in situ biodegradation: facts and challenges. Environonmental Science and Technology, 25(10), 1663-1673.

Maini, G., Sharman, A. K., Knowles, C. J., Sunderland, G., \& Jackman, S. A. (2000). Electrokinetic remediation of metals and organics from historically contaminated soil. Journal of Chemical Technology and Biotechnology, 75(8), 657-664.

Major, D. W., McMaster, M. L., Cox, E. E., Edwards, E. A., Dworatzek, S. M., Hendrickson, E. R., ... Buonamici, L. W. (2002). Field Demonstration of Successful Bioaugmentation To Achieve Dechlorination of Tetrachloroethene To Ethene. Environmental Science and Technology, 36(23), 5106-5116.

Mao, X., Wang, J., Ciblak, A., Cox, E. E., Riis, C., Terkelsen, M., ... Alshawabkeh, A. N. (2012). Electrokinetic-enhanced bioaugmentation for remediation of chlorinated solvents contaminated clay. Journal of Hazardous Materials, 213-214, 311-317.

Maturi, K., Reddy, K. R., \& Cameselle, C. (2009). Surfactant-enhanced electrokinetic remediation of mixed contamination in low permeability soil. Separation Science and Technology, 44(10), 2385-2409.

Maymó-Gatell, X., Anguish, T., \& Zinder, S. H. (1999). Reductive dechlorination of chlorinated ethenes and 1, 2-dichloroethane by "Dehalococcoides ethenogenes" 195. Applied and Environmental Microbiology, 65(7), 3108-3113.

Megharaj, M., Ramakrishnan, B., Venkateswarlu, K., Sethunathan, N., \& Naidu, R. (2011). Bioremediation approaches for organic pollutants: A critical perspective. Environment International, 37, 1362-1375.

Mitchell, J. K., \& Soga, K. (2005). Fundamentals of Soil Behavior (Third). New Jersey: John Wiley \& Sons, Inc. 
Moran, M. J., Zogorski, J. S., \& Squillace, P. J. (2007). Chlorinated solvents in groundwater of the United States. Environmental Science and Technology, 41(1), 74-81.

Mundle, K., Reynolds, D. A., West, M. R., \& Kueper, B. H. (2007). Concentration rebound following in situ chemical oxidation in fractured clay. Ground Water, 45(6), 692-702.

Nales, M., Butler, B. J., \& Edwards, E. A. (1998). Anaerobic Benzene Biodegradation: A Microcosm Survey. Bioremediation Journal, 2(2), 125-144.

Pankow, J. F., \& Cherry, J. A. (1996). Dense Chlorinated Solvents and other DNAPLs in Groundwater: History, Behavior, and Remediation. Waterloo Press.

Parker, B. L., Chapman, S. W., \& Guilbeault, M. A. (2008). Plume persistence caused by back diffusion from thin clay layers in a sand aquifer following TCE source-zone hydraulic isolation. Journal of Contaminant Hydrology, 102(1-2), 86-104.

Pazos, M., Rosales, E., Alcántara, T., Gómez, J., \& Sanromán, M. A. (2010).

Decontamination of soils containing PAHs by electroremediation: A review. Journal of Hazardous Materials, 177(1-3), 1-11.

Rasa, E., Chapman, S. W., Bekins, B. A., Fogg, G. E., Scow, K. M., \& Mackay, D. M. (2011). Role of back diffusion and biodegradation reactions in sustaining an MTBE/TBA plume in alluvial media. Journal of Contaminant Hydrology, 126(3-4), 235-247.

Reddy, K. R., \& Saichek, R. E. (2003). Effect of Soil Type on Electrokinetic Removal of Phenanthrene Using Surfactants and Cosolvents. Journal of Environmental Engineering, 129(4), 336-346.

Riesenfeld, C. S., Schloss, P. D., \& Handelsman, J. (2004). METAGENOMICS: Genomic Analysis of Microbial Communities. Annual Review of Genetics, 38, 525552.

Riis, C., Bymose, M., Cox, E., Wang, J., Gent, D., \& Terkelsen, M. (2012). Succesfull Pilot Test of Electrokinetic-Enhanced Bioremediation (EK-BIO) as an Innovative Remedial Approach for PCE DNAPL Source Area. Oslo, Norway: NORDROCS 2012: 4th Nordic Joint Meeting on Remediation of Contaminated Sites, International Conference.

Ritalahti, K. M., Amos, B. K., Sung, Y., Wu, Q., Koenigsberg, S. S., \& Löffler, F. E. (2006). Quantitative PCR Targeting 16S rRNA and Reductive Dehalogenase Genes Simultaneously Monitors Multiple Dehalococcoides Strains. Applied and Environmental Microbiology, 72(4), 2765-2774. 
Saichek, R. E., \& Reddy, K. R. (2005). Electrokinetically enhanced remediation of hydrophobic organic compounds in soils: A review. Critical Reviews in Environmental Science and Technology, 35(2), 115-192.

Schaefer, C. E., Lippincott, D. R., \& Steffan, R. J. (2010). Field-Scale Evaluation of Bioaugmentation Dosage for Treating Chlorinated Ethenes. Ground Water Monitoring \& Remediation, 30(3), 113-124.

Scheutz, C., Durant, N. D., Dennis, P., Hansen, M. H., Jorgensen, T., Jakobsen, R., ... Bjerg, P. L. (2008). Concurrent Ethene Generation and Growth of Dehalococcoides Containing Vinyl Chloride Reductive Dehalogenase Genes During an Enhanced Reductive Dechlorination Field Demonstration. Environmental Science and Technology, 42(24), 9302-9309.

Shackelford, C. D., \& Daniel, D. E. (1991). Diffusion in Saturated Soil . I: Background. Journal of Geotechnical Engineering, 117(3), 467-484.

Silva-Castro, G. A., SantaCruz-Calvo, L., Uad, I., Perucha, C., Laguna, J., GónzalezLópez, J., \& Calvo, C. (2012). Treatment of diesel-polluted clay soil employing combined biostimulation in microcosms. International Journal of Environmental Science and Technology, 9(3), 535-542.

Sturman, P. J., Stewart, P. S., Cunningham, A. B., Bouwer, E. J., \& Wolfram, J. H. (1995). Engineering scale-up of in situ bioremediation processes: a review. Journal of Contaminant Hydrology, 19(19), 171-203.

Suni, S., Malinen, E., Kosonen, J., Silvennoinen, H., \& Romantschuk, M. (2007). Electrokinetically enhanced bioremediation of creosote-contaminated soil: Laboratory and field studies. Journal of Environmental Science and Health - Part A Toxic/Hazardous Substances and Environmental Engineering, 42(3), 277-287.

Thomas, J. M., \& Ward, C. H. (1992). Subsurface microbial ecology and bioremediation. Journal of Hazardous Materials, 32(2-3), 179-194.

Tyagi, M., da Fonseca, M. M. R., \& de Carvalho, C. C. C. R. (2011). Bioaugmentation and biostimulation strategies to improve the effectiveness of bioremediation processes. Biodegradation, 22(2), 231-241.

Virkutyte, J., Sillanpää, M., \& Latostenmaa, P. (2002). Electrokinetic soil remediation Critical overview. Science of the Total Environment, 289(1-3), 97-121.

Vizcaíno, R. L., Yustres, A., Asensio, L., Saez, C., Canizares, P., Rodrigo, M., \& Navarro, V. (2018). Enhanced electrokinetic remediation of polluted soils by anolyte $\mathrm{pH}$ conditioning.

Wick, L. y, Mattle, P. A., Wattiau, P., \& Harms, H. (2004). Electrokinetic Transport of PAH-Degrading Bacteria in Model Aquifers and Soil. Environmental Science and Technology, 38(17), 4596-4602. 
Wu, X., Alshawabkeh, A. N., Gent, D. B., Larson, S. L., \& Davis, J. L. (2007). Lactate Transport in Soil by DC Fields. Journal of Geotechnical and Geoenvironmental Engineering, 133(12), 1587-1596.

Wu, X., Gent, D. B., Davis, J. L., \& Alshawabkeh, A. N. (2012). Lactate injection by electric currents for bioremediation of tetrachloroethylene in clay. Electrochimica Acta, 86, 157-163. 


\section{Chapter 3}

\section{Electrokinetically-enhanced emplacement of lactate in a chlorinated solvent contaminated clay site to promote bioremediation}

\subsection{Introduction}

Bioremediation has been successfully used as an in-situ remediation strategy in various field applications including the treatment of chlorinated solvents and other halogenated organic contaminants. Under anaerobic conditions, halogenated organic compounds can be used as the electron acceptor by organohalide respiring bacteria (OHRB) and become reduced to less halogenated products. (Hug et al., 2013; Leys et al., 2013). Bioremediation of chlorinated solvents thus relies on the presence of OHRB in the subsurface, either naturally or by the addition of a bacterial culture (bioaugmentation). The OHRB Dehalococcoides, known to result in the complete reduction of chlorinated ethenes (Adrian \& Loffler, 2016; Maymó-Gatell et al., 1999), is a key component of bioaugmentation cultures such as KB-1 (Major et al., 2002). To assist in the stimulation of the bacterial populations, electron donors and nutrients are often injected (biostimulation). Bioaugmentation and biostimulation are well proven techniques in strata exhibiting moderate to high permeability and can be used as complementary strategies (Adetutu et al., 2015; Hood et al., 2008; Major et al., 2002; Scheutz et al., 2008; Tyagi et al., 2011).

Successful in-situ bioremediation requires amendment delivery to the contaminant zone which is limited in low permeability media (Thomas \& Ward, 1992). Transport of amendments by advection is almost negligible in clay strata. Due to the challenges in treating low permeability zones, back-diffusion is often a long-term source of contamination even after measures have been taken to reduce contaminant concentrations in higher permeability strata (Chapman \& Parker, 2005; Parker et al., 2008; Tatti et al., 2018). 
Electrokinetics (EK) is a technology that has been proposed to enhance the delivery of remediation amendments into silts and clays. EK applies a low voltage direct current between two electrodes installed in the ground (Acar \& Alshawabkeh, 1993). The voltage gradient serves as the driving force for the transport of groundwater and charged species via 3 main transport mechanisms: (i) Electromigration (EM) transports anions towards the anode and cations towards the cathode, (ii) Electrophoresis (EP) transports changed nanoparticles or colloids towards the oppositely charged electrode, and (iii) Electroosmosis (EO) is the movement of bulk pore fluid towards the cathode when the soil surface is negatively charged, which is typical of clay (Acar \& Alshawabkeh, 1993). Under typical geochemical conditions, EM is at least an order of magnitude larger than EO (Acar \& Alshawabkeh, 1993).

Electrokinetics has the potential to allow in-situ bioremediation to occur in low permeability media (Thevanayagam \& Rishindran, 1998). Laboratory studies demonstrated lactate delivery by EM at rates between 3 and $3.7 \mathrm{~cm} /$ day, much faster than those of hydraulic transport in the clay cell (Mao et al., 2012; X. Wu et al., 2007, 2012). One laboratory study documented KB-1 culture transport in clay by EO (Mao et al., 2012). In two of the above laboratory studies, EK-enhanced delivery of lactate and the addition of KB-1 culture caused anaerobic degradation of chlorinated solvents (Mao et al., 2012; X. Wu et al., 2012). EK application does not negatively affect soil microbial health; therefore biotic activity under EK should be sustainable as long as soil and operational parameters such as $\mathrm{pH}$ are maintained at suitable conditions for microbial communities (Kim et al., 2010; Lear et al., 2004). Although several pilot tests using electrokinetic bioremediation have been performed by consultants with the first in Demark in 2012, there are currently no peer- reviewed journal publications investigating the field-scale application of electrokinetic bioremediation to treat organic contaminants in clay.

The goal of this work was to conduct a field pilot test of electrokinetics for enhanced bioremediation in clay to better understand the potential and the challenges. The specific objectives of this study were: (1) Evaluate lactate transport in clay under EK, (2) quantify the influence of the delivered lactate on the bacterial abundance and community 
structure, and (3) determine if chlorinated solvent concentrations decreased. The pilot test was applied to a chlorinated solvent-contaminated site dominated by clay. Groundwater and soil samples were collected before, during and for one year after the 71-day field test and analyzed for a wide suite of chemical and biological parameters. This pilot field study has provided original insights into the field application of electrokinetic-enhanced bioremediation for the treatment of chlorinated solvents in low permeability porous media.

\subsection{Site Description and Operation}

\subsubsection{Site Description}

The site is a former drum storage area at a decommissioned chlorinated production facility contaminated with chlorinated ethenes and ethanes, in particular 1,2dichloroethane (1,2-DCA) (Figure A.1). The site is characterized by about $2.5 \mathrm{~m}$ of fill material on top of approximately $3 \mathrm{~m}$ of weathered brown clay underlain by a grey clay of

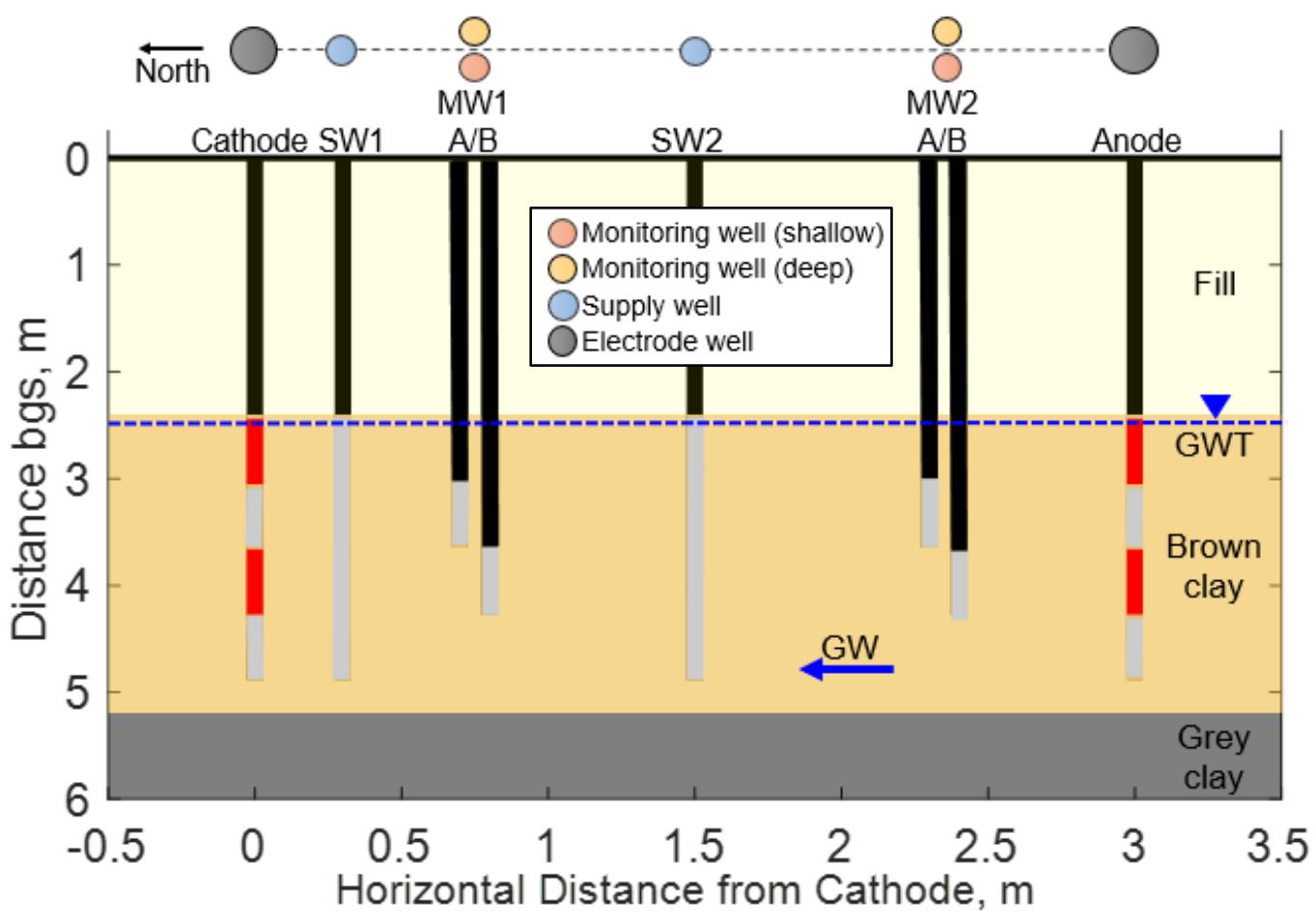

Figure 3.1 Plan view and cross section of EK-Bio, where red indicates the electrodes and grey indicates the screened intervals. 
higher moisture content and plasticity. The targeted treatment area for the pilot test is within the brown clay layer (Figure 3.1). Ambient groundwater flow on the site is estimated at $1.4 \times 10^{-5} \mathrm{~m} /$ day to the north, calculated using the site hydraulic conductivity of $8.6 \times 10^{-4} \mathrm{~m} /$ day and hydraulic gradient of 0.008 (Jacobs (formerly $\mathrm{CH} 2 \mathrm{M}$ Hill), personal communication, April 1, 2008).

The pilot test design, including the design of the transect layouts, well construction and operation parameters, was performed by Geosyntec Consultants based on prior experience. Parallel transects were installed in the contaminated clay such that natural ground water flow was in the opposite direction of expected lactate transport due to EM. The control cell (Control) had no amendment injection and no electric field applied. The cell of interest (EK-Bio) applied electrokinetics to enhance the emplacement of lactate to stimulate bioremediation (Figure 3.1). Electrode wells were installed $3 \mathrm{~m}$ apart, with the cathode to the north and the anode to the south of the site. Mixed metal oxide (MMO) electrodes, composed of titanium and coated with WS-30 $\mathrm{IrO}_{2}$, were located in the electrode wells at depths of $2.44 \mathrm{~m}$ to $3.05 \mathrm{~m}$ bgs and $3.65 \mathrm{~m}$ to $4.27 \mathrm{~m}$ bgs. Amendment supply wells (SW) and electrode wells were screened from $2.40 \mathrm{~m}$ to $4.88 \mathrm{~m}$ bgs. Monitoring wells (MW) were nested with 2 depths at each location. Each monitoring well in the nested pair were offset from the centre line by $0.20 \mathrm{~m}$. MW1A and MW2A were screened from $3.05 \mathrm{~m}$ to $3.65 \mathrm{~m}$ bgs and MW1B and MW2B were screened from $3.65 \mathrm{~m}$ to $4.27 \mathrm{~m}$ bgs. The control cell contained only one set of monitoring wells and no supply or electrode wells. The Control cell was located 22 meters to the east of the EK-Bio cell. Different EK-enhanced remediation techniques were tested in two other cells located on the same site (Figure A.2) but those results are outside the scope of this project.

\subsubsection{EK Operation and Lactate Injection}

The EK-Bio cell received a one-time injection of $2 \mathrm{~L}$ of KB-1 bioaugmentation culture (SiREM, Guelph ON, Canada) into each supply well 2 weeks prior to the start of the EK and lactate injection phase. That phase involved injection of $40 \mathrm{~g} / \mathrm{L}$ sodium lactate solution into both supply wells while direct current was applied between the electrodes for 71 days. The lactate solution was prepared by diluting a stock solution of $60 \%(\mathrm{w} / \mathrm{w})$ 
sodium lactate and stored in a $1000 \mathrm{~L}$ tote. The lactate was injected into SW1 and SW2 using a FLEXFLO peristaltic pump. A total of $1490 \mathrm{~L}$ of lactate solution was injected into the supply wells. A constant head of lactate solution was maintained in the supply wells using a float switch located at $0.61 \mathrm{~m}$ bgs.

The direct current was applied with a target system current of 9 A shared between $4 \mathrm{EK}$ transects on the site each with 2 pairs of electrodes. This corresponds to a target current of 1.125 A applied to each electrode (Figure 3.2a). EK application began on September 28, 2016 and ended December 8, 2016. The system automatically recorded the input current and resulting voltage across the electrodes in 5-minute intervals for the duration of EK application. The applied current was initially low and increased over time towards the target, resulting in an increase in the voltage gradient over time (Figure 3.2b). DC power was not applied at all times since the system needed to be shut down for weekly sampling and for occasional system maintenance; DC was on for 45 days of the 71 days (Figure A.3).
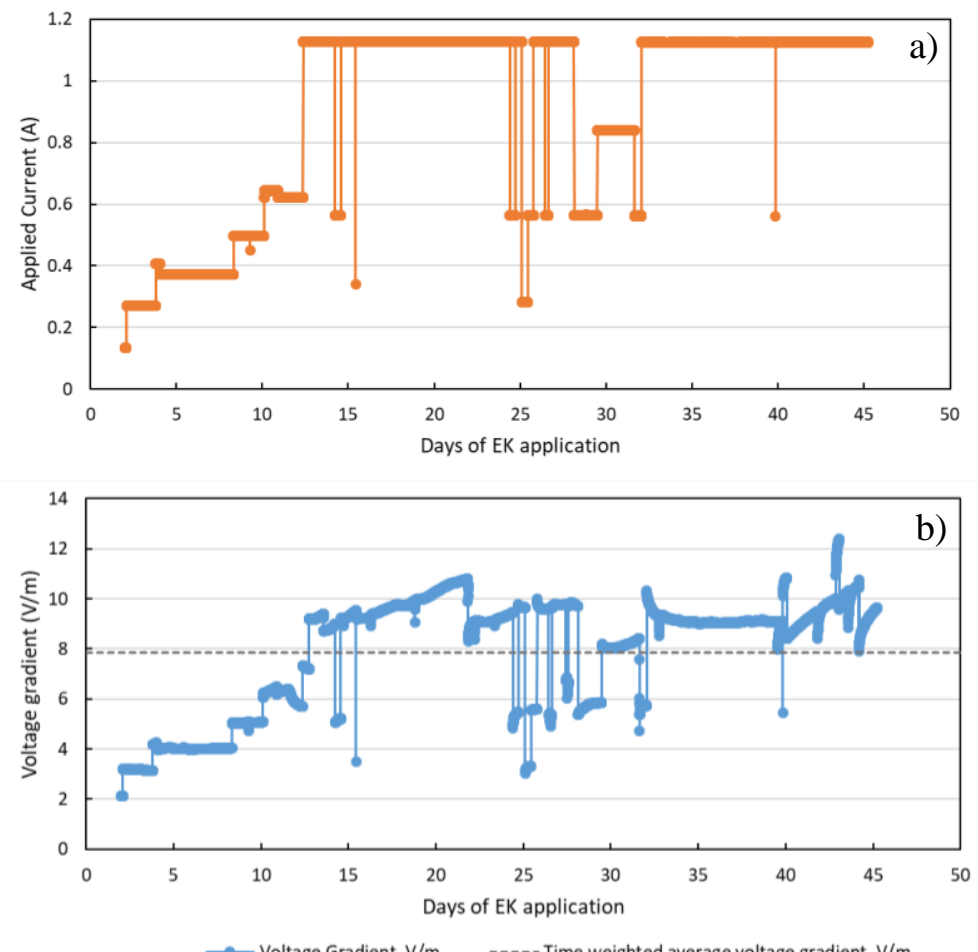

Figure 3.2 Applied current to each electrode (a) and resulting voltage gradient (b) over days of EK application (i.e. power on). Time weighted average voltage gradient of $0.079 \mathrm{~V} / \mathrm{m}$ is indicated. 
To control $\mathrm{pH}$, a buffer solution with $4 \mathrm{~g} / \mathrm{L}$ of monosodium phosphate and $4 \mathrm{~g} / \mathrm{L}$ of disodium phosphate was circulated in the electrode wells at a rate of $13 \mathrm{~mL} / \mathrm{min}$. A cross-circulation system was set up such that the solution exiting the electrode wells went back into the balancing tank, and was readjusted with additional buffer before being injected back into the electrode wells. Float switches in the electrode wells ensured that the electrodes were fully submerged with buffer solution at all times. Buffering at the electrodes was successful, as evidenced by the fact that the $\mathrm{pH}$ in all EK-Bio monitoring wells remained between 6.5 and 7 during the injection of lactate and application of EK. Process flow diagrams of the sodium lactate injection and buffering recirculation are provided in Figure A.4 to Figure A.7 obtained from Geosyntec 90\% Design Drawings for all EK cells in operation on site, including EK-Bio.

\subsection{Materials and Methodology}

\subsubsection{Groundwater and Soil Sampling}

Aqueous sampling occurred weekly during EK application and lactate injection and four additional times over the following year. When preparing for an aqueous sampling event, all monitoring wells were purged then allowed to recover for one week due to the slow recovery of the clay. Water levels in all wells were measured using a water level tape prior to sampling. Samples were collected using a peristaltic pump and the first $200 \mathrm{~mL}$ of water was discarded. $40 \mathrm{~mL}$ zero headspace samples preserved with sodium bisulfate were collected in duplicate for chlorinated volatile organic compound (cVOC) analysis. The majority of samples were stored at $4^{\circ} \mathrm{C}$ for no more than 14 days, with a small fraction stored up to 28 days before analysis. Also, $100 \mathrm{~mL}$ samples were collected for dissolved organic carbon (DOC) and sodium analysis and stored in the dark at $4^{\circ} \mathrm{C}$. In addition, groundwater was filtered through Sterivex filters (Millipore, Billericia, MA) in the field with a target filtered volume of $200 \mathrm{~mL}$ typically achieved except in a few cases where the high silt content of the water clogged the filter at a lower volume. The filters were sealed with paraffin film and frozen at $-20^{\circ} \mathrm{C}$ until DNA was extracted. 
Soil samples were collected prior to the injection of amendments during well installation at all well locations. Soil samples were again collected approximately 2 and 8 months post-injection at specific locations (Figure A.2). A hollow stem auger with a split spoon sampler was used for the drilling of wells and background soil core collection. Soil cores were collected using direct push drilling for post-injection rounds, and one additional soil core was collected north of the EK-Bio cell outside the treatment zone also using direct push drilling. At specific locations and depths, approximately $5 \mathrm{~g}$ soil samples were collected in $40 \mathrm{~mL}$ vials and preserved in $10 \mathrm{~mL}$ of methanol for cVOC analysis. Duplicate samples were collected. Bulk soil samples at the corresponding locations were packed into $50 \mathrm{~mL}$ jars for moisture content quantification. All soil samples were stored at $4^{\circ} \mathrm{C}$ until analysis was performed (EPA Method 5035A).

\subsubsection{Groundwater Sample Analysis}

cVOCs were extracted from $250 \mu \mathrm{L}$ aliquots of groundwater samples by equilibrating with $1 \mathrm{~mL}$ of hexane for 2 hours. $1 \mu \mathrm{L}$ of the extracted cVOCs in hexane was injected by the autosampler into an Agilent 7890 gas chromatograph (GC) with an electron capture detector and a DB-624 capillary column $(75 \mathrm{~m} \times 0.45 \mathrm{~mm} \times 2.55 \mu \mathrm{m})$ to analyze for higher chlorinated ethenes and ethanes (Modified EPA Method 8021). Lesser chlorinated compounds were analyzed from headspace (EPA Method 5021). $1 \mathrm{~mL}$ of groundwater samples were allowed to equilibrate in $2 \mathrm{~mL} \mathrm{GC}$ vials for 30 minutes before $0.25 \mathrm{~mL}$ headspace samples were manually injected in the Agilent 7890 GC. Chlorinated compounds were separated using a GS-Gaspro column (30 m x $320 \mu \mathrm{m}$ I.D.) and measured with a flame ionization detector on the Agilent 7890 GC. For the complete details of these methods for cVOC analysis see Method B.1.

Dissolved organic carbon (DOC) was quantified as an indicator for lactate. Prior to the analysis of DOC, the bulk groundwater samples were filtered through $25 \mathrm{~mm}$ syringe filters with $0.45 \mu \mathrm{m}$ polyethersulfone membranes (Acrodisc, PALL Corporation, Port Washington, NY). Using an iTOC Aurora 1030 (OI Analytical, College Station, TX, USA), DOC concentration was measured with the persulfate wet oxidation method. Sodium was analyzed from the bulk groundwater samples by inductively coupled plasma 
optical emission spectrometry (ICP-OES) (Varian Vista-Pro Axial, Agilent, Santa Clara, CA).

\subsubsection{Soil Sample Analysis}

The exact mass of soil that was previously added to each vial containing methanol in the field was determined. The methanol containing the solubilized cVOCs was then diluted with deionized water at a 10:1 water to methanol ratio. The diluted methanol was shaken for approximately 10 seconds, then using a gastight syringe, samples were taken and immediately added to the appropriate GC vials following the same procedure outlined previously for aqueous cVOC analysis. cVOCs were quantified using the Agilent 7890 GC following the methods outlined above for aqueous cVOCs. To quantify soil moisture content soil collected in the bulk jars were oven dried at $105^{\circ} \mathrm{C}$ for 24 hours and weighed before and after. Soil cVOC concentrations are then reported on a dry-weight basis (EPA Method 8000C).

\subsubsection{DNA Extraction and Analysis}

Sterivex filters were opened and the filter paper was cut into small squares approximately $0.5 \mathrm{~cm} \times 0.5 \mathrm{~cm}$ in size using sterile blades. DNA was then extracted from the paper squares using DNeasy PowerSoil Kit (MoBio Laboratories, Carlsbad, CA) following the manufacturer's procedure. The extracted DNA was eluded with $50 \mu \mathrm{L}$ of sterile DNase/RNase free water and stored at $-80^{\circ} \mathrm{C}$.

A quantitative Polymerase Chain Reaction (qPCR) thermocycler (Bio-Rad Laboratories, Hercules, CA) was used to measure the total abundance of $16 \mathrm{~S}$ rRNA in the DNA samples. A dilution series from 10 to $10^{8}$ gene copies $/ \mu \mathrm{L}$ was made using a Dehalococcoides plasmid of known concentration to create a standard curve. DNA samples from the Control and EK-Control locations were diluted at 1:50 to reduce interferences. EK-Bio DNA samples were diluted at 1:10 due to lower DNA concentrations in these samples. All dilutions were made with sterile UltraPure DNase/RNase free water (Invitrogen, Carlsbad, CA). Reactions were set up in a UV chamber after dilutions were completed. A Master Mix was made containing $7 \mu \mathrm{L}$ of UV 
treated DNase/RNase free water, $10 \mu \mathrm{L}$ of SsoFast EvaGreen Supermix (Bio-Rad Laboratories, Hercules, CA), and $0.5 \mu \mathrm{L}$ each of $10 \mu \mathrm{M}$ forward and reverse general bacteria primers. The following primer sets were used: Dehalococcoides 16S rRNA

Dhc1f (5'-GATGAACGCTAGCGGCG-3') and Dhc264r (5'CCTCTCAGACCAGCTACCGATCGAA-3'); General Bacteria 16S rRNA Genbac1055f (5'-ATGGCTGTCGTCAGCT-3') and Genbac1392r (5'-ACGGGCGGTGTGTAC-3'). Each qPCR reaction contained $18 \mu \mathrm{L}$ of the Master Mix along with $2 \mu \mathrm{L}$ of DNA samples or standards. DNA samples were run in triplicates while standards were run in duplicates. Each plate also contained a minimum of 2 blanks containing only Master Mix.

DNA samples were prepared following the $16 \mathrm{~S}$ Metagenomic Sequencing Library Preparation protocol for the preparation of $16 \mathrm{~S}$ ribosomal RNA gene amplicon for the Illumina MiSeq system (Illumina Part \# 15044223 Rev. B) (Illumina Inc., 2013). Illumina MiSeq was used to sequence the pooled sample library after the preparation of the $16 \mathrm{~S}$ rRNA library using Illumina forward primer (5'-CCTACGGGNGGCWGCAG-3') and Illumina reverse primer (5'-GACTACHVGGGTATCTAATCC-3') to target the $16 \mathrm{~S}$ V3 and V4 region. MetaAmp was then used for analysis which performs quality control and merges the forward and reverse paired-end reads generated during sequencing (Method B.2) (Dong et al., 2017).

\subsubsection{Determining Local Hydraulic Conductivity}

Slug testing was performed 7 months after the last groundwater sampling event so that it would have no impact on sampling results. Analysis of slug testing results using the Hvorslev Model (1951) were used to estimate the local hydraulic conductivity at each monitoring well in the EK-Bio cell (Hvorslev, 1951). To perform the slug test, a known volume of water was added to the well at time zero then water levels were measured every 30 seconds for around the first 5 minutes, then periodically for another several hours. The data was plotted and the hydraulic conductivity was estimated following the same procedure outlined in Ola et al (2016) for estimating hydraulic conductivity in contaminated wells using Hvorslev Method (1951) (Ola et al., 2016). 


\subsection{Results and Discussion}

\subsubsection{Lactate Transport under EK}

Heterogeneities in the electric field applied throughout the EK-Bio cell were observed. The voltage gradients measured in-situ between supply and monitoring wells were lower than the recorded voltage gradient across the system between electrodes, likely due to losses at the electrodes and in-situ. The time-weighted average voltage gradient across the EK-Bio cell was $0.079 \mathrm{~V} / \mathrm{cm}$, with the voltage gradient increasing over time due to an increased applied current (Figure 3.2). In addition, heterogeneities in the applied electric field were observed with depth and with distance from the cathode (Figure A.9). These spatial and temporal variations in the application of the electric field may have influenced any electrokinetic transport processes occurring on site, since local EK transport rates are related to the local voltage gradient.

Lactate was successfully delivered to all EK-Bio monitoring locations (Figure 3.3). Meanwhile, no increase in DOC was present in the Control cell as expected since no lactate was injected (Figure A.8). This validates that the increase in DOC is a result of lactate arrival, and that there are no fluctuations in the background DOC without lactate

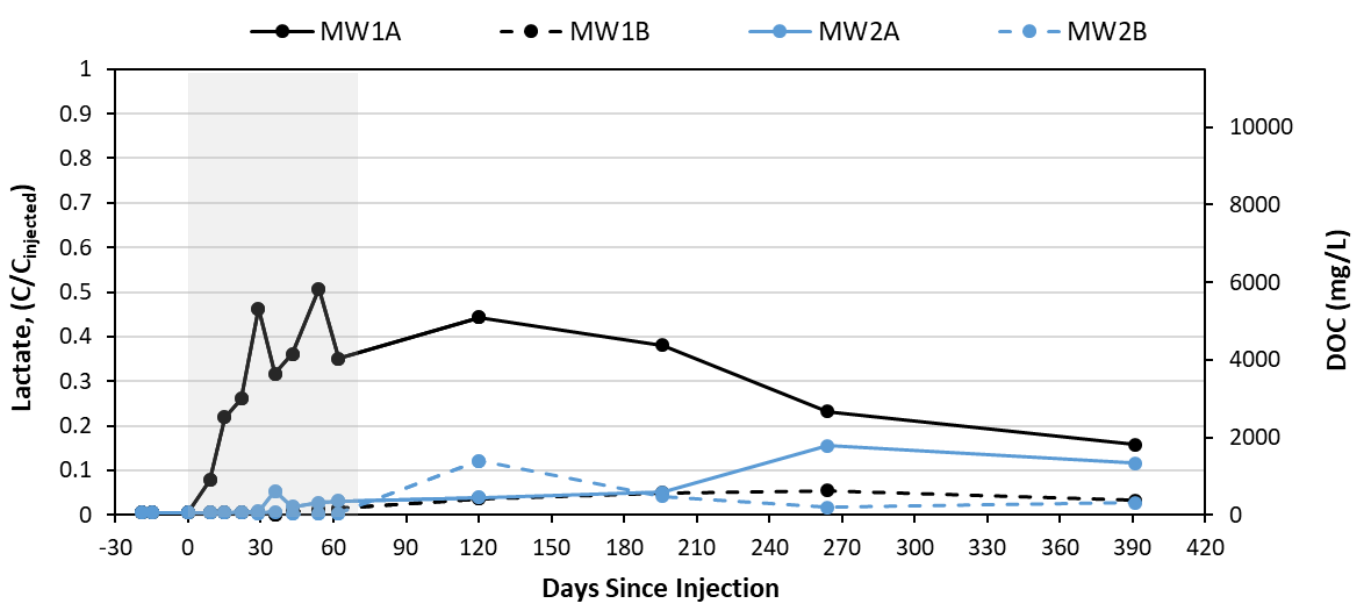

Figure 3.3 Fraction of lactate breakthrough determined from DOC concentrations over time in the EK-Bio cell. Average DOC measurement of injected lactate solution was $11500 \mathrm{mg} / \mathrm{L}$. DOC concentration was a single measurement. Grey region indicates duration in which EK was applied and sodium lactate solution was injected. 
injection. The DOC concentration in the bulk lactate solution injected into the EK-Bio cell was measured to be $11500 \mathrm{mg} / \mathrm{L}$. However, the lactate concentration that reached each well varied, representing an uneven distribution of lactate across the cell (Figure 3.3). MW1A had the highest breakthrough relative to the injected lactate concentration (51\%) followed by MW2A (15\%), MW2B (12\%) and MW1B (5\%).

Potential EK-induced lactate transport rates were determined based on the days of EK applied when lactate first arrived at each monitoring well and the distance to the closest supply well (e.g. Distance from SW1 to MW1B is $40 \mathrm{~cm}$, EK had been applied for 31 days when lactate appeared in MW1B, so the EK transport rate was found by dividing distance by days to get $1.3 \mathrm{~cm} /$ day). Lactate transport under a direct current is expected to occur via electromigration (EM) and therefore lactate would travel towards the anode (Mao et al., 2012; X. Wu et al., 2007, 2012). Assuming first arrival was due to EM only, lactate transport rates were at least $7.4 \mathrm{~cm} /$ day to MW1A, $3.0 \mathrm{~cm} /$ day to MW2A, 1.3 $\mathrm{cm} /$ day to MW1B and $1.8 \mathrm{~cm} /$ day to MW2B. It is noted that EM transport rates likely increased with time due to increases in the voltage gradient (Acar \& Alshawabkeh, 1993; M. Z. Wu et al., 2012), but these increased rates cannot be measured with the monitoring methods used. However, the local voltage gradients during the period in which lactate first arrives at each well (i.e., $0.015 \mathrm{~V} / \mathrm{cm}$ to MW1A, $0.014 \mathrm{~V} / \mathrm{cm}$ to MW2A, $0.036 \mathrm{~V} / \mathrm{cm}$ to MW1B, $0.018 \mathrm{~V} / \mathrm{cm}$ to MW2B; Figure A.9) were not proportional to the observed lactate transport rates, counter to expectations based on theory (M. Z. Wu et al., 2012). This observation supports that there was variability in the subsurface of the EK-Bio cell influencing the transport of lactate.

It is hypothesized that non-EK transport processes may have contributed to lactate transport. While unusual for clay sites, the potential here is due to high hydraulic gradients associated with injection conditions, short distances between wells, and observed site soil heterogeneities. Borehole logs and core images qualitatively indicate a higher plasticity clay with some sand from $3.20 \mathrm{~m}$ to $3.66 \mathrm{~m}$ bgs at MW1, while other depths and monitoring locations were classified as a low plasticity brown clay (Figure A.11). It is noted that supply wells were pumped dry and the adjacent monitoring wells' water levels did not change in 6 hours, confirming no direct connections existed between 
wells. Slug tests revealed a local hydraulic conductivity $(\mathrm{K})$ on the order of $10^{-2} \mathrm{~m} / \mathrm{day}$ at MW1A, MW1B and MW2B (Calculation A.6). These hydraulic conductivities correspond to high end values of stratified clay or mid-range values for very fine sand and silts (Bear, 1972). Local K was an order of magnitude lower at MW2A.

High hydraulic gradients were created between the constant heads in the supply wells (i.e., $0.6 \mathrm{~m} \mathrm{bgs}$ ) and the heads in the monitoring wells during lactate injection (i.e., hydraulic gradient between SW1 and MW1A of 2.43, between SW1 and MW1B of 6.80, between SW2 and MW2A of 3.02, and between SW2 and MW2B of 2.08; Calculation A.4). In order to determine potential advective lactate transport rates, the total days since initial lactate injection to the supply wells was used. The advective lactate transport rate at MW1A would be $4.44 \mathrm{~cm} /$ day, assuming the first arrival of lactate is due to advection from SW1 only. Given the high induced hydraulic gradient between SW1 (injection) and MW1, calculations indicate that the measured local $\mathrm{K}$ at MW1A is consistent with advection of lactate at this location (Figure A.14). Calculated advective lactate transport rates at MW1B and MW2B of $0.93 \mathrm{~cm} /$ day and $1.12 \mathrm{~cm} /$ day respectively, are also consistent with the local K tests (Figure A.15 \& Figure A.17), suggesting that advective transport had the potential to contribute to lactate breakthrough at these wells.

Sodium, which was added to both the supply wells and the electrode wells as part of the lactate and buffer solutions, provides a means to determine if lactate breakthrough was at all attributable to advection or if it was a result of EM alone. Given that sodium is a cation it would move towards the cathode due to EM transport (i.e., opposite to that of lactate). Therefore any initial sodium arrival in MW1A/B should only be due to advection from SW1, while sodium arrival in MW2A/B would be due to advective transport from SW2. At MW1A, increases in sodium and lactate were observed to be coincident, suggesting advection resulted in the first arrival of lactate (Figure $3.3 \&$ Figure 3.4). Both lactate and sodium have a similar effective ionic mobility and thus should have similar EM transport rates, however occurring in opposite directions (Calculation A.1 \& A.2). Since sodium arrived and peaked around the same time as lactate in MW1A, this suggests that sodium counter transport by EM was small in comparison to the advective transport at this location. It is therefore likely that advection was also a more significant 
contributor to the transport of lactate at this location in comparison to EM. This could be due to the low applied current in the time frame where lactate first appeared, resulting in minimal EM transport (Figure A.3). At MW2B there was also an increase in sodium concentration suggesting advection also contributed to the arrival of lactate at this location (Figure 3.4). Increases in lactate concentrations are not observed until after the peak of sodium at MW2B, so it is suspected that lactate is being rapidly consumed at this location. Counter transport of sodium, due to EM towards the cathode, and additional forward transport of lactate by EM can have some impact on the differences between the maximum concentrations of each ion. Since there is no increase in sodium concentration at MW2A or MW1B (Figure 3.4) the initial lactate arrival to these locations was ascribed to EM. If any advection is occurring in these wells, the counter transport of sodium by EM must be greater than advective transport in order to account for the lack of sodium breakthrough. This supports the conclusion that EM transport of lactate would be greater than that of advection at these locations, due to the similar effective ionic mobility of sodium and lactate.

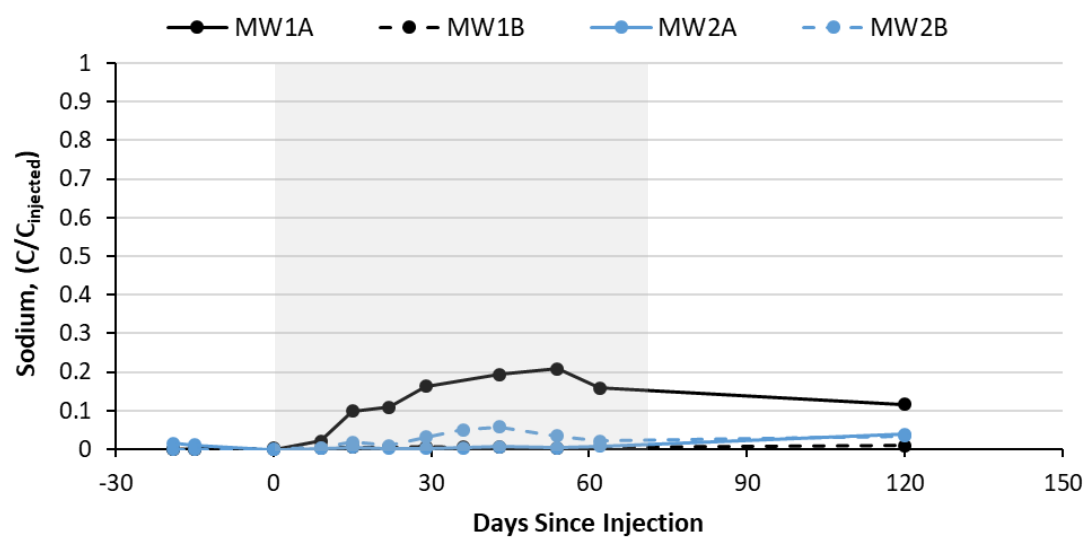

Figure 3.4 Fraction of sodium breakthrough in EK-Bio from injected concentration of $357 \mathrm{mM}$ in the sodium lactate solution. Grey region indicates duration in which EK was applied and sodium lactate solution was injected.

Lactate concentrations continue to increase in MW2A, MW2B and MW1B, with the maximum lactate breakthrough in these wells achieved after the application of the direct current ceased (Figure 3.3). This continued increase in lactate therefore could not be due 
to electrokinetic processes. With sodium lactate solution remaining in the supply wells after the injection and EK phase ceased, the induced hydraulic gradient between the supply wells and monitoring wells remains as the only potential driving force for additional lactate transport. Therefore, these increases in lactate concentration postinjection phase provides evidence that advection contributed to lactate transport to some extent at all monitoring locations. However, while EK was applied, EM resulted in faster lactate transport at MW1B and MW2A, which was concluded due to the lack of sodium breakthrough in these locations during the EK and injection phase.

Lactate transport rates due to EM can be estimated and compared at MW1B $(1.3 \mathrm{~cm} /$ day $)$ and MW2A (3.0 cm/day) as the evidence suggests EM alone resulted in the initial arrival of lactate at these locations. Previous laboratory tests reported lactate transport rates, from 3 to $3.7 \mathrm{~cm} /$ day (Mao et al., 2012; X. Wu et al., 2007, 2012), which are on the same order of magnitude as those observed in this field study. The reason for the approximately double EK-induced transport rate at the shallower monitoring elevation in this pilot test is considered. Using the applied current of $1.125 \mathrm{~A}$ at each electrode and assuming the electric field extended radially $1.5 \mathrm{~m}$ (half the distance between the anode and cathode), the current density resulting from each electrode was roughly $0.5 \mathrm{~A} / \mathrm{m}^{2}$. However, it is likely that the vertical propagation of the electric field from the upper and lower electrodes would overlap (Figure A.10). The shallow monitoring wells (MW1A and MW2A) are screened between the upper and lower electrode depths and therefore the overlap in the electric field would correspond with the depth of those screens. The overlap in the electric fields would result in double the applied current density (i.e., approximately $1 \mathrm{~A} / \mathrm{m}^{2}$ ) at the shallower monitoring well depth. This would explain EM lactate transport rates at the shallower MW2A that are approximately double that at the deeper MW1B. The EM lactate transport rate at MW2A is in the same range as those observed in laboratory studies that used current densities about 5 times greater than this estimated current density in the field (Mao et al., 2012; X. Wu et al., 2007, 2012). Therefore, it appears that similar EM transport rates can be achieved in the field as in the laboratory while using much lower current densities in the field. This is often the case in practical field EK applications, despite the fact that it has not be documented in the 
literature (D. Gent, personal communication, May 23, 2018). The reasons for this observation require further study.

\subsubsection{Bacterial Abundance and Community Structure}

Total bacterial concentration increased in all EK-Bio wells where lactate broke through while changes in total bacterial concentration in the Control cell monitoring wells were orders of magnitude smaller (Figure 3.5). MW1A and MW2B had the largest increase in total bacteria concentration during lactate injection (2 and 3 orders of magnitude, respectively). The total bacterial concentration does not increase to the same extent in MW2A, although it had similar observed concentrations of lactate as MW2B. It was previously stated that rapid consumption of lactate is suspected in MW2B and therefore the more significant increase in total bacterial abundance at MW2B further supports this hypothesis. The increase in total bacterial concentration at MW1B was smaller than other wells likely due to the low lactate concentration. Biostimulation through the addition of an electron donor is known to increase bacterial abundance of dechlorinating bacteria (Adetutu et al., 2015; Hood et al., 2008). Therefore, these increases in total bacterial abundance resulted from stimulation by lactate and a component of these increases is possibly bacteria specific to anaerobic degradation. The bacterial concentration in the Control cell samples were initially higher than those in the EK-Bio samples. It is hypothesized that this is due to the fact that the initial total molar cVOC concentrations in the Control cell were approximately 4 times lower than those in the EK-Bio cell. As a result, bacteria were likely able to thrive without external stimulation better in the Control cell than the EK-Bio cell where high chlorinated solvent concentrations could have toxic effects on the bacterial populations (Koenig et al., 2014). 


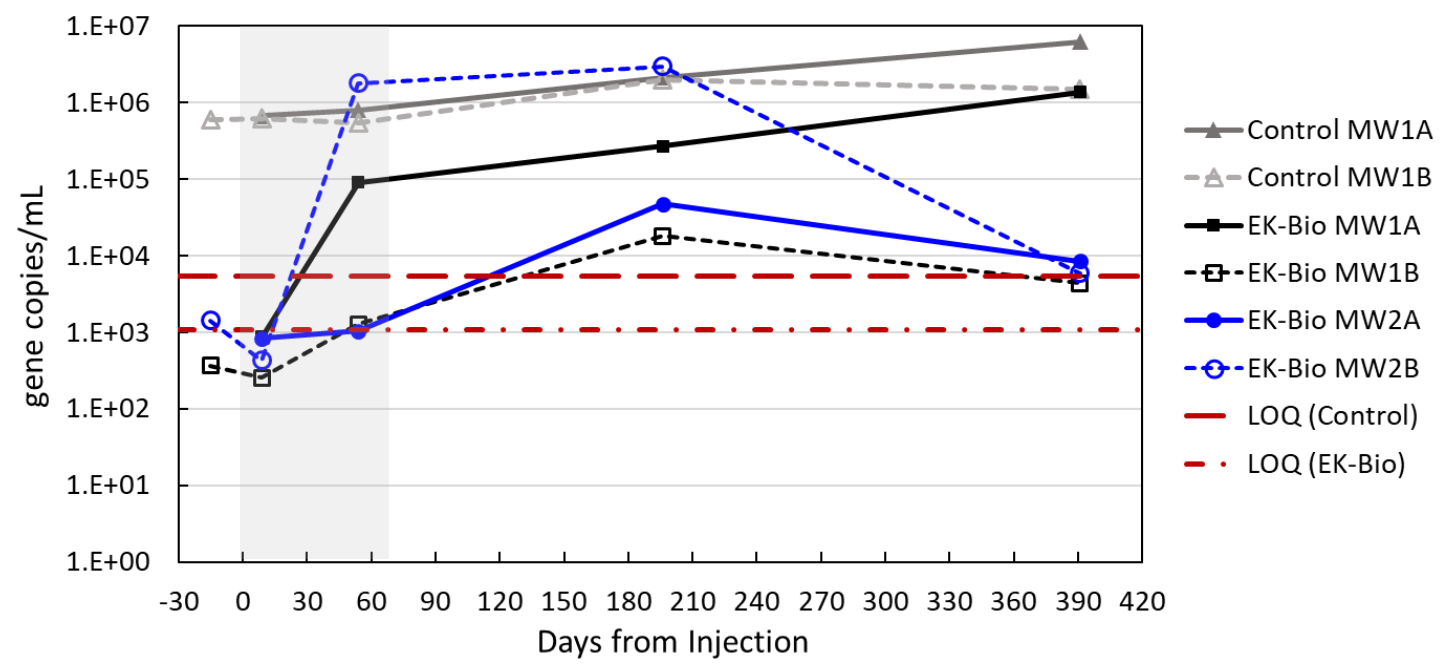

Figure 3.5 General bacteria concentration in Control and EK-Bio aqueous samples determined via qPCR. Grey region indicates duration in which EK was applied and lactate was injected. Limit of quantification (LOQ) for Control and EK-Bio samples are indicated by red dashed lines.

Principle coordinate analysis (PCoA) of the metagenomic sequencing results was used to look at the dissimilarities in bacterial community structure between samples over time and thus evaluate the influence of lactate delivery. The Control cell had few differences in the samples over time, which can be observed by the clustering of all Control samples in the PCoA (Figure 3.6). This is expected since no lactate was delivered to this cell. EKBio samples at 9 days also cluster and over time the distance between samples becomes larger moving towards the upper right quadrant of Figure 3.6. This reflects more dissimilarities in samples as lactate reaches the wells and has time to impact the microbial communities. The distances between EK-Bio MW1B samples increases the least of all EK-Bio wells, with most samples remaining in the lower right quadrant over time (Figure 3.6). This reflects less differences in these samples over time, which is not surprising due to the low concentration of lactate delivered to this location. This provides more evidence that the delivery of a sufficient lactate concentration is necessary to alter the microbial communities in such a way that it is beneficial to the potential for biodegradation. Control and EK-Bio samples at early time do not cluster with each other since these different cell locations initially have different microbial community structures, which could be a result of variation in contaminant distribution from West to East across the study site. 


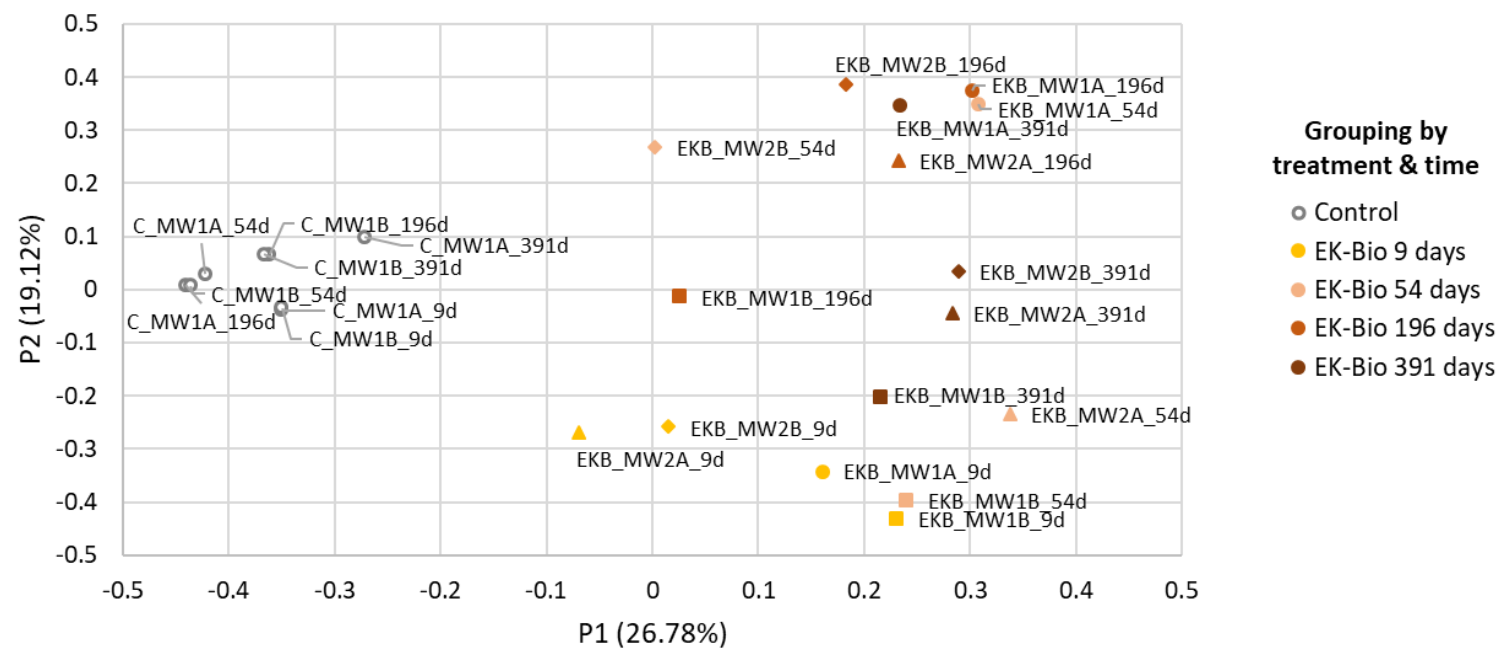

Figure 3.6 Principle Coordinates Analysis of axes 1 and axes 2 showing dissimilarities between Control and EK-Bio samples, created through Illumina sequencing and MetaAmp analysis. 26.78 \% of the variation is captured in axis 1 and $19.12 \%$ of the variation is captured in axes 2 . The further the distance between the samples, the more dissimilar the samples are. EK-Bio monitoring wells each are represented by a different symbol: MW1A $=$ circle $(\bullet)$, MW1B $=$ square $(\square)$, MW2A $=$ triangle $(\triangle)$, MW2B = diamond (४). Colours change based on time as shown in the legend.

Changes in the relative abundance of phyla known to be responsible for anaerobic degradation of contaminants similar to those found on site (e.g., Firmicutes, Chloroflexi) were explored to determine the impact of lactate delivery and the associated potential for anaerobic degradation on site. The phylum Firmicutes contains a large set of genera that are characterized as fermentative bacteria, and both Chloroflexi and Firmicutes contain strict anaerobes, some of which can degrade cVOCs (as discussed below). Within the Chloroflexi phylum, the total abundance of Dehalococcoides (Dhc) was quantified using qPCR. Initial Dhc abundance in EK-Bio MW1B, MW2A and MW2B was very low (i.e. below/near limit of quantification or no amplification) but the total abundance of $D h c$ increased in all EK-Bio wells after the lactate injection phase to an abundance on the order of $10^{3}$ to $10^{4}$ gene copies $/ \mathrm{mL}$ (Figure A.25). This increased $D h c$ abundance exceeds the threshold for possible transformation of cVOCs to ethene, suggesting that this later stimulation of Dhc could have a long-term influence on cVOC concentrations (Lebrón et al., 2011; Lu et al., 2006). It is difficult to distinguish between stimulation of the $D h c$ by lactate or increases due to any transport of KB-1 since the main OHRB in the KB-1 
culture is Dhc (Major et al., 2002). Therefore, the increases in Dhc abundance could provide evidence of success in the delivery of KB-1 but this cannot be confirmed with the available data.

Although long-term increases in Dhc were observed, Chloroflexi was not the dominant phylum and its relative abundance remained relatively low over time (Figure 3.7). This suggests that Chloroflexi was not the most impacted phylum by the treatment. The phylum most impacted by the delivery of lactate was the Firmicutes, which increased in relative abundance between 39 and 44\% in in all EK-Bio monitoring wells except MW1B (Figure 3.7). Within the Firmicutes phylum the relative abundance of several fermentative bacteria increase after lactate injection (i.e., Trichococcus, Clostridium, Proteiniclasticum, and Sedimentibacter) in all EK-Bio monitoring wells except MW1B where any increases are small and at a later time (Figure 3.7). This provides evidence that anaerobic bacteria are being stimulated and that lactate is being fermented, which is important to produce hydrogen to be used as the electron donor by organohalide respiring bacteria (OHRB). The low lactate concentration at MW1B was likely not a sufficient source for the fermentative bacteria to grow at that location. Expectedly, there is no trend in Firmicutes relative abundance in the Control cell and no increase in fermentative bacteria (Figure A.27). Of the fermentative genera present, it is specifically noted that many species of Clostridium have the ability to use lactate as the substrate for fermentation and can produce hydrogen even under high chlorinated solvent concentrations (Bowman et al., 2009; De Vos et al., 2009). An increase in formic acid, acetic acid, and propionic acid was observed in EK-Bio wells providing further evidence that bacteria are fermenting the delivered lactate (Figure A.26). Since lactate is being fermented it is worth noting that the DOC results presented previously could be representing not only lactate but also these carbon-based fermentation products.

The most abundant OHRB on site is Desulfitobacterium and most Desulfitobacterium spp., which are part of the Firmicutes phylum, can perform reductive dehalogenation (Villemur et al., 2006). With the presence of Desulfitobacterium, dechlorination of chlorinated ethenes and ethanes, including 1,2-DCA can occur. Complete 1,2-DCA transformation to ethene is possible by the Desulfitobacterium dichloroeliminans strain 
$D C A 1$, therefore reduction of 1,2-DCA could occur due to the possible presence of this bacteria on site (De Wildeman et al., 2004; Villemur et al., 2006). Increases in Desulfitobacterium relative abundance in MW1A, MW2A and MW2B EK-Bio monitoring wells from initial lactate injection to 391 days were greater than increases in the Control wells, suggesting some stimulation by lactate (Figure 3.7 \& Figure A.27). Much lower increases in Desulfitobacterium at MW1B was observed which is consistent with limited lactate delivery as well as limited change in community structure, as discussed above. There was a large increase in general bacteria concentration in MW1A and MW2B, so the total abundance of Desulfitobacterium likely increased by several orders of magnitude in these locations.
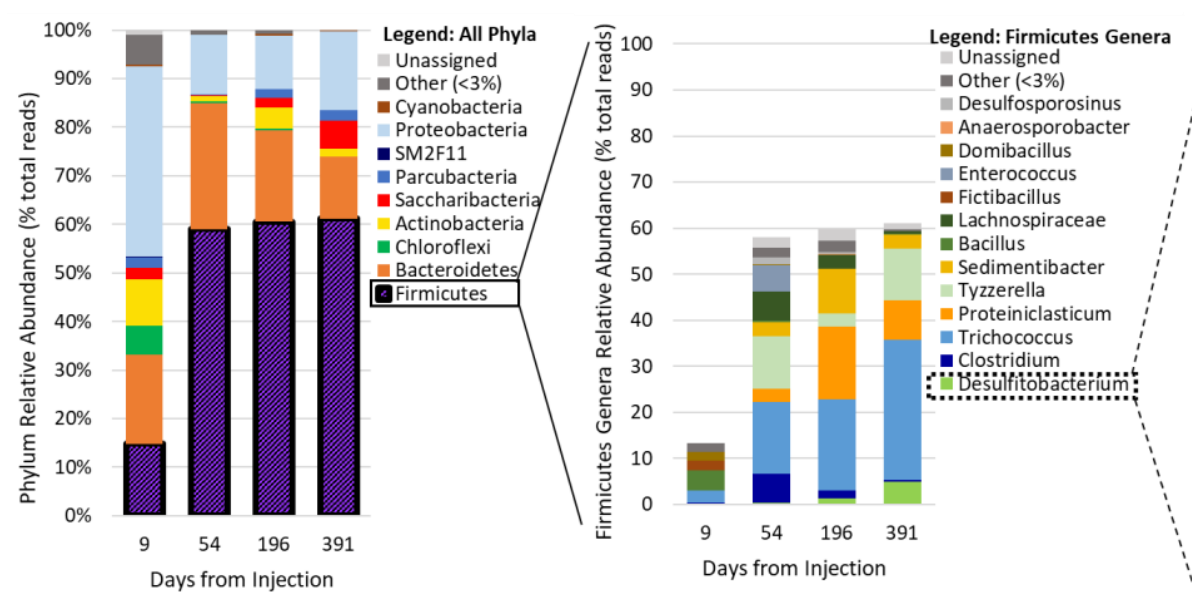

a)

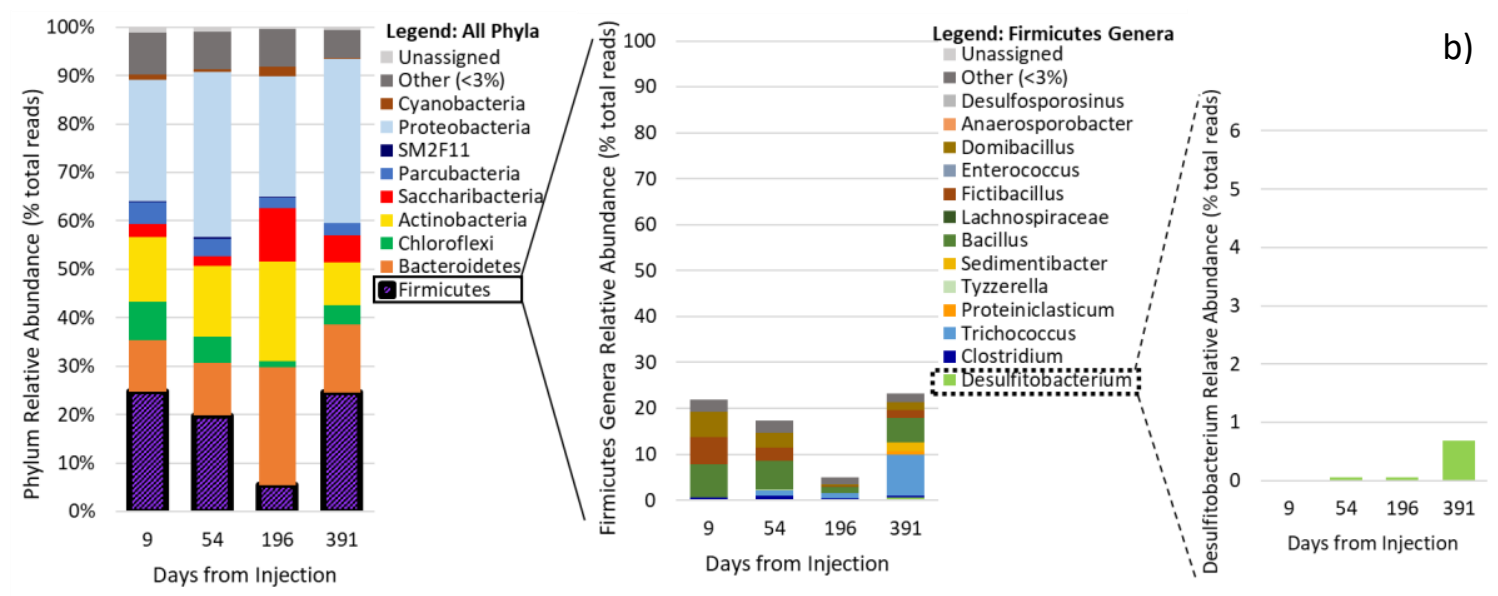



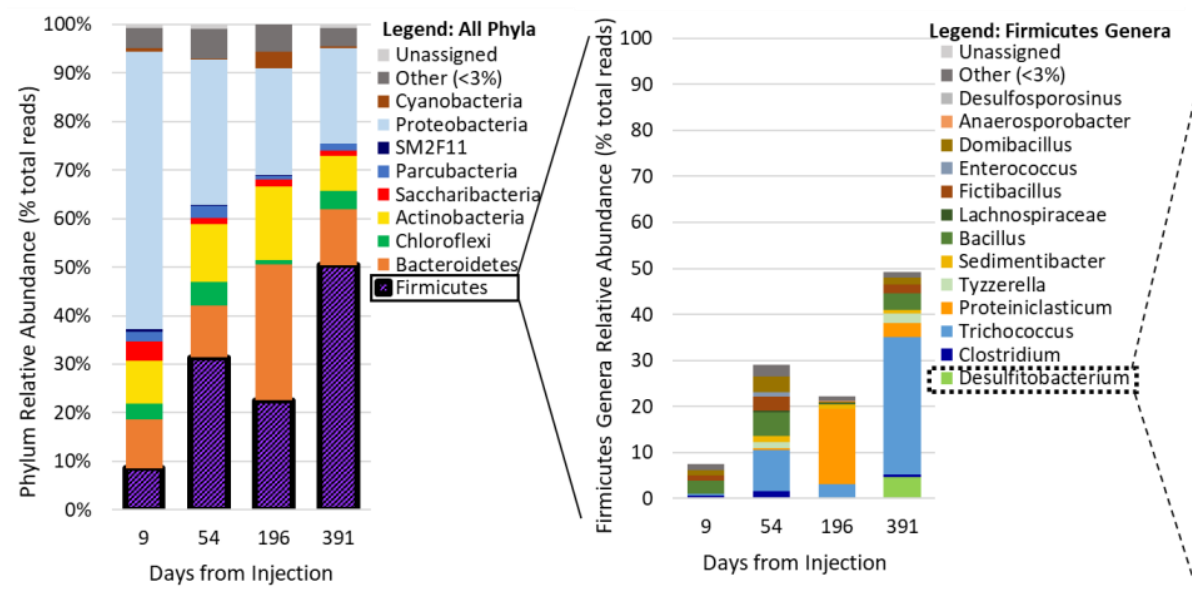

c)

Days from Injection
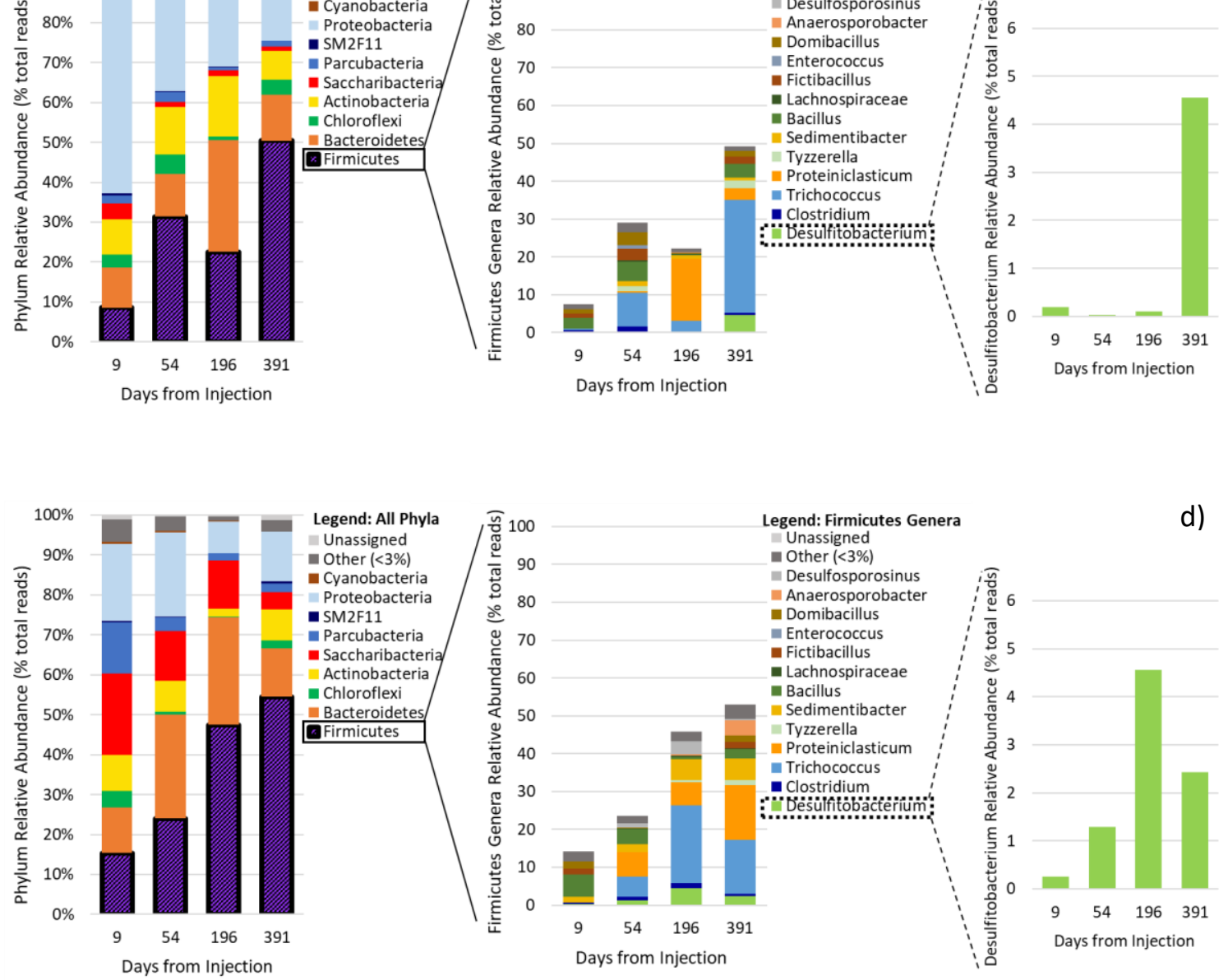

d)

Figure 3.7 EK-Bio temporal changes in relative abundance of Phyla and Firmicutes genera determined from Illumina sequencing and MetaAmp analysis: a) MW1A b) MW1B c) MW2A d) MW2B 


\subsubsection{Changes in Chlorinated Solvent Concentrations}

\subsubsection{Aqueous Chlorinated Solvent Concentrations}

Large decreases in chlorinated volatile organic compound (cVOC) aqueous concentrations were observed at MW1A and MW2B during lactate injection and EK application (Figure 3.8). No decreases in cVOC concentrations were observed in MW1B or MW2A. There was also no change in the cVOC concentration in the Control cell (Figure A.30).
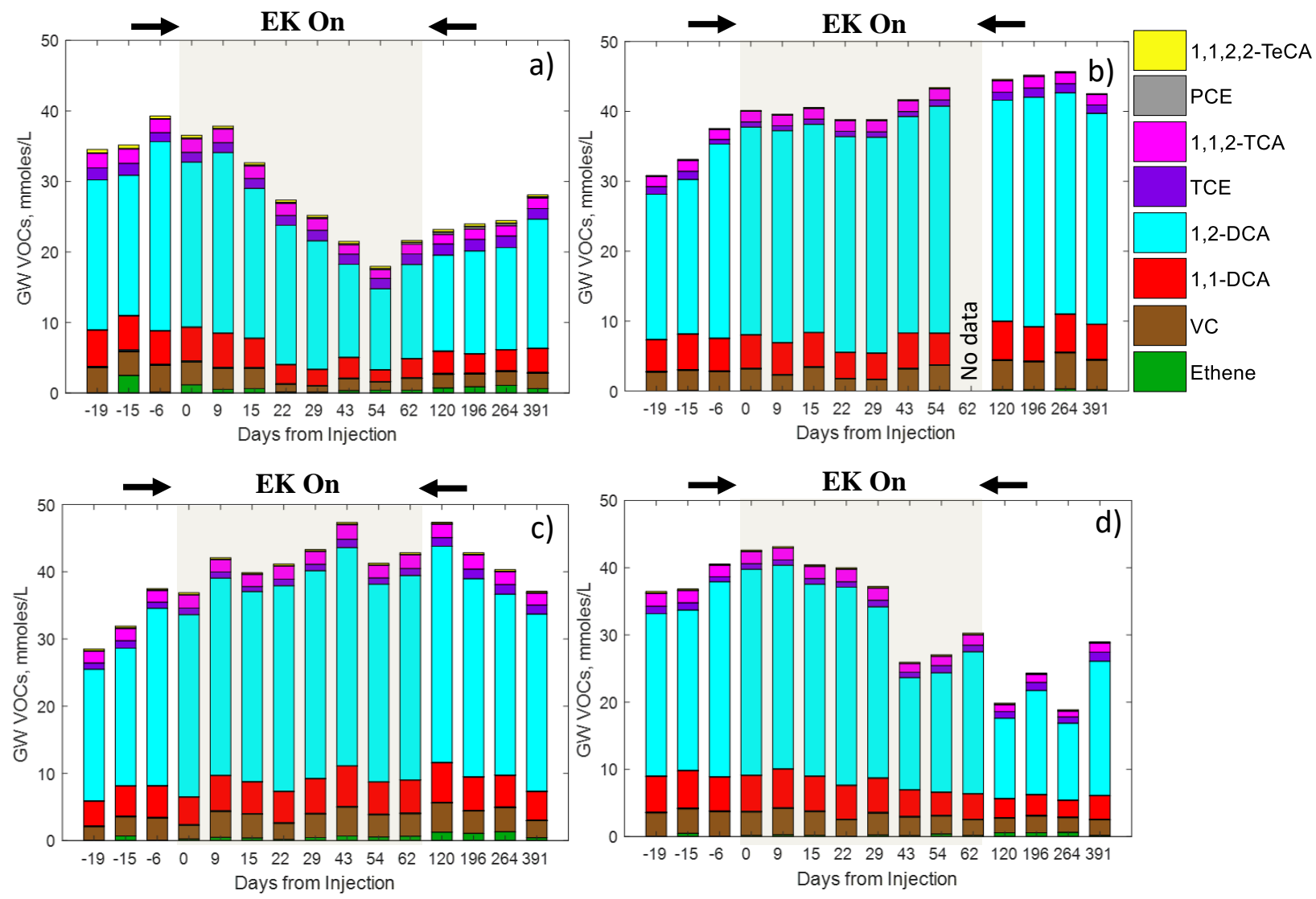

Figure 3.8 EK-Bio total aqueous molar concentration of cVOCs: a) MW1A b) MW1B c) MW2A d) MW2B. Decreases in cVOC concentrations evident in MW1A and MW2B during EK application. All other compounds not shown in legend do not show up at concentrations greater than $0.2 \mathrm{mM}$ in any samples. Duplicate samples were analyzed for each data point with an average error between duplicate samples of total cVOC concentrations equal to $\pm 0.4 \mathrm{mM}$. 
Concentration decreases are suspected to be due to a combination of dilution and biodegradation. Wells with decreases in cVOC concentrations (i.e., MW1A and MW2B) had orders of magnitude increases in microbial abundance (Figure 3.5) and shifts in microbial community structure, including increases in relative abundance of fermenters and strict anaerobes with the potential for anaerobic dechlorination of cVOCs. Although these observations are suggestive that cVOC decreases could be due to microbial activity, it is noted there was no increase in degradation products typical of anaerobic degradation. Specifically, during amendment injection, there are no observed increases in ethene corresponding with a $20 \mathrm{mM}$ decrease in 1,2-DCA. Decreases in total cVOC concentrations but a constant temporal cVOC relative abundance is consistent with what would be expected with dilution.

The source of water responsible for dilution was investigated so that the contribution of dilution to the total $\mathrm{cVOC}$ decreases could be estimated. Electroosmosis can result in the movement of water but the estimated electroosmotic flux is very small for the applied current in our system (Calculation A.3) and would not contribute a large enough volume of water to result in a notable decrease in aqueous phase cVOC concentrations. As discussed earlier, advection resulted in the arrival of sodium lactate solution at MW1A and MW2B. The arrival of the sodium lactate solution in MW1A and MW2B due to advection would result in cVOC dilution during the injection period. It is noted however that the soil phase is highly contaminated; therefore during the 10 to 40 day travel time from the supply well to these monitoring locations, it is likely that significant soil phase cVOCs would partition to the aqueous phase. As such, any injection solution that reaches the monitoring wells through advection is likely contaminated. The total cVOC concentrations in MW1A plateau, with signs of rebounding after lactate injection ceases, providing further evidence for dilution of $\mathrm{cVOC}$ concentrations during lactate injection phase, and partitioning of cVOCs to the aqueous phase. In MW2B, a small increase in ethene is observed post-injection, suggesting some reductive dechlorination in this well. Since this increase in ethene does not occur until after lactate injection, decreases in total cVOCs during amendment injection appears to also be in part due to dilution. Due to the noise in the results, it is not clear if cVOC concentrations in MW2B plateau after the EK phase, or if they continue to decrease at a slower rate. Any decreases in cVOCs that have 
occurred post injection would be the result of biotic processes. The contribution of anaerobic degradation during the injection period could be masked by dilution and partitioning from the solid phase, perhaps making its smaller changes in the cVOC composition difficult to detect.

The percent of cVOC decreases that can be attributed to both dilution and biodegradation in MW1A and MW2B is roughly estimated using the amount of advection previously estimated using the fraction of sodium breakthrough. Using sodium breakthrough provides a conservative estimate of the amount of decreases due to dilution since not all injected sodium would reach the monitoring wells by advection due to counter transport of sodium ions by electromigration towards the cathode. The effect of the counter transport of sodium by EM on the maximum sodium concentration is neglected, and thus this calculation method provides only a simplified estimate of the contribution of dilution. Using this method of estimation, it is determined that about $40 \%$ and $10 \%$ of cVOC decreases are due to dilution from the sodium lactate solution in MW1A and MW2B respectively (Figure 3.9). Therefore, based on estimations using the relative sodium concentrations, it is suspected that biodegradation could contribute to about $60 \%$ of the cVOC decreases in MW1A and 90\% of the cVOC decreases in MW2B.
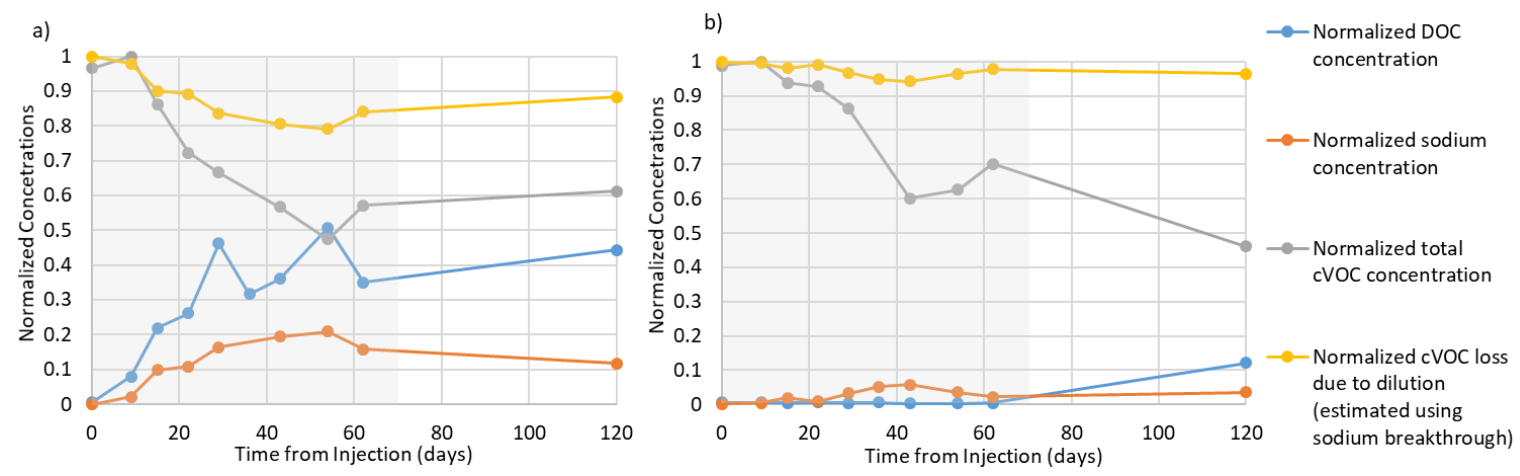

Figure 3.9 Normalized breakthrough of sodium and lactate, concentration decreases of cVOCs, and estimates of contribution of dilution to cVOC decreases in MW1A (a) and MW2B (b) in EK-Bio cell. The grey region indicates the duration in which sodium lactate solution was injected and EK was applied. 


\subsubsection{Soil Chlorinated Solvent Concentrations}

The background concentrations of cVOCs in the EK-Bio cell are quite variable with depth but more consistent from north to south with the highest concentrations of cVOCs found from 3.5 to $4.5 \mathrm{~m}$ bgs (Figure A.31). These background soil concentrations give an idea of the cVOC distribution but due to significant variations in the drilling and sampling methods between the background and post-injection sampling rounds, it is difficult to compare the background and post-injection concentrations. Therefore, a borehole was drilled and sampled north of the EK-Bio cell, outside the influence of EK application or lactate injection, using the same methods as post-injection soil samples. This location is used as the most comparable representation of pre-treatment soil cVOC concentrations, but it is necessary to be aware that this borehole is not an exact representation of background conditions at each post-injection drilling location. For all soil sampling locations see Figure A.2.

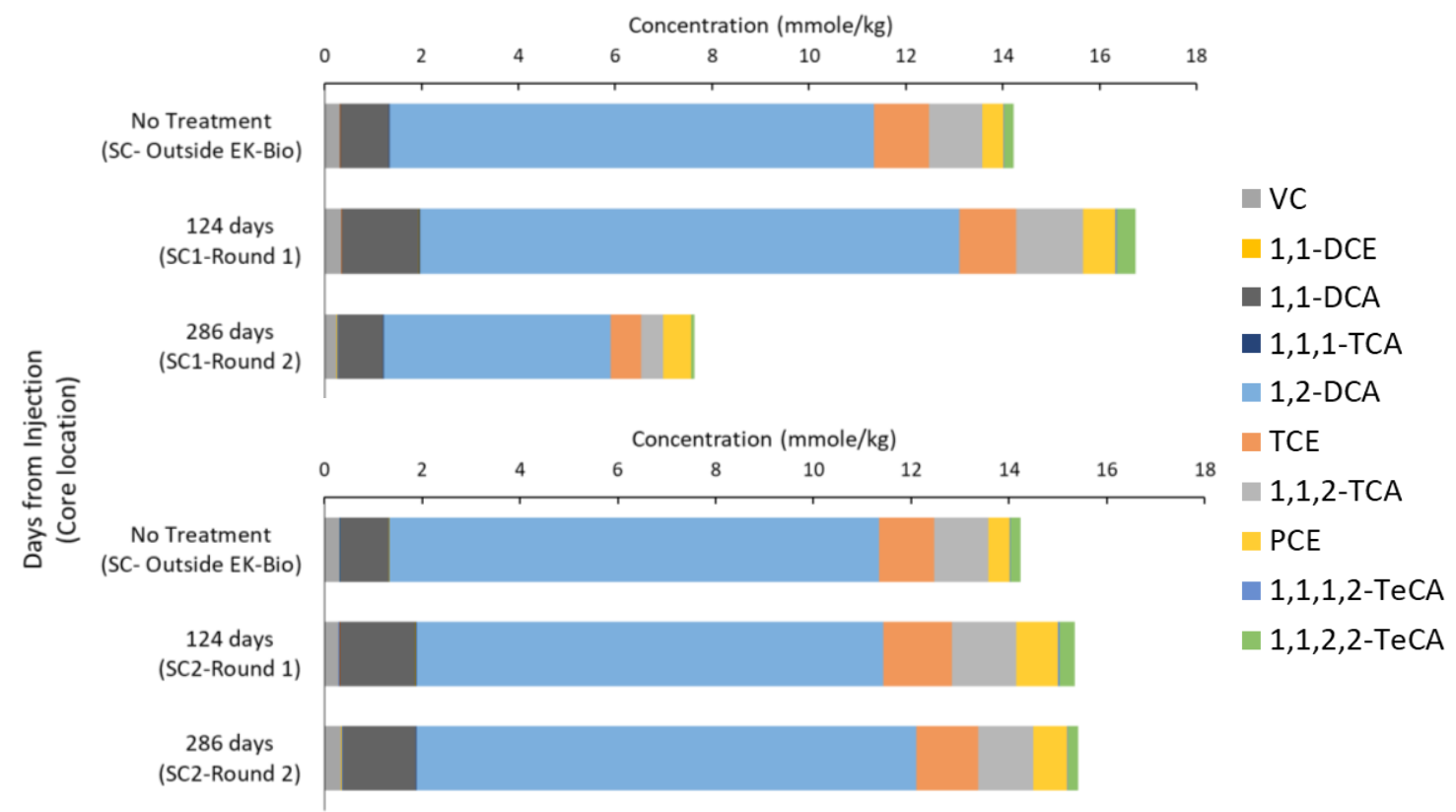

Figure 3.10 EK-Bio total soil molar concentration of cVOCs for sampling rounds post-EK application and sample location outside EK-application. This is an average concentration over the same set of sample depths at each location (Samples collected at $2.9 \mathrm{~m}, 3.35 \mathrm{~m}, 3.66 \mathrm{~m}, 3.96 \mathrm{~m}, 4.27 \mathrm{~m}$ and $4.72 \mathrm{~m}$ bgs). All compounds not given in legend were not at concentrations greater than 0.02 mmoles/kg in any samples. 
No decrease in the average soil cVOCs was noted at $\mathrm{SC} 1$ or $\mathrm{SC} 2$ locations between pretreatment and 124 days post initial lactate injection (Figure 3.10). EK application and lactate injection ended after 71 days and therefore the initial delivery of lactate did not have an immediate effect on the soil cVOC concentrations. This differs from the rapid decrease observed in the aqueous cVOC concentrations in this time. Between 124 and 286 days the average soil cVOCs at SC1 decreased by $54 \%$ while no change is observed in this same time frame at $\mathrm{SC} 2 . \mathrm{SC} 1$ is located closest to MW1, and these decreases are similar to the aqueous cVOC decreases observed in MW1A. Although the total molar concentration of cVOCs decreases at 286 days at $\mathrm{SC} 1$, the relative abundance of each compound remained relatively consistent over the 3 sample times at both SC1 and SC2 (Figure A.34).

Focusing in on the most abundant compound, 1,2-DCA, the concentration profile with depth can be examined (Figure A.33). Between 3.35 and $4.27 \mathrm{~m}$ bgs, samples at SC1 all have decreases in 1,2-DCA from 124 to 286 days. The average concentration of 1,2-DCA over the consistent 6 discrete sampling locations reiterates the trends observed above by the total soil cVOCs. No change is observed between the background samples and 124 days. SC1 has decreases in average 1,2-DCA at 286 days while SC2 location still has no change in average 1,2-DCA concentrations at this time.

It is not clear why the decreases in soil cVOCs, including 1,2-DCA, did not occur before 124 days since similar total cVOC decreases are observed much sooner in the aqueous phase. Microbial stimulation was first observed during the injection period, but this evidence of stimulation increased after the treatment period. Therefore, this delay in additional microbial stimulation could have caused a delay in some of the soil cVOC concentration decreases if they were due to biotic processes. Since cVOC concentrations were reduced in the aqueous phase in part due to dilution during lactate injection, it is most likely that the delayed decrease in cVOCs in the soil at SC1 was due to desorption of the cVOCs. This would then explain why there is no observed change in relative distribution of the cVOCs in the soil that would be reflective of anaerobic dechlorination (Figure A.34) and could explain the signs of cVOC concentration rebound in the aqueous phase at MW1A. It is unclear exactly why cVOC concentration decreases occur at SC2 
but not at SC1 but is likely related to the soil heterogeneities discussed previously. SC2 location is closer to MW2 where lower permeability zones were observed while SC1 location is closest to MW1 where higher permeability zones were observed. Groundwater cVOC concentrations in higher permeability zones would have experienced more dilution during the injection period than other areas. Since there are less of these higher permeability zones near SC2, there is likely to be a lower concentration gradient between the sorbed and aqueous phase. This lower concentration gradient would result in less desorption and is a possible explanation for the lack of change in soil cVOC concentrations at SC2.

\subsubsection{Combined Discussion of All Results}

It is useful to clarify the relationships between several monitored parameters that have been previously discussed by comparing only two monitoring locations (i.e., MW1A and MW1B) with different dominant processes (Figure 3.11). Specifically, the dissolved organic carbon, cVOC concentrations, general bacteria concentration and relative abundance of Firmicutes and Desulfitobacterium are compared at each well. At MW1A it is noted that there is a large and rapid increase in lactate concentration, represented by the increase in DOC. An increase in general bacteria concentrations and the relative abundance of Firmicutes concentration occurs at the same time as the increase in lactate supporting the successful stimulation of bacteria due to the delivery of lactate (Figure 3.11). Desulfitobacterium relative abundance increases more slowly over time, with the majority of the increase long after injection. This suggests that there is potential for long term anaerobic degradation with a high relative abundance of a potential dechlorinating bacteria, high concentration of lactate remaining, and a high relative abundance of fermentative bacteria. Concentrations of aqueous cVOCs decrease rapidly during the injection period then plateau and show a slight rebound post-injection. The cVOC concentration decreases are coincident with the rapid increase of lactate breakthrough, and since it has been established that the initial arrival of lactate into MW1A is due to advection, dilution from the arrival of the lactate solution would likely have a large contribution to the cVOC decreases. At MW1B, the lowest lactate concentration was delivered by electromigration alone, and as a result there was little response from the 
bacterial communities and no change in cVOC concentration (Figure 3.11), validating that sufficient concentrations need to be able to be delivered by EM for successful biotic stimulation. These relationships are more difficult to relate in the other monitoring wells (Figure A.35), and this complexity is likely attributed to several heterogeneities on site such as spatial variation in soil properties as well as lactate, contaminant and microbial distribution. Like MW1A, MW2B is suspected to a have achieved bacterial stimulation through the delivery of lactate from both advection and electromigration, and therefore a combination of dilution and anaerobic degradation is responsible for changes in cVOC a) concentrations. MW2A achieved the most successful delivery of lactate by electromigration alone which was able to stimulate bacterial populations but did not result in notable cVOC decreases in the time frame monitored.
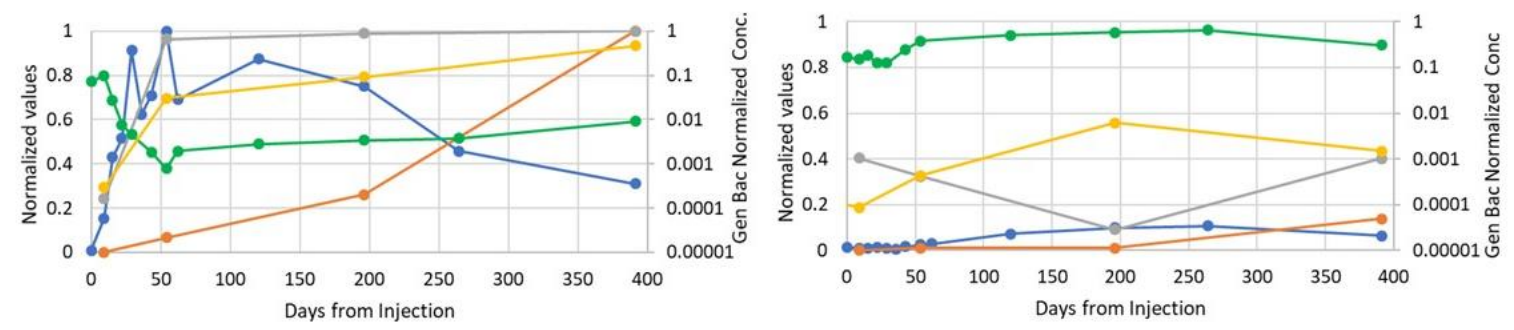

$\rightarrow$ Dissolved Organic Carbon $\rightarrow-$ Relative Abundance Desulfitobacterium $\rightarrow$ Relative Abundance Firmicutes $\rightarrow-G W$ total cVOCs $\multimap-$ Conc of gen bac

Figure 3.11 Monitored groundwater parameters for MW1A (a) and MW1B (b) normalized to the maximum value of each parameter measured on site.

\subsection{Conclusions}

This research demonstrates, at the field scale, the use of electrokinetics to successfully enhance the delivery of lactate through a chlorinated solvent-contaminated clay subsurface. Lactate transport rates observed in the field site under the electric field were 3 orders of magnitude larger than the transport rates that would be due to the natural groundwater velocity through homogenous brown clay, without a high induced hydraulic gradient in supply wells. Surprisingly, it was determined that advection of injected sodium lactate solution needs to be considered even when implementing this technology at clay sites, due to the high hydraulic gradients induced by the injection wells. Locations with relatively high (for clay) hydraulic conductivities $\left(>10^{-2} \mathrm{~m} /\right.$ day) had 
contributions of advection and electromigration to the transport of lactate. At MW1B and MW2A, initial arrival of lactate was dominated by electromigration. The lactate transport rates due to electromigration were comparable with those achieved in lab-scale studies that applied much higher current densities, suggesting that a lower current density in the field can result in similar EK-induced lactate transport rates. This is a puzzling yet beneficial finding that requires further investigation.

The delivery of lactate throughout the EK-Bio cell stimulated the bacterial populations associated with all wells, with only minimal stimulation observed at MW1B where the lowest lactate concentration was achieved. The relative abundance of the phylum Chloroflexi does not increase and therefore although there are increases in the known dechlorinating bacteria, Dehalococcoides, this phylum is not the most influenced by the lactate delivery. The phylum Firmicutes, containing fermenters and strict anaerobes, increased over time where sufficient lactate concentrations were present, providing evidence of fermentation of injected lactate. The organohalide respiring bacteria present in highest and increasing relative abundance is Desulfitobacterium, which therefore has the possibility of contributing to the degradation of chlorinated solvents on site.

Decreases in aqueous cVOC concentrations occurred at MW1A and MW2B and are determined to be in part due to dilution through advection of injected sodium lactate solution. Biodegradation is also suspected to contribute to the cVOC decreases since bacterial stimulation was successful at corresponding locations. The decreases in aqueous cVOCs during lactate injection are therefore likely due to a combination of biodegradation and dilution. Delayed decreases in soil cVOCs is suspected to be due to long term desorption or biodegradation. The spatial variation in soil cVOC decreases is difficult to explain with certainty but is likely a result of heterogeneities in soil properties, contaminant distribution and treated groundwater locations.

Various types of heterogeneities on site have been determined to have a strong influence on the success of electrokinetically-enhanced bioremediation. One of these which impacted much of the results were heterogeneities in the hydraulic conductivity of the subsurface material. Another was the heterogonous distribution of the electric field. In 
combination, these heterogeneities and their impact on lactate transport and bacterial stimulation are responsible for the variable success between different locations and depths. More thorough characterization and a better conceptual understanding of a site prior to the application of EK-Bio could help avoid some of the spatial variability in the success of the remedial activity.

There are no current peer-reviewed journal publications that validate that electrokinetics can effectively be used to enhance the delivery of lactate in a clay subsurface at a field site, as demonstrated in this study. In addition, this study addresses some of the challenges that can arise when applying EK-Bio in the field, so future implementation can be more successful. With the lack of effective technology to target contamination in low permeability media, electrokinetically-enhanced bioremediation has potential to be a possible option for the treatment of chlorinated solvents in low permeability media with further investigation at a field scale. Further investigation into some of the identified unknowns was outside the scope of this study, but these unknowns along with the more conclusive findings, can be used as building blocks in the continued research and development of this technology for field application.

\subsection{References}

Acar, Y. B., \& Alshawabkeh, A. N. (1993). Principles of Electrokinetic Remediation. Environmental Science and Technology, 27(13), 2638-2647.

Adetutu, E. M., Gundry, T. D., Patil, S. S., Golneshin, A., Adigun, J., Bhaskarla, V., ... Ball, A. S. (2015). Exploiting the intrinsic microbial degradative potential for fieldbased in situ dechlorination of trichloroethene contaminated groundwater. Journal of Hazardous Materials, 300, 48-57.

Adrian, L., \& Loffler, F. E. (2016). Organohalide-Respiring Bacteria. Berlin: Springer.

Bear, J. (1972). Dynamics of Fluids in Porous Media. New York: American Elsevier.

Bowman, K. S., Rainey, F. A., \& Moe, W. M. (2009). Production of hydrogen by clostridium species in the presence of chlorinated solvents. FEMS Microbiology Letters, 290(2), 188-194.

Chapman, S. W., \& Parker, B. L. (2005). Plume persistence due to aquitard back diffusion following dense nonaqueous phase liquid source removal or isolation. Water Resources Research, 41(12), 1-16. 
De Vos, P., Garrity, G. M., Jones, D., Krieg, N. R., Ludwig, W., Rainey, F. A., ... Whitman, W. B. (2009). The Firmicutes. Bergey's Manual of Systematic Bacteriology (Second, Vol. 3). New York: Springer.

De Wildeman, S., Linthout, G., Van Langenhove, H., \& Verstraete, W. (2004). Complete lab-scale detoxification of groundwater containing 1,2-dichloroethane. Applied Microbiology and Biotechnology, 63(5), 609-612.

Dong, X., Kleiner, M., Sharp, C. E., Thorson, E., Li, C., Liu, D., \& Strous, M. (2017). Fast and simple analysis of MiSeq amplicon sequencing data with MetaAmp. Frontiers in Microbiology, 8, 1-8.

Hood, E. D., Major, D. W., Quinn, J. W., Yoon, W. S., Gavaskar, A., \& Edwards, E. A. (2008). Demonstration of enhanced bioremediation in a TCE source area at Launch Complex 34, Cape Canaveral Air Force Station. Ground Water Monitoring and Remediation, 28(2), 98-107.

Hug, L. A., Maphosa, F., Leys, D., Loffler, F. E., Smidt, H., Edwards, E. A., \& Adrian, L. (2013). Overview of organohalide-respiring bacteria and a proposal for a classification system for reductive dehalogenases. Philosophical Transactions of the Royal Society B: Biological Sciences, 368(1616), 20120322-20120322.

Hvorslev, M. J. (1951). Time Lag and Soil Permeability in Ground-Water Observations. Bulletin n. 36.

Illumina Inc. (2013). 16S Metagenomic Sequencing Library: Preparation Preparing 16S Ribosomal RNA Gene Amplicons for the Illumina MiSeq System.

Kim, S. H., Han, H. Y., Lee, Y. J., Kim, C. W., \& Yang, J. W. (2010). Effect of electrokinetic remediation on indigenous microbial activity and community within diesel contaminated soil. Science of the Total Environment, 408(16), 3162-3168.

Koenig, J. C., Groissmeier, K. D., \& Manefield, M. J. (2014). Tolerance of Anaerobic Bacteria to Chlorinated Solvents. Microbes and Environments, 29(1), 23-30.

Lear, G., Harbottle, M. J., Van Der Gast, C. J., Jackman, S. A., Knowles, C. J., Sills, G., \& Thompson, I. P. (2004). The effect of electrokinetics on soil microbial communities. Soil Biology and Biochemistry, 36(11), 1751-1760.

Lebrón, C., Petrovskis, E., Löffler, F., \& Henn, K. (2011). Guidance Protocol: Application of Nucleic Acid-Based Tools for Monitoring Monitored Natural Attenuation (MNA), Biostimulation, and Bioaugmentation at Chlorinated Solvent Sites (Report ESTCP ER-0518). Alexandria, VA: ESTCP.

Leys, D., Adrian, L., \& Smidt, H. (2013). Organohalide respiration: microbes breathing chlorinated molecules. Philosophical Transactions of the Royal Society B: Biological Sciences, 368(1616). 
Lu, X., Kampbell, D. H., \& Wilson, J. T. (2006). Evaluation of the Role of Dehalococcoides Organisms in the Natural Attenuation of Chlorinated Ethylenes in Ground Water. Cinninnati, $\mathrm{OH}$.

Major, D. W., McMaster, M. L., Cox, E. E., Edwards, E. A., Dworatzek, S. M., Hendrickson, E. R., ... Buonamici, L. W. (2002). Field Demonstration of Successful Bioaugmentation To Achieve Dechlorination of Tetrachloroethene To Ethene. Environmental Science and Technology, 36(23), 5106-5116.

Mao, X., Wang, J., Ciblak, A., Cox, E. E., Riis, C., Terkelsen, M., ... Alshawabkeh, A. N. (2012). Electrokinetic-enhanced bioaugmentation for remediation of chlorinated solvents contaminated clay. Journal of Hazardous Materials, 213-214, 311-317.

Maymó-Gatell, X., Anguish, T., \& Zinder, S. H. (1999). Reductive dechlorination of chlorinated ethenes and 1, 2-dichloroethane by "Dehalococcoides ethenogenes" 195. Applied and Environmental Microbiology, 65(7), 3108-3113.

Ola, S. A., Fadugba, O. ., \& Uduebor, M. A. (2016). Slug Tests for Determination of Hydraulic Conductivity of Contaminated Wells. Environment and Natural Resources Research, 6(2), 156.

Parker, B. L., Chapman, S. W., \& Guilbeault, M. A. (2008). Plume persistence caused by back diffusion from thin clay layers in a sand aquifer following TCE source-zone hydraulic isolation. Journal of Contaminant Hydrology, 102(1-2), 86-104.

Scheutz, C., Durant, N. D., Dennis, P., Hansen, M. H., Jorgensen, T., Jakobsen, R., ... Bjerg, P. L. (2008). Concurrent Ethene Generation and Growth of Dehalococcoides Containing Vinyl Chloride Reductive Dehalogenase Genes During an Enhanced Reductive Dechlorination Field Demonstration. Environmental Science and Technology, 42(24), 9302-9309.

Tatti, F., Papini, M. P., Sappa, G., Raboni, M., Arjmand, F., \& Viotti, P. (2018). Contaminant back-diffusion from low-permeability layers as affected by groundwater velocity: A laboratory investigation by box model and image analysis. Science of The Total Environment, 622-623, 164-171.

Thevanayagam, S., \& Rishindran, T. (1998). Injection of Nutrients and TEAs in Clayey Soils Using Electrokinetics. Journal of Geotechnical and Geoenvironmental Engineering, 124(April), 330-338.

Thomas, J. M., \& Ward, C. H. (1992). Subsurface microbial ecology and bioremediation. Journal of Hazardous Materials, 32(2-3), 179-194.

Tyagi, M., da Fonseca, M. M. R., \& de Carvalho, C. C. C. R. (2011). Bioaugmentation and biostimulation strategies to improve the effectiveness of bioremediation processes. Biodegradation, 22(2), 231-241. 
Villemur, R., Lanthier, M., Beaudet, R., \& Lépine, F. (2006). The Desulfitobacterium genus. FEMS Microbiology Reviews, 30(5), 706-733.

Wu, M. Z., Reynolds, D. A., Fourie, A., Prommer, H., \& Thomas, D. G. (2012). Electrokinetic in situ oxidation remediation: Assessment of parameter sensitivities and the influence of aquifer heterogeneity on remediation efficiency. Journal of Contaminant Hydrology, 136-137, 72-85.

Wu, X., Alshawabkeh, A. N., Gent, D. B., Larson, S. L., \& Davis, J. L. (2007). Lactate Transport in Soil by DC Fields. Journal of Geotechnical and Geoenvironmental Engineering, 133(12), 1587-1596.

Wu, X., Gent, D. B., Davis, J. L., \& Alshawabkeh, A. N. (2012). Lactate injection by electric currents for bioremediation of tetrachloroethylene in clay. Electrochimica Acta, 86, 157-163. 


\section{Chapter 4}

\section{Conclusions and Recommendations}

\subsection{Conclusions}

The ability for electrokinetics (EK) to enhance bioremediation of chlorinated solvents in clay at the field scale was evaluated. This was completed by performing a pilot field test where lactate was injected into clay under a direct current to determine if its emplacement could be enhanced through electrokinetic transport mechanisms. The ability for any delivered lactate to result in necessary bacterial stimulation for anaerobic degradation and the effects on chlorinated solvents concentrations in the clay were also investigated. Groundwater samples were collected before, during and after lactate injection and EK application to track lactate delivery, total bacterial abundance and community structure changes and any changes in chlorinated solvents concentrations. Soil samples were also collected pre and post- injection to identify any changes in soil chlorinated solvent concentrations.

Results from the pilot field tests suggest that:

- Lactate delivery in clay can successfully be enhanced by electrokinetics with evidence of lactate transport by electromigration between 1.3 to $3.0 \mathrm{~cm} / \mathrm{day}$. This is 3 orders of magnitude faster than transport due to natural groundwater flow on the site.

- EK-induced transport rates comparable to those achieved in previous bench scale studies that used applied current densities 5 to 10 times higher than used in this pilot test. This suggests that lower current densities can be used in the field while still achieving sufficient lactate transport by electromigration.

- Soil heterogeneities can result in advective transport contributing to the delivery of lactate when a strong hydraulic gradient is induced between the supply wells and monitoring wells and when zones of higher permeability (for clay) are present. 
- Lactate emplacement in clay successfully stimulates the bacterial populations resulting in increases in the total bacterial abundance. Specifically increases in the relative abundance of Firmicutes, including strict anaerobes and fermentative bacteria, was observed, providing evidence for the fermentation of lactate.

- There were increases in abundance of organohalide respiring bacteria. There was a long-term increase in total abundance of Dehalococcoides (Chloroflexi) which could contribute to the long-term fate chlorinated solvents on site. There was also an increase in the relative abundance of Desulfitobacterium (Firmicutes) which is suspected to contribute to the occurrence of anaerobic degradation on site.

- Decreases in chlorinated solvent concentrations in the groundwater of approximately $50 \%$ were in part due to dilution from the advection of sodium lactate supply well solution while also partly due to anaerobic degradation.

- Decreases in soil chlorinated solvent concentrations post-injection are likely due to desorption resulting from the decreases in the aqueous phase concentration or are due to long term increased microbial activity.

- Heterogeneities were observed in the electric field distribution, lactate transport, bacterial response, and remedial performance.

This novel research is one of the first field scale studies to validate that electrokinetics can effectively be used to enhance the delivery of lactate in a clay subsurface, with no existing peer-reviewed journal publications evaluating this on a field site. Electrokinetically enhanced bioremediation has the potential to be an option for targeting contamination in low permeability zones, since there is a lack of existing technology with the ability to overcome the remedial challenges associated with low permeability media. This study addressed some of the challenges that could be faced when implementing this technology at the field scale. Although not all uncertainties could be addressed within the scope of this research, these findings should be considered in future investigation and implementation of electrokinetically-enhanced bioremediation in the field. 


\subsection{Recommendations}

While this study provided many useful insights into the application of electrokinetic bioremediation on a field site, further investigation at the field scale is still recommended for it to be most effectively implemented as a remediation strategy in contaminated clay. Prior to implementation, a better characterization of the site including contaminant distribution, soil properties, and existing microbial communities would be beneficial in applying this technology more successfully since much of the uncertainties and challenges that arose during this pilot field test were a result of unexpected heterogeneities in these properties. Additionally, the extent and effect of the electric field in the application of electrokinetics for enhanced lactate delivery should be further explored. Modelling of the electric field and transport of lactate with the specific electrode configuration would be useful. There is evidence that voltage gradients and current densities due to the applied direct current are not uniform. As such, it is likely that different electrode configurations or operation schemes could result in a more uniform electric field and in turn more uniform EK-enhanced lactate transport and remedial success. It is still puzzling as to why similar EK-induced lactate transport rates can be achieved in the field as in the laboratory while using a much lower current density. This is a beneficial finding for the future of this technology in field applications but the explanation for this observation requires further investigation.

This study specifically focused on chlorinated solvent contamination and biostimulation through the injection of lactate, but the principle and these findings could be applied to a broader range of organic contaminants and biostimulants as long as the required microbial populations are present. Investigation into the application of electrokineticenhanced bioremediation at the field scale for other organic contaminants could be useful in the future to allow this technology to be used in more sites with contaminated clay that cannot be treated with existing techniques. 


\section{Appendices}

\section{A. Appendix A: Supplementary Figures, Tables and Calculations}
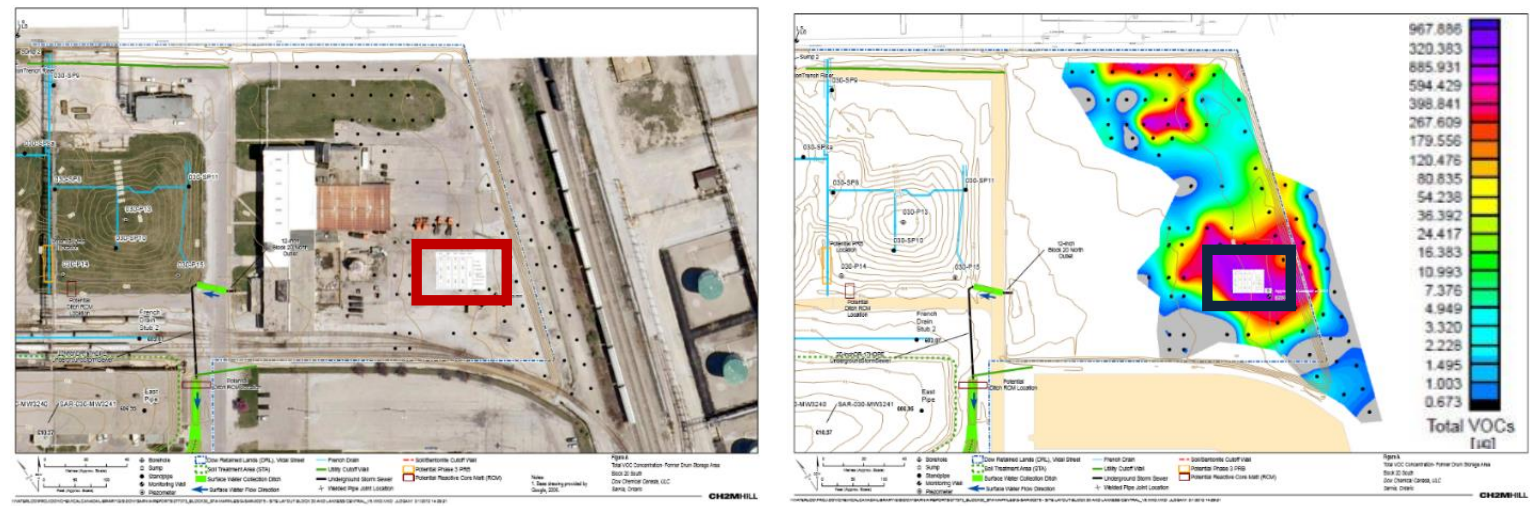

Figure A.1 Plan views of field site provided by Jacobs (previously CH2M Hill). Black points indicate GoreSorber locations and boxes indicate the location of the study site. a) Aerial view of site from Google 2006 b) Map of total cVOCs [ $\mu$ g] with concentrations from GoreSorber locations. Study site is set up to target the highest concentration region.

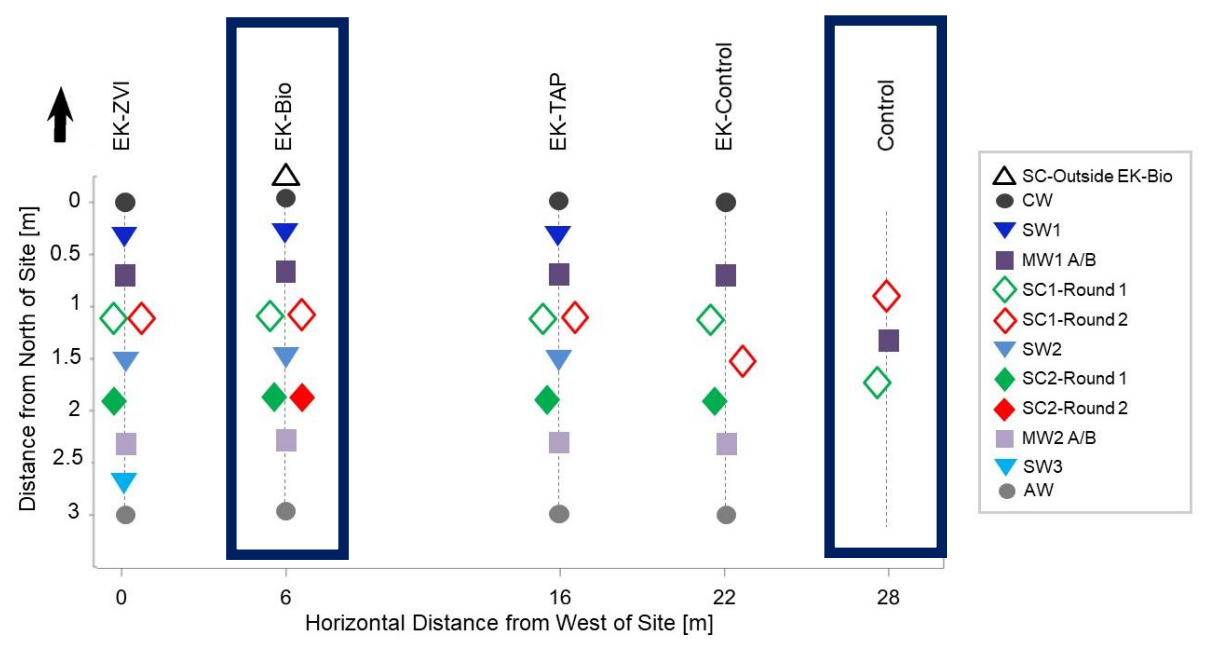

Figure A.2 Plan view layout of entire EK test site. Cells of interest for this project are indicated with boxes. Soil coring locations are indicated. 

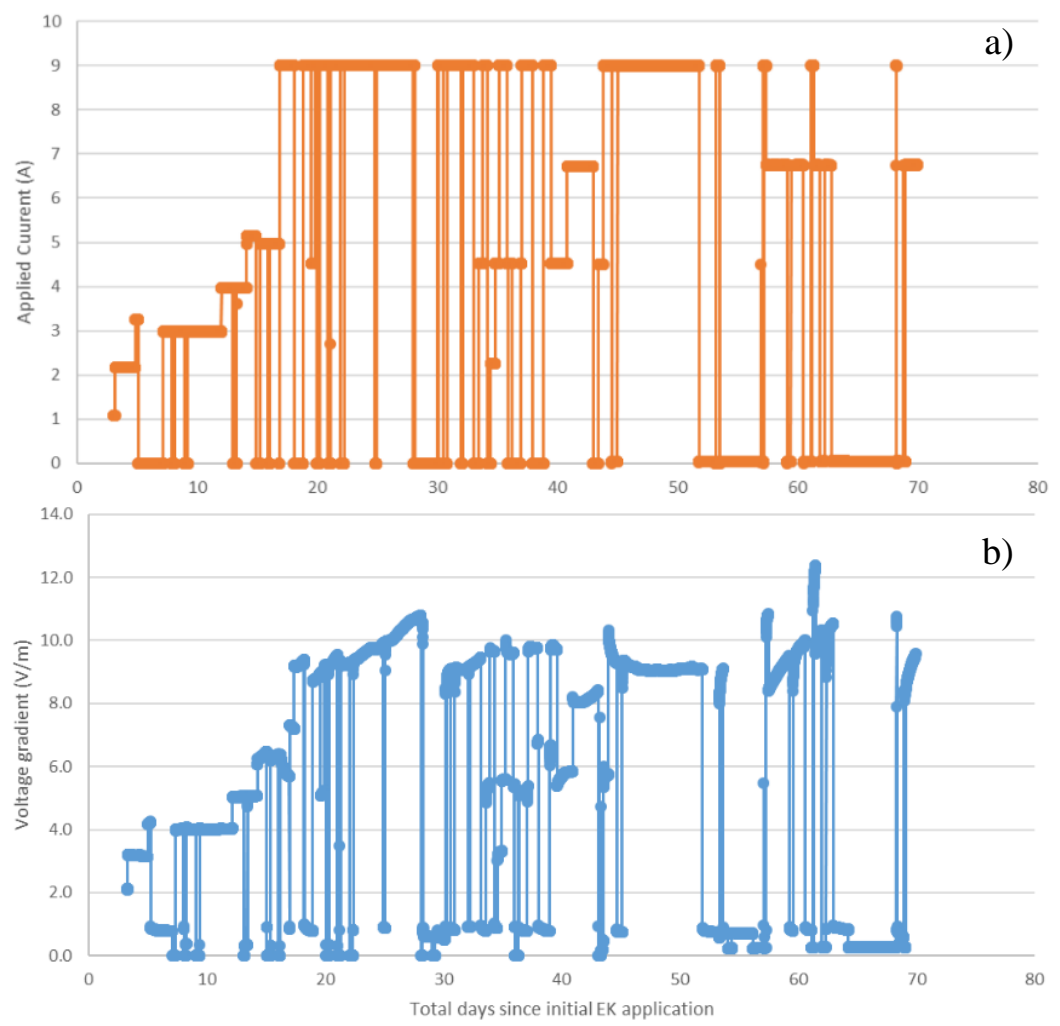

Figure A.3 Total applied current across all EK cells (a) and resulting voltage gradient (b) over total time since initial EK application. Note discontinuities in system operation due to power off while addressing operational issues and for sampling events. 


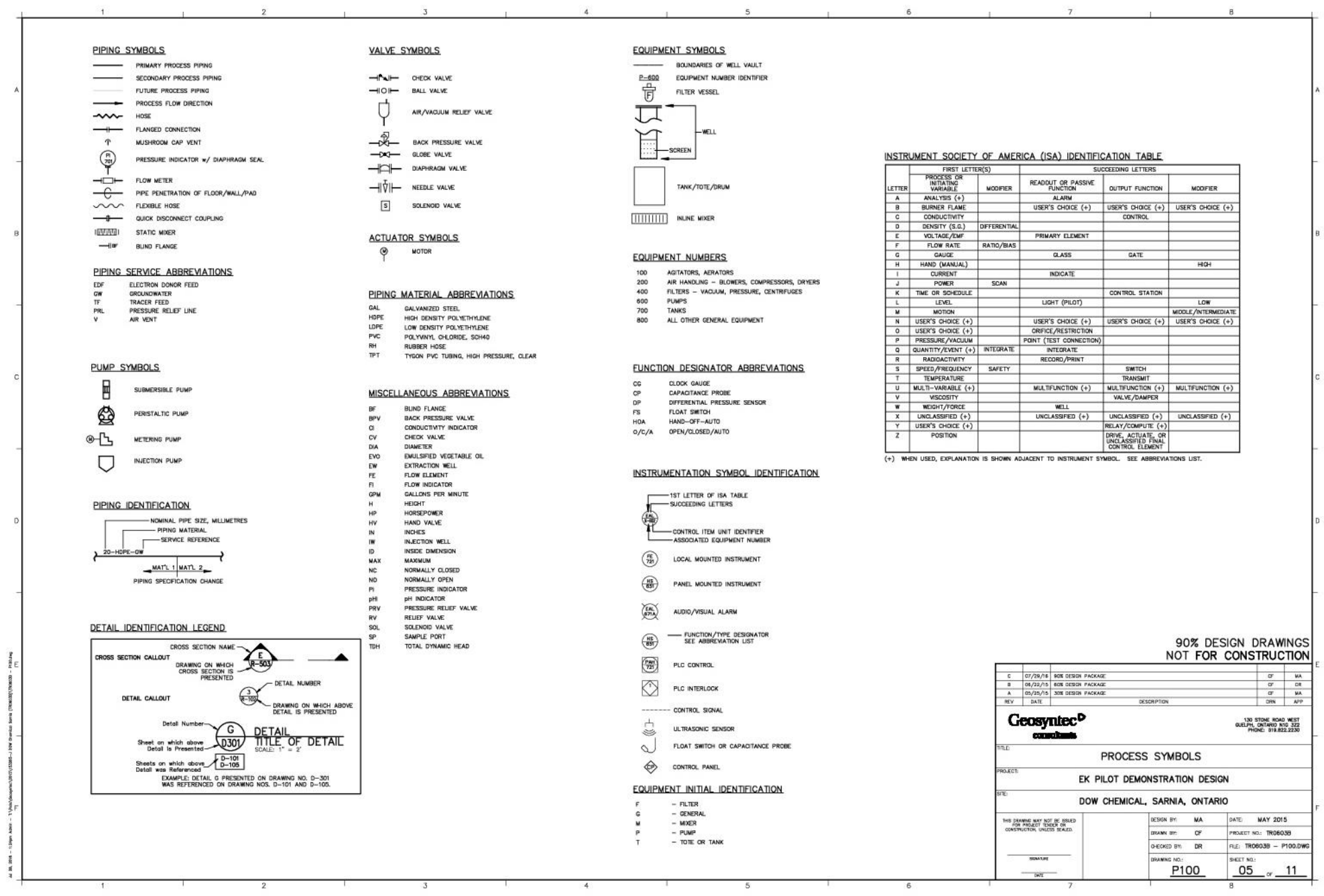

Figure A.4 Process Symbols for Process Flow Diagrams provided by Geosyntec Consultants in 90\% Design Drawings 


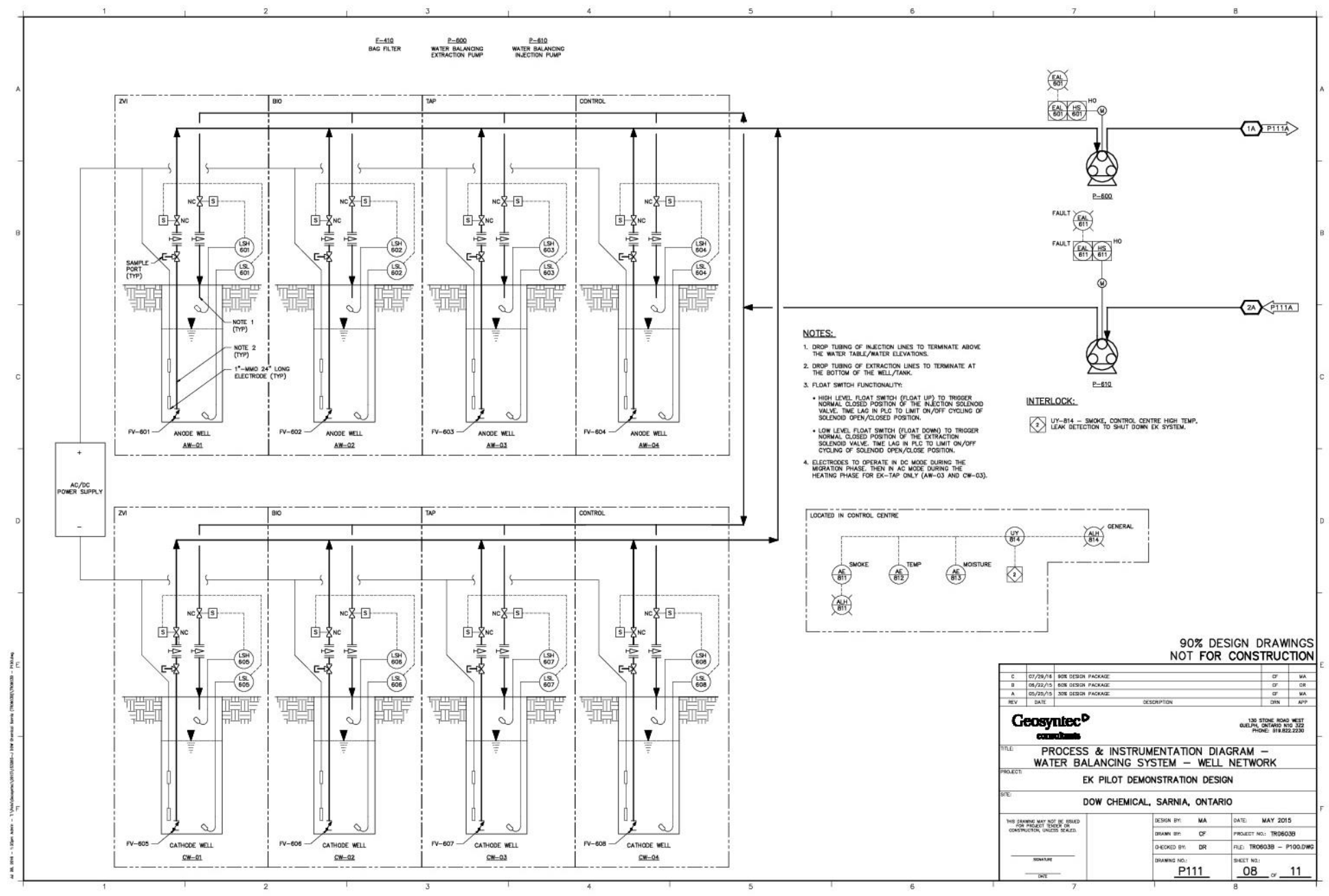

Figure A.5 Process and Instrumentation Diagram- Water Balancing System - Well Network (Provided by Geosyntec) 


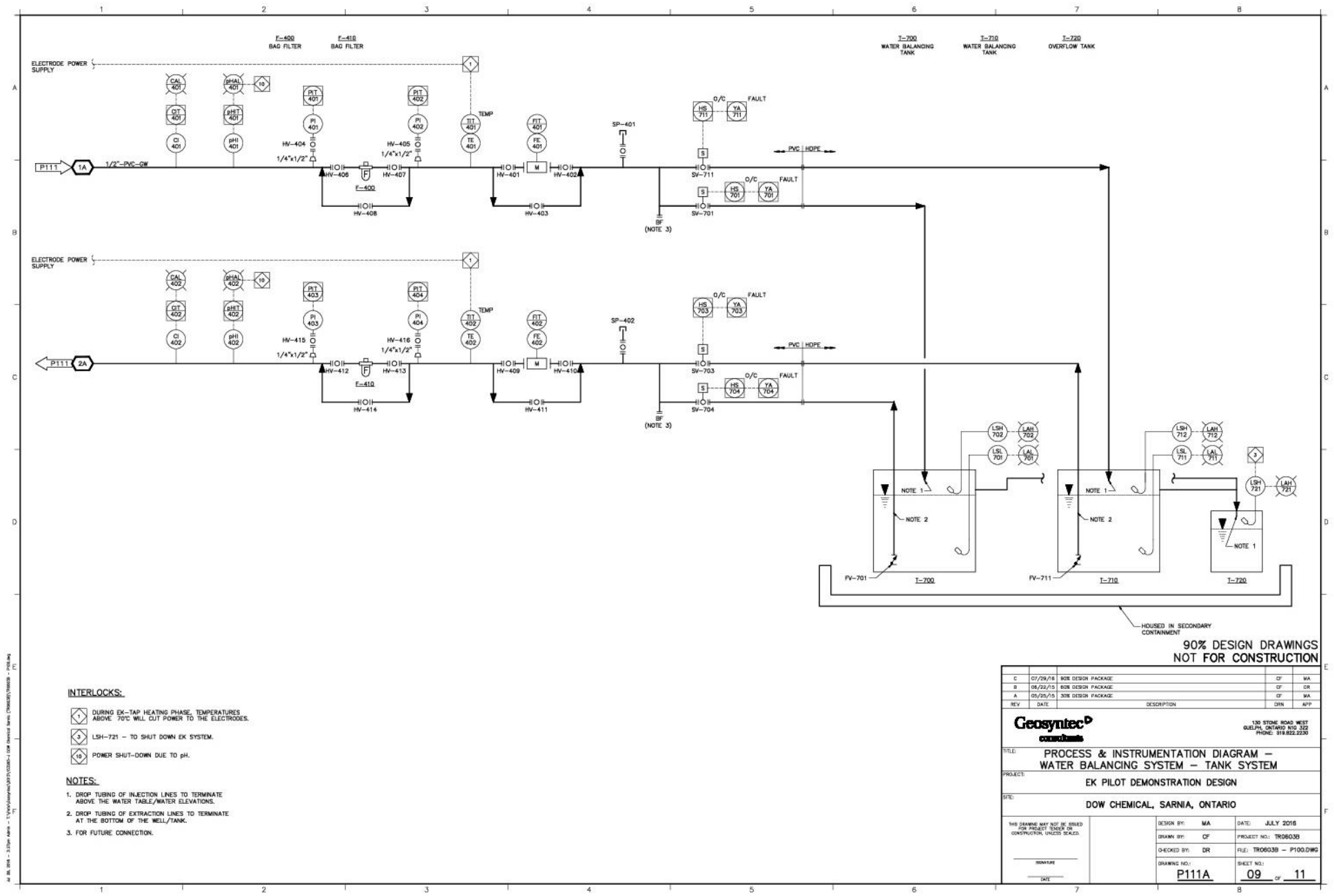

Figure A.6 Process and Instrumentation Diagram- Water Balancing System - Tank System (Provided by Geosyntec) 


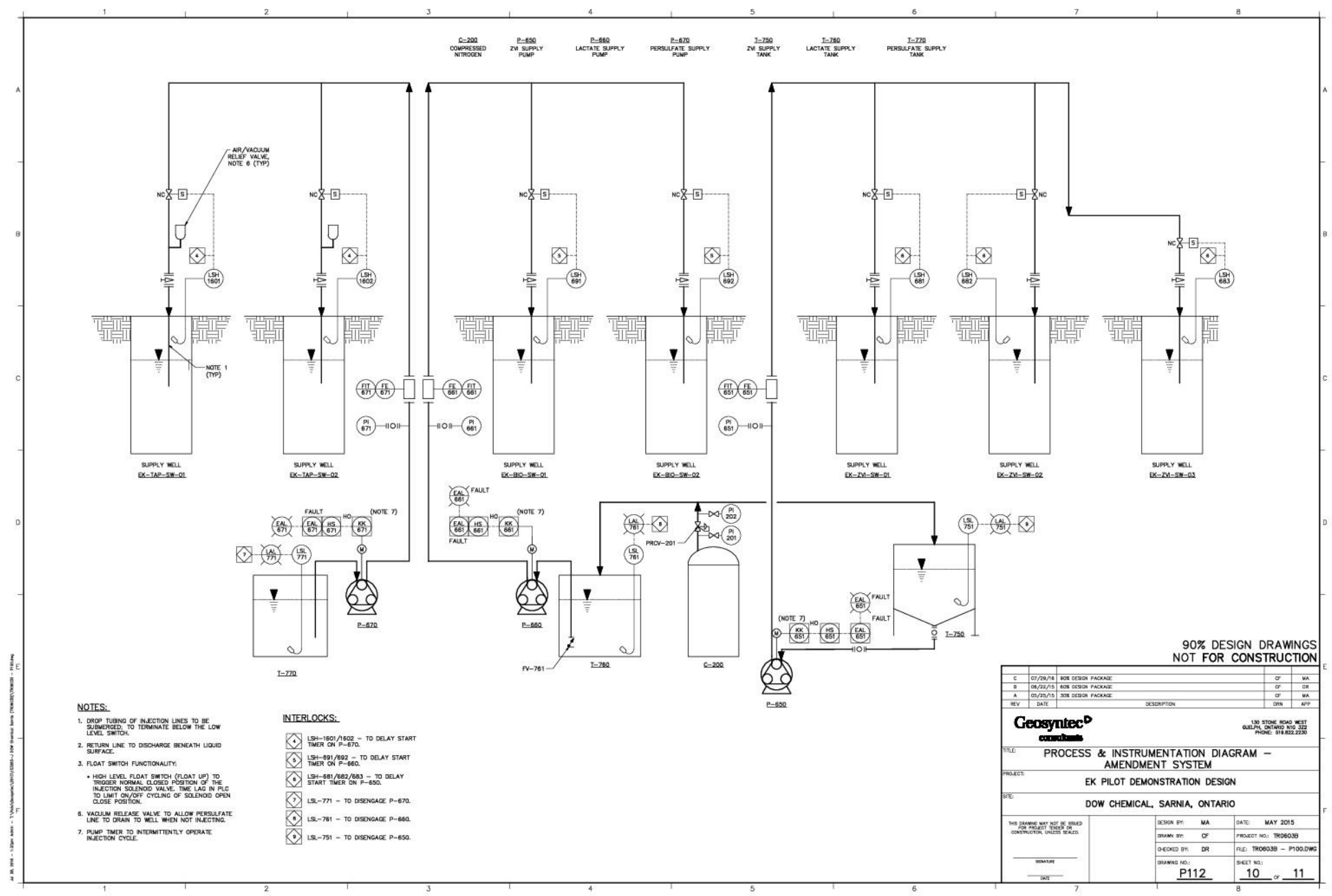

Figure A.7 Process and Instrumentation Diagram- Amendment System (Provided by Geosyntec) 


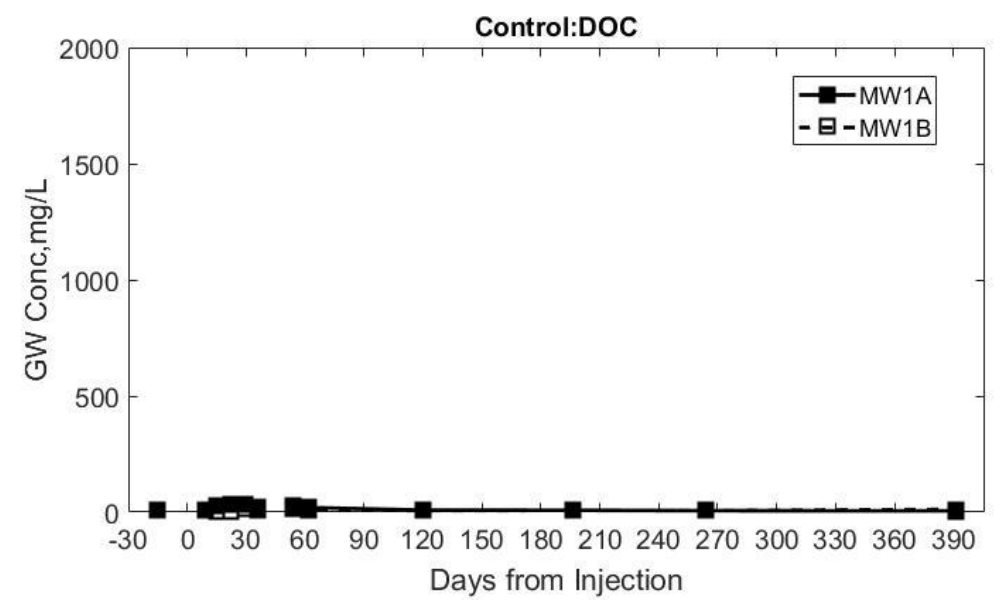

Figure A.8 Control DOC concentrations over time (Note any changes in concentration comparable with EK-Bio increases between 600 and $6000 \mathrm{mg} / \mathrm{L}$ would appear in this scale)

Table A.1 Average voltage gradients for entire duration of EK measured in-situ for various depths and sections of the EK-Bio cell (using a time-weighted average).

\begin{tabular}{|c|c|c|c|}
\hline & $\begin{array}{c}\text { SW1 to MW1 } \\
\text { (North transport path) }\end{array}$ & $\begin{array}{c}\text { SW2 to MW2 } \\
\text { (South transport path) }\end{array}$ & $\begin{array}{c}\text { SW1 to MW2 } \\
\text { (Overall) }\end{array}$ \\
\hline A (Shallow) & $0.0441 \mathrm{~V} / \mathrm{cm}$ & $0.0192 \mathrm{~V} / \mathrm{cm}$ & $0.0241 \mathrm{~V} / \mathrm{cm}$ \\
\hline B (Deep) & $0.0399 \mathrm{~V} / \mathrm{cm}$ & $0.0181 \mathrm{~V} / \mathrm{cm}$ & $0.0207 \mathrm{~V} / \mathrm{cm}$ \\
\hline
\end{tabular}

Table A.2 Average voltage gradients measured in-situ at each well before lactate breakthrough (using a time-weighted average).

\begin{tabular}{|c|c|c|}
\hline & $\begin{array}{c}\text { SW1 to MW1 } \\
\text { (North transport path) }\end{array}$ & $\begin{array}{c}\text { SW2 to MW2 } \\
\text { (South transport path) }\end{array}$ \\
\hline A (Shallow) & $0.0154 \mathrm{~V} / \mathrm{cm}$ & $0.0138 \mathrm{~V} / \mathrm{cm}$ \\
\hline B (Deep) & $0.0359 \mathrm{~V} / \mathrm{cm}$ & $0.0181 \mathrm{~V} / \mathrm{cm}$ \\
\hline
\end{tabular}


Table A.3 Observed EM lactate transport rates into each well assuming first arrival is only due to EM.

\begin{tabular}{|c|c|c|}
\hline & $\begin{array}{c}\text { SW1 to MW1 } \\
\text { (North transport path) }\end{array}$ & $\begin{array}{c}\text { SW2 to MW2 } \\
\text { (South transport path) }\end{array}$ \\
\hline A (Shallow) & $7.4 \mathrm{~cm} /$ day & $3.0 \mathrm{~cm} /$ day \\
\hline B (Deep) & $1.3 \mathrm{~cm} /$ day & $1.8 \mathrm{~cm} /$ day \\
\hline
\end{tabular}

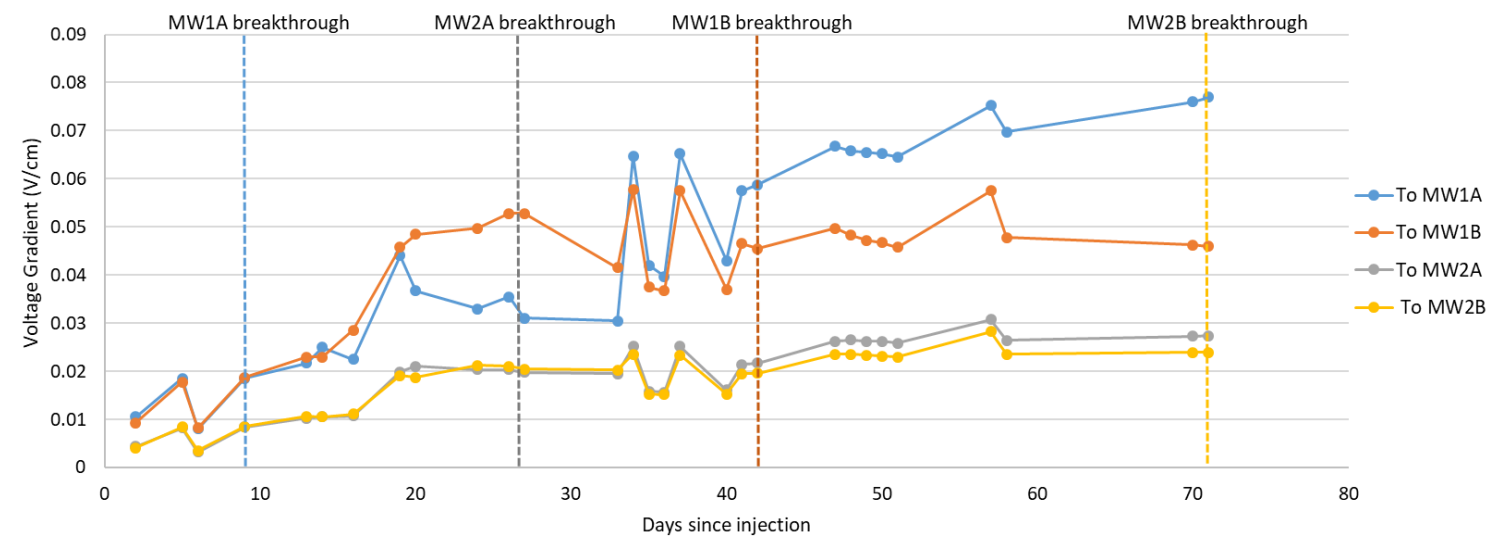

Figure A.9 Measured in-situ voltage gradient at various intervals and depths of the site while EK was applied. Vertical lines indicate first observed breakthrough of lactate into each monitoring well. 


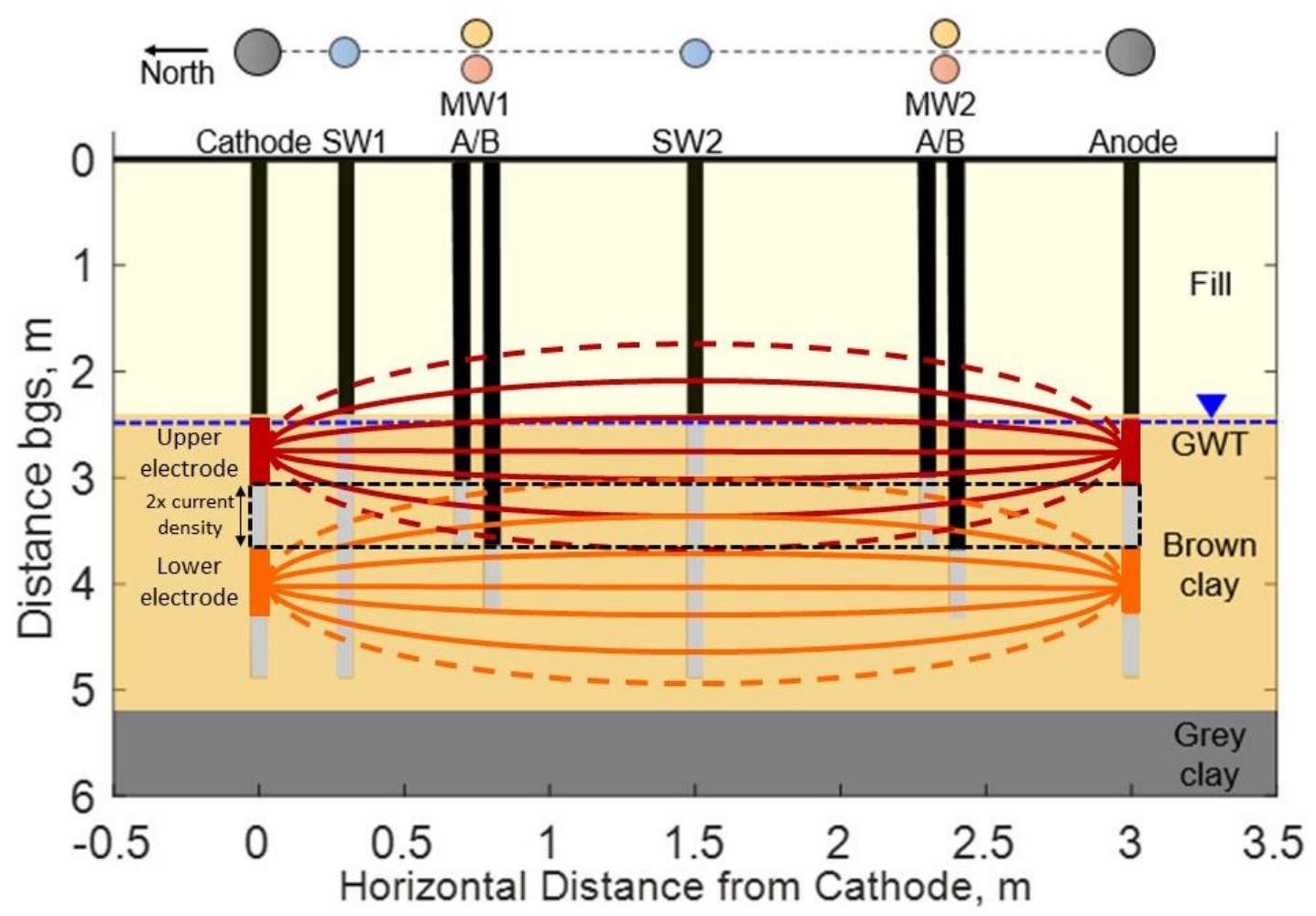

Figure A.10 Hypothetical electric field and overlap between upper and lower electrodes.

\section{Calculation A.1 Theoretical electromigration lactate transport rates}

The electromigration (EM) transport rate and EM mass flux of lactate can be estimated using Equation A.1 and Equation A.2 respectively (Acar \& Alshawabkeh, 1993)

$$
\begin{gathered}
U=u_{i}^{*} i_{e} \\
J_{E M}=U c_{i}
\end{gathered}
$$

(Equation A.1)

Where $U$ is the EM transport rate (m/day), $u_{i}^{*}$ is the effective ionic mobility of the ion in certain site conditions $\left(\mathrm{m}^{2} / \mathrm{V}\right.$-day), $\mathrm{i}_{\mathrm{e}}$ is the voltage gradient $(\mathrm{V} / \mathrm{m}), J_{E M}$ is the EM mass flux ( $\mathrm{g} / \mathrm{m}^{2}$-day), and $c_{i}$ is the injected concentration $\left(\mathrm{g} / \mathrm{m}^{3}\right) . u_{i}{ }^{*}$ is a function of diffusivity at infinite dilution, $D_{o}\left(\mathrm{~m}^{2} /\right.$ day), porosity, $n(-)$, tortuosity, $\tau(-)$ that varies between 0.01 and 0.84 (Shackelford \& Daniel, 1991), valence, $z_{i}$ (-), Faraday's constant, F (96485 $\mathrm{C} / \mathrm{mol})$, the gas constant, $\mathrm{R}(8.314 \mathrm{~J} / \mathrm{mol}-\mathrm{K})$, and Temperature, $\mathrm{T}(\mathrm{K})$. 
For lactate with $D_{o}=1.03 \times 10^{-5} \mathrm{~cm}^{2} / \mathrm{s}=8.90 \times 10^{-5} \mathrm{~m}^{2} / \mathrm{d}$ (Lide, 1990), with $n=0.41$ and $\tau=0.35$ at standard temperature $(293 \mathrm{~K}), \mathrm{u}_{\mathrm{i}}{ }^{*}$ is $5.07 \times 10^{-4} \mathrm{~m}^{2} / \mathrm{V}$-day (Using Equation 2.4). This represents typical low plasticity lean clay conditions. The resulting estimated theoretical transport rate is as follows.

$$
\begin{gathered}
U=\left(5.07 \times 10^{-4} \mathrm{~m}^{2} / \mathrm{Vday}\right)(7.9 \mathrm{~V} / \mathrm{m}) \\
U=4.0 \times 10^{-3} \mathrm{~m} / \text { day }=0.4 \mathrm{~cm} / \text { day }
\end{gathered}
$$

For $n=0.64$ and $\tau=0.84$ at standard temperature (293 K), $u_{i}{ }^{*}$ is $1.90 \times 10^{-3} \mathrm{~m}^{2} / \mathrm{V}$-day (Using Equation 2.4). This represents the upper range of silty or sandy clay conditions. The resulting estimated theoretical transport rate is as follows.

$$
\begin{gathered}
U=\left(1.90 \times 10^{-3} \mathrm{~m}^{2} / \mathrm{Vday}\right)(7.9 \mathrm{~V} / \mathrm{m}) \\
U=1.5 \times 10^{-2} \mathrm{~m} / \text { day }=1.5 \mathrm{~cm} / \text { day }
\end{gathered}
$$

\section{Calculation A.2 Theoretical electromigration sodium transport rates}

For sodium with $D_{o}=1.33 \times 10^{-5} \mathrm{~cm}^{2} / \mathrm{s}=1.15 \times 10^{-4} \mathrm{~m}^{2} / \mathrm{d}$ (Lide, 1990), with $n=0.41$ and $\tau=0.35$ at standard temperature $(293 \mathrm{~K}), \mathrm{u}_{\mathrm{i}}{ }^{*}$ is $6.55 \times 10^{-4} \mathrm{~m}^{2} / \mathrm{V}$-day (Using Equation 2.4). This represents typical low plasticity lean clay conditions. The resulting estimated theoretical transport rate is as follows.

$$
\begin{gathered}
U=\left(6.55 \times 10^{-4} \mathrm{~m}^{2} / \mathrm{Vday}\right)(7.9 \mathrm{~V} / \mathrm{m}) \\
U=5.2 \times 10^{-3} \mathrm{~m} / \text { day }=0.5 \mathrm{~cm} / \text { day }
\end{gathered}
$$

For $n=0.64$ and $\tau=0.84$ at standard temperature (293 K), $u_{i}{ }^{*}$ is $2.45 \times 10^{-3} \mathrm{~m}^{2} / \mathrm{V}$-day (Using Equation 2.4). This represents the upper range of silty or sandy clay conditions. The resulting estimated theoretical transport rate is as follows.

$$
\begin{aligned}
& U=\left(2.45 \times 10^{-3} \mathrm{~m}^{2} / \mathrm{Vday}\right)(7.9 \mathrm{~V} / \mathrm{m}) \\
& U=1.9 \times 10^{-2} \mathrm{~m} / \text { day }=1.9 \mathrm{~cm} / \text { day }
\end{aligned}
$$


Calculation A.3 Electroosmotic transport rate based on electroosmotic conductivity observed by Wu et al. (2007).

The observed electroosmotic conductivity in the lab scale test by Wu et al. (2007) was on the order of $10^{-5} \mathrm{~cm}^{2} / \mathrm{V} \cdot \mathrm{s}(\mathrm{X}$. Wu et al., 2007). Since the exact soil properties on the field site are not known, the electroosmotic conductivity expected in the site soil cannot be calculated. Instead this electroosmotic conductivity from idealized lab scale conditions is used to obtain an order of magnitude prediction of possible EO flow based on the applied voltage gradient on site.

$$
\text { EO flow }=k_{e} i
$$

(Equation A.3)

Where $k e$ is the EO conductivity $\left(\mathrm{cm}^{2} / \mathrm{Vs}\right)$ and $i$ is the voltage gradeint $(\mathrm{V} / \mathrm{cm})$.

$$
\begin{gathered}
\text { EO flow }=\left(10^{-5} \mathrm{~cm}^{2} / \mathrm{V} \cdot \mathrm{s}\right)(0.079 \mathrm{~V} / \mathrm{cm}) \\
E O \text { flow }=0.07 \mathrm{~cm} / \text { day }
\end{gathered}
$$

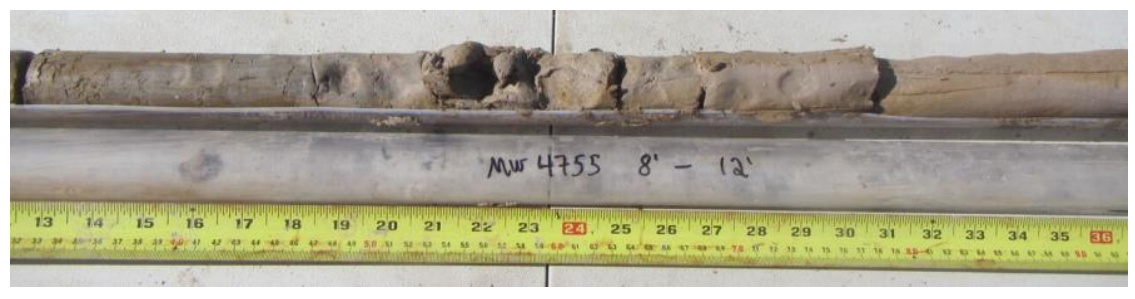

Figure A.11 EK-Bio MW1 location core from $2.44 \mathrm{~m}$ to $3.66 \mathrm{~m}$ showing distinct visual differences from the low plasticity brown clay seen at other EK-Bio monitoring locations. This is evidence for a potentially higher permeability layer due to some silt and sand within a higher plasticity clay. MW1A screened interval is $3.05 \mathrm{~m}$ to $3.66 \mathrm{~m}$ bgs.

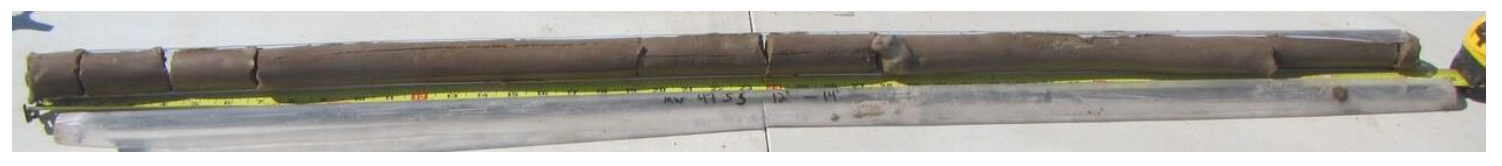

Figure A.12 EK-Bio MW1 location core from $3.66 \mathrm{~m}$ to $4.27 \mathrm{~m}$ showing homogenous low plasticity brown clay. MW1B screened interval is $3.66 \mathrm{~m}$ to $4.27 \mathrm{~m}$ bgs 


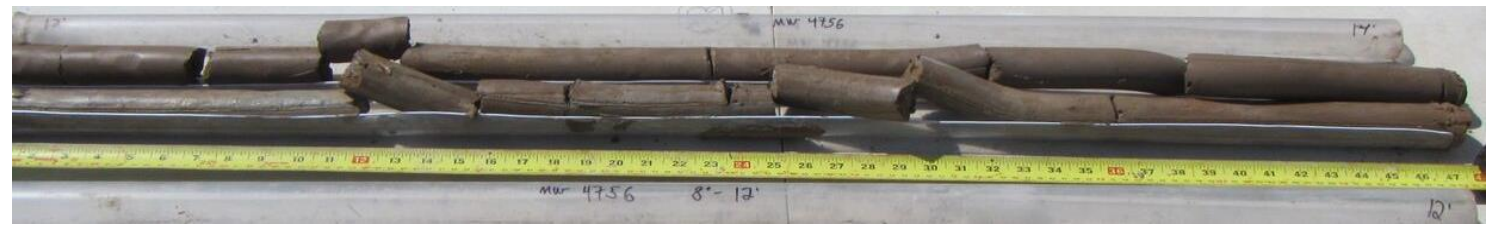

Figure A.13 EK-Bio MW2 location cores showing homogenous low plasticity brown clay in $2.44 \mathrm{~m}$ to 3.66 $\mathrm{m}$ interval (bottom) and $3.66 \mathrm{~m}$ to $4.27 \mathrm{~m}$ interval (top). MW2A screened interval is $3.05 \mathrm{~m}$ to 3.66 $\mathrm{m}$ bgs and MW2B screened interval is $3.66 \mathrm{~m}$ to $4.27 \mathrm{~m}$ bgs.

Calculation A.4 Advective lactate transport rates and hydraulic conductivities Advection from SW1 to MW1A:

The hydraulic gradient from SW1 to MW1A is calculated conservatively assuming that MW1A is fully recovered at most times (even though gradient would be stronger immediately after purging MW1A for sampling).

Average recovered water level in MW1A during lactate solution injection = 183.13 masl

Maintained constant water level in SW1 = 184.10 masl

Distance between SW1 and MW1A $=0.4 \mathrm{~m}$

Hydraulic gradient from SW1 to MW1A:

$$
\begin{aligned}
i=\frac{h_{S W 1}-h_{M W 1 A}}{L} & =\frac{184.10 m-183.13 m}{0.4 m} \\
i & =2.43
\end{aligned}
$$

Darcy's flux is then calculated using this conservative hydraulic gradient and a range of hydraulic conductivities. The resulting lactate transport rates (neglecting dispersion and retardation) are plotted against the hydraulic conductivities to determine what range of hydraulic conductivities, and corresponding soil types, that would need to be present to result in lactate delivery to MW1A solely by advective transport. Assuming the first 
arrival of lactate into MW1A was due to advection from SW1, then the observed lactate transport rate is $4.44 \mathrm{~cm} /$ day which is plotted in red in Figure A.14.

Sample calculation of simplified lactate transport with suspected site clay hydraulic conductivity (as provided by Jacobs):

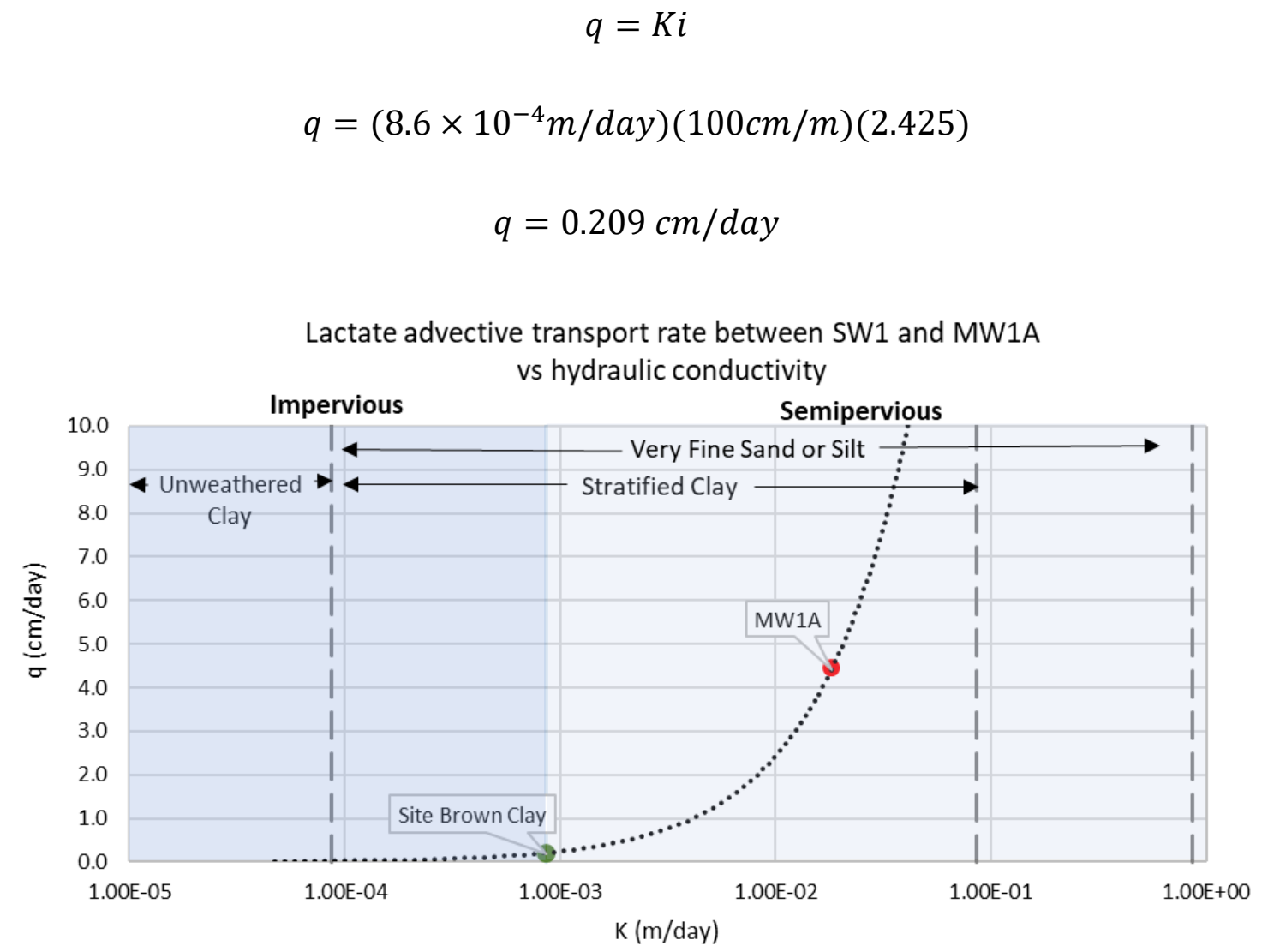

Figure A.14 Advective transport rates due to the hydraulic gradient between SW1 and MW1A for various hydraulic conductivities. Typical ranges of hydraulic conductivity for various soil types are labelled and shaded regions indicate hydraulic conductivities that are representative of impervious or semipervious soils (Bear, 1972). The green point indicates the previously determined hydraulic conductivity of the brown clay on the site (provided by Jacobs) and the resulting advective transport rate. The red point indicates the observed lactate transport rate into MW1A and the corresponding hydraulic conductivity that must be present at that location if initial lactate arrival was dominated by advective transport. 


\section{Advection from SW1 to MW1B:}

The hydraulic gradient from SW1 to MW1B is calculated conservatively assuming that MW1B is at its recorded water level after 7 days of recovery (even though gradient would be stronger immediately after purging MW1B for sampling).

Average recovered water level in MW1B during lactate solution injection $=181.38$ masl

Maintained constant water level in SW1 = 184.10 masl

Distance between SW1 and MW1B = $0.4 \mathrm{~m}$

Hydraulic gradient from SW1 to MW1B: $i=6.80$

Darcy's flux is then calculated using this hydraulic gradient and a range of hydraulic conductivities. The resulting lactate transport rates (neglecting dispersion and retardation) are plotted against the hydraulic conductivities to determine what range of hydraulic conductivities, and corresponding soil types, that would need to be present to result in lactate delivery to MW1B by advective transport. If the first arrival of lactate into MW1B was due to advection from SW1, then the observed lactate transport rate is $0.93 \mathrm{~cm} /$ day which is plotted in red in Figure A.15. 


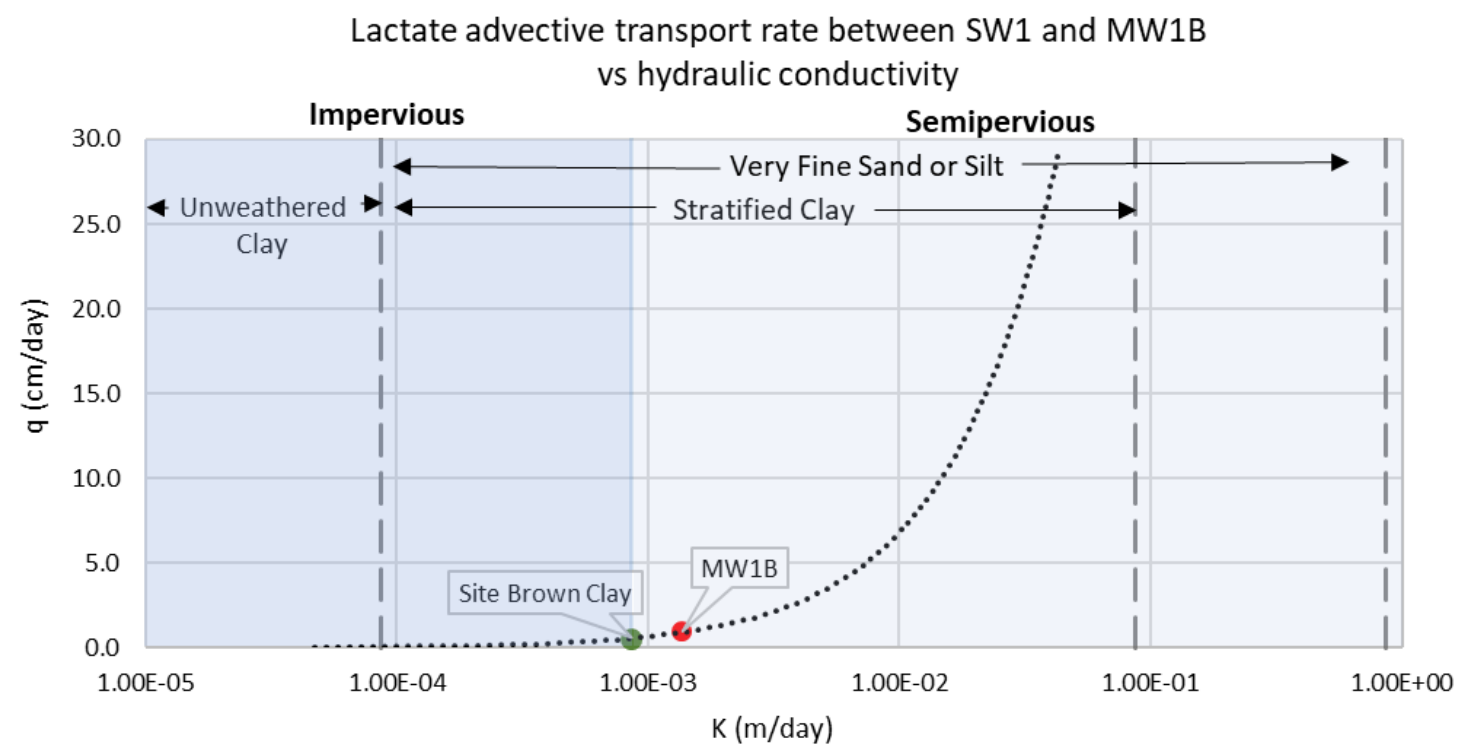

Figure A.15 Advective transport rates due to the hydraulic gradient between SW1 and MW1B for various hydraulic conductivities. Typical ranges of hydraulic conductivity for various soil types are labelled and shaded regions indicate hydraulic conductivities that are representative of impervious or semipervious soils (Bear, 1972). The green point indicates the previously determined hydraulic conductivity of the brown clay on the site (provided by Jacobs) and the resulting advective transport rate. The red point indicated the observed lactate transport rate into MW1B if due to advection and the corresponding hydraulic conductivity that must be present at that location if initial lactate arrival was dominated by advective transport.

\section{Advection from SW2 to MW2A:}

The hydraulic gradient from SW2 to MW2A is calculated conservatively assuming that MW2A is at its recorded water level after 7 days of recovery (even though gradient would be stronger immediately after purging MW2A for sampling).

Average recovered water level in MW2A during lactate solution injection $=181.68$ masl

Maintained constant water level in SW2 $=184.10$ masl

Distance between SW2 and MW2A $=0.8 \mathrm{~m}$

Hydraulic gradient from SW2 to MW2A: $i=3.02$ 
Darcy's flux is then calculated using this hydraulic gradient and a range of hydraulic conductivities. The resulting lactate transport rates (neglecting dispersion and retardation) are plotted against the hydraulic conductivities to determine what range of hydraulic conductivities, and corresponding soil types, that would need to be present to result in lactate delivery to MW2A by advective transport. If the first arrival of lactate into MW2A was due to advection from SW2, then the observed lactate transport rate is 2.76 $\mathrm{cm} /$ day which is plotted in red in Figure A.16.

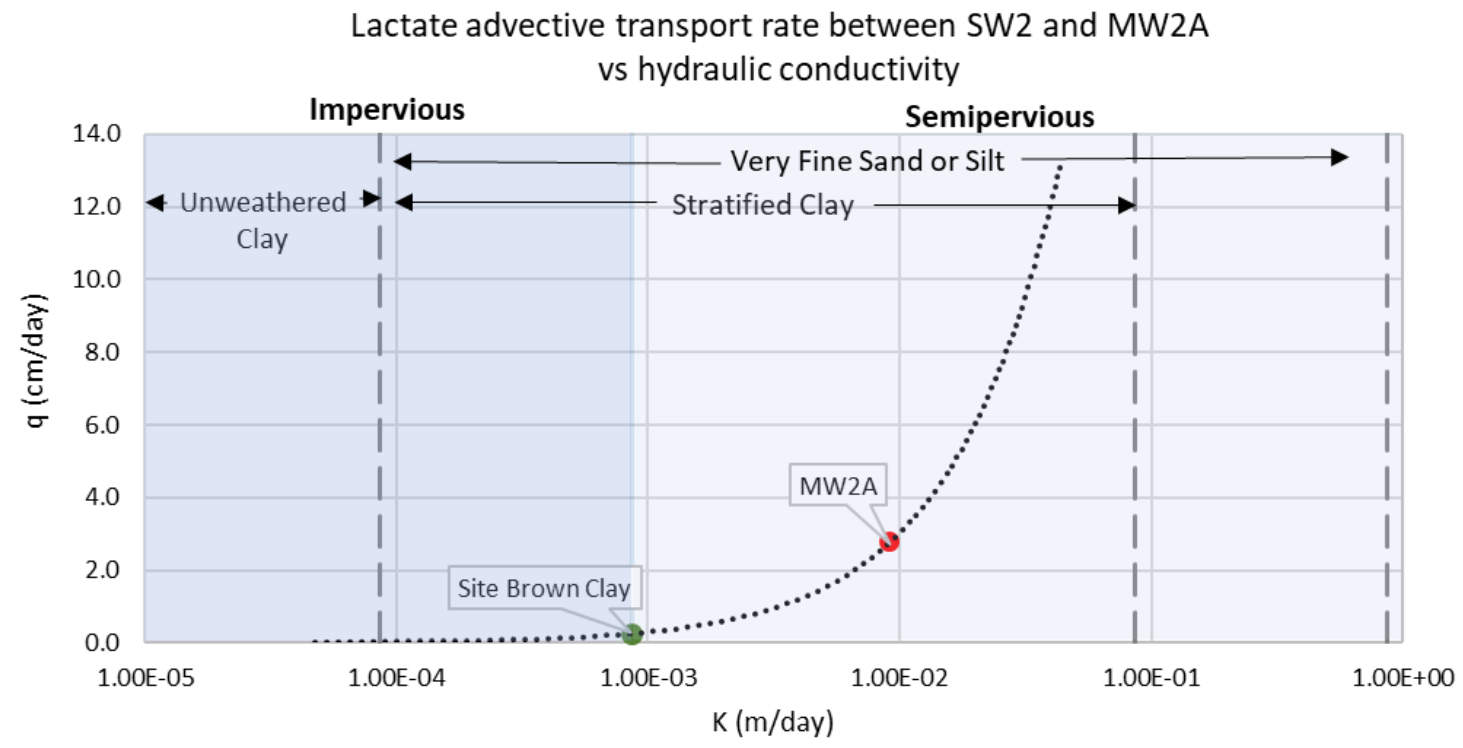

Figure A.16 Advective transport rates due to the hydraulic gradient between SW2 and MW2A for various hydraulic conductivities. Typical ranges of hydraulic conductivity for various soil types are labelled and shaded regions indicate hydraulic conductivities that are representative of impervious or semipervious soils (Bear, 1972). The green point indicates the previously determined hydraulic conductivity of the brown clay on the site (provided by Jacobs) and the resulting advective transport rate. The red point indicated the observed lactate transport rate into MW2A if due to advection and the corresponding hydraulic conductivity that must be present at that location if initial lactate arrival was dominated by advective transport. 


\section{Advection from SW2 to MW2B:}

The hydraulic gradient from SW2 to MW2B is calculated conservatively assuming that MW2B is at its recorded recovered water level (even though gradient would be stronger immediately after purging MW2B for sampling).

Average recovered water level in MW2B during lactate solution injection = 182.44 masl

Maintained constant water level in SW2 = 184.10 masl

Distance between SW2 and MW2B $=0.8 \mathrm{~m}$

Hydraulic gradient from SW2 to MW2B: $i=2.08$

Darcy's flux is then calculated using this hydraulic gradient and a range of hydraulic conductivities. The resulting lactate transport rates (neglecting dispersion and retardation) are plotted against the hydraulic conductivities to determine what range of hydraulic conductivities, and corresponding soil types, that would need to be present to result in lactate delivery to MW2B by advective transport. If the first arrival of lactate into MW2B was due to advection from SW2, then the observed lactate transport rate is $1.12 \mathrm{~cm} /$ day which is plotted in red in Figure A.17. 


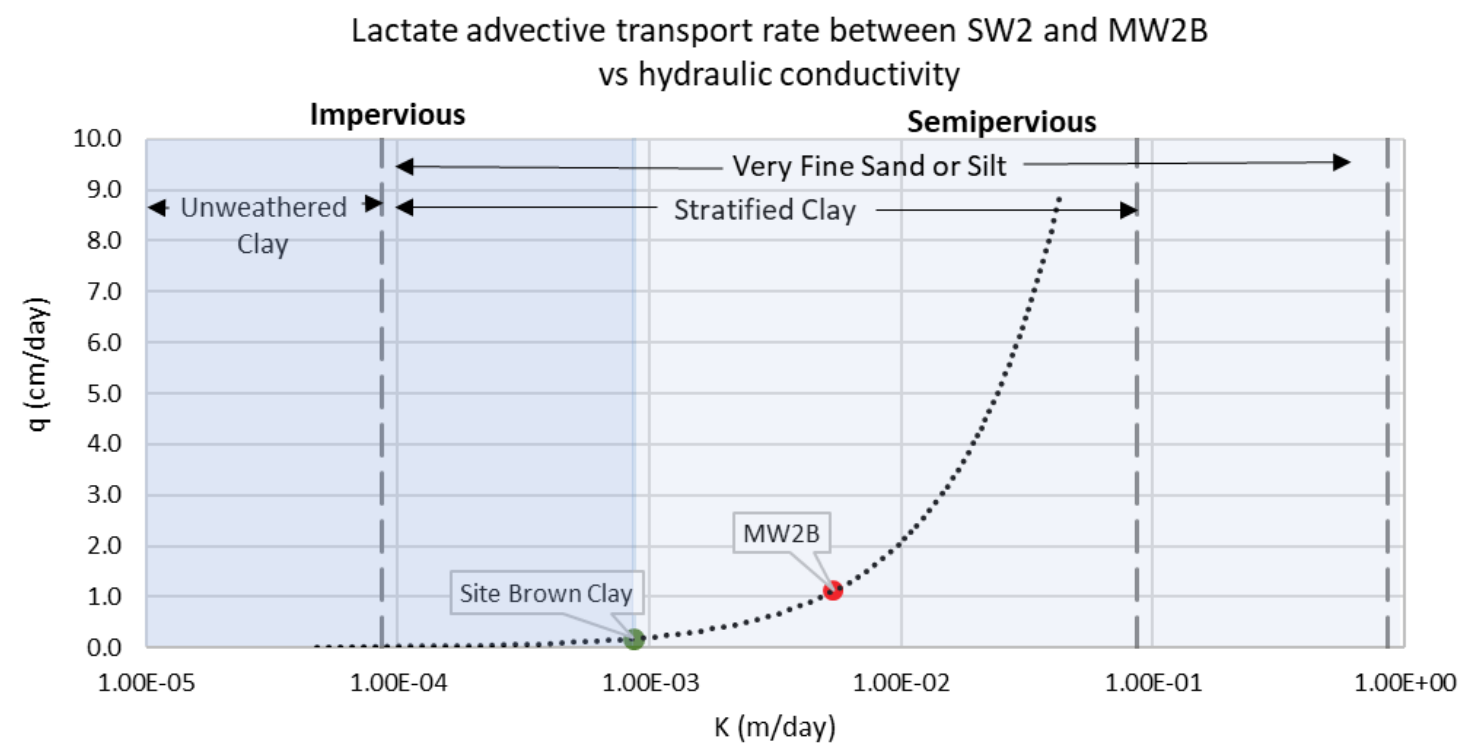

Figure A.17 Advective transport rates due to the hydraulic gradient between SW2 and MW2B for various hydraulic conductivities. Typical ranges of hydraulic conductivity for various soil types are labelled and shaded regions indicate hydraulic conductivities that are representative of impervious or semipervious soils (Bear, 1972). The green point indicates the previously determined hydraulic conductivity of the brown clay on the site (provided by Jacobs) and the resulting advective transport rate. The red point indicated the observed lactate transport rate into MW2B if due to advection and the corresponding hydraulic conductivity that must be present at that location if initial lactate arrival was dominated by advective transport.

Calculation A.5 Simplified Radius of Influence of Lactate Solution in Supply Wells

To perform an estimate of radius of influence of lactate solution around the supply well, it is assumed that there is only horizontal flow out of the screened interval of supply well and that half of the total volume of lactate solution was injected into each supply well. The volume of lactate solution injected into each well was $0.745 \mathrm{~m}^{3}$. The screened interval of the supply wells is $2.438 \mathrm{~m}$. An average soil porosity of 0.5 is assumed, and the effect of any heterogeneities are not taken into account. The radius of influence is calculated as follows: 


$$
V_{\text {injected solution }}=h \pi r^{2} \varnothing
$$

Where $\mathrm{V}$ is the total volume of injected solution into one well, $\mathrm{h}$ is the length of the screened interval, $\mathrm{r}$ is the radius of influence, and $\varnothing$ is the porosity.

$$
\begin{gathered}
r=\sqrt{\frac{V_{\text {injected solution }}}{h \pi \emptyset}} \\
r=\sqrt{\frac{0.745 \mathrm{~m}^{3}}{(2 . .438 \mathrm{~m}) \pi(0.5)}} \\
r=0.44 \mathrm{~m}
\end{gathered}
$$

\section{Calculation A.6 Estimating hydraulic conductivity at each monitoring well location}

Slug test data was plotted and the hydraulic conductivity was estimated following the same procedure outlined in Ola et al (2016) for estimating hydraulic conductivity in contaminated wells using Hvorslev Method (1951) (Ola et al., 2016). The plots and calculation of estimated hydraulic conductivity for each well is as follows.

$$
k=\frac{r^{2} \ln \left(\frac{L}{R}\right)}{2 L T_{0}}
$$

Where $\mathrm{k}$ is hydraulic conductivity, $\mathrm{r}$ is radius of well casing $(0.051 \mathrm{~m}), \mathrm{R}$ is radius of well screen/filter packing $(0.114 \mathrm{~m}), \mathrm{L}$ is the length of the well screen $(0.610 \mathrm{~m}), \mathrm{T}_{0}$ is the time required for the water level to reach $37 \%$ of the initial change in water level (ho) obtained from the log-normal h/ho plot. 


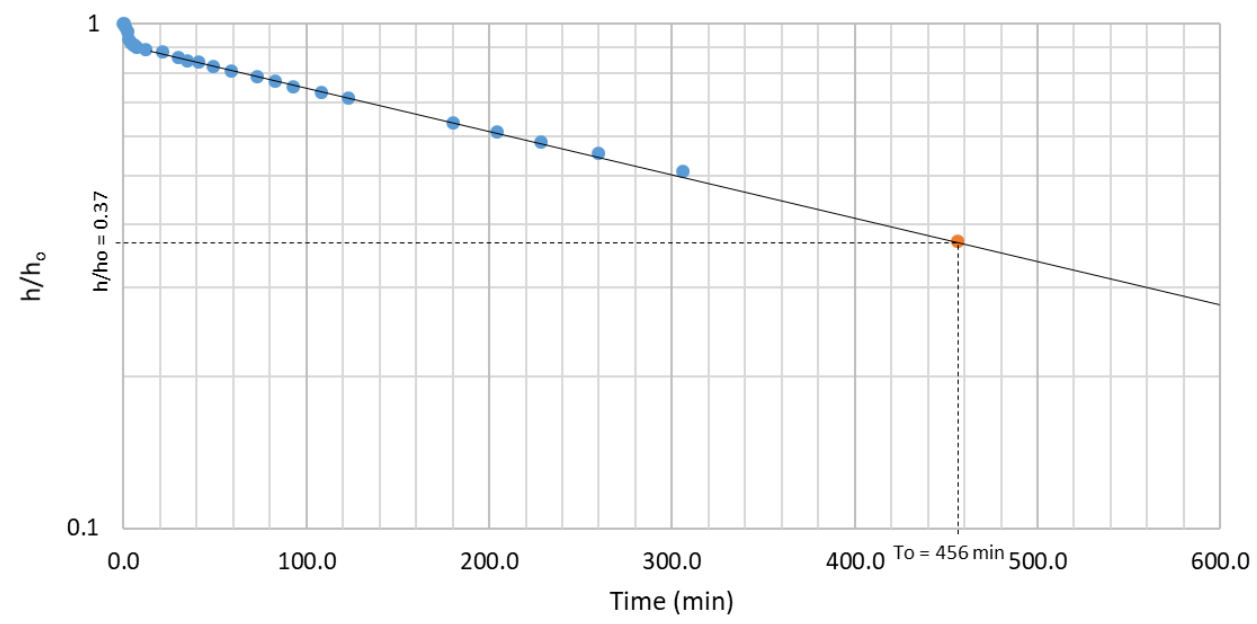

Figure A.18 h/ho vs time plot for EK-Bio MW1A

$k_{M W 1 A}=\frac{(0.051 \mathrm{~m})^{2} \ln \left(\frac{0.610 \mathrm{~m}}{0.114 \mathrm{~m}}\right)}{2(0.610 \mathrm{~m})(456 \mathrm{~min})}=7.83 \times 10^{-6} \mathrm{~m} / \mathrm{min}=1.1 \times 10^{-2} \mathrm{~m} / \mathrm{day}$

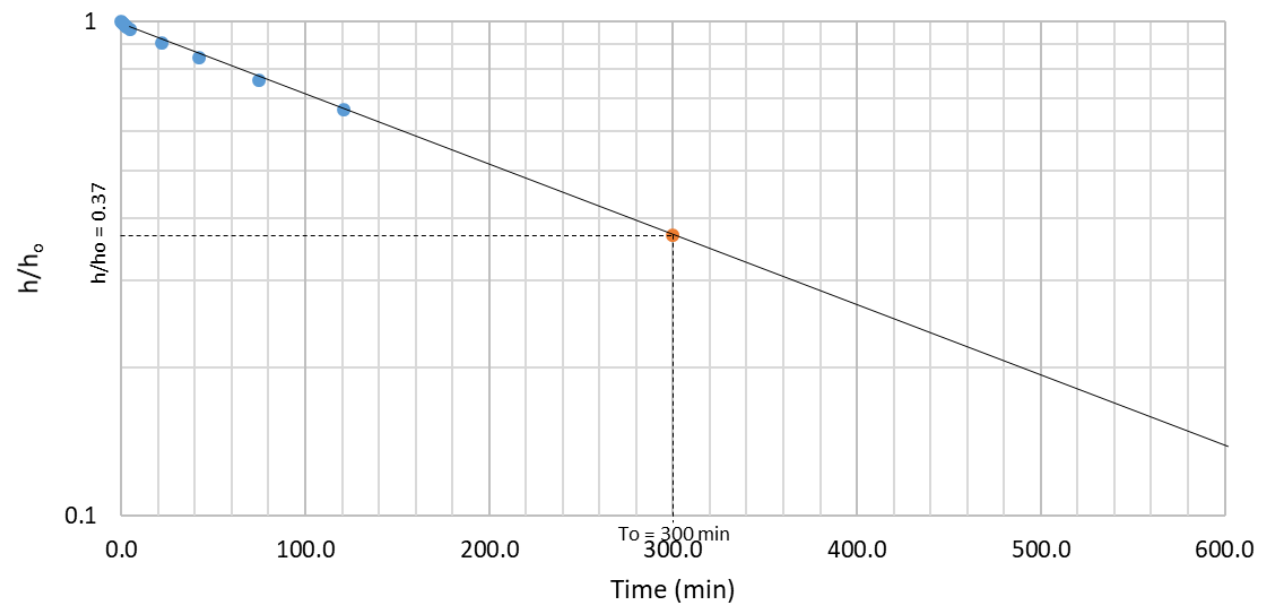

Figure A.19 h/ho vs time plot for EK-Bio MW1B

$$
k_{M W 1 B}=\frac{(0.051 \mathrm{~m})^{2} \ln \left(\frac{0.610 \mathrm{~m}}{0.114 \mathrm{~m}}\right)}{2(0.610 \mathrm{~m})(300 \mathrm{~min})}=1.19 \times 10^{-5} \mathrm{~m} / \mathrm{min}=1.7 \times 10^{-2} \mathrm{~m} / \text { day }
$$




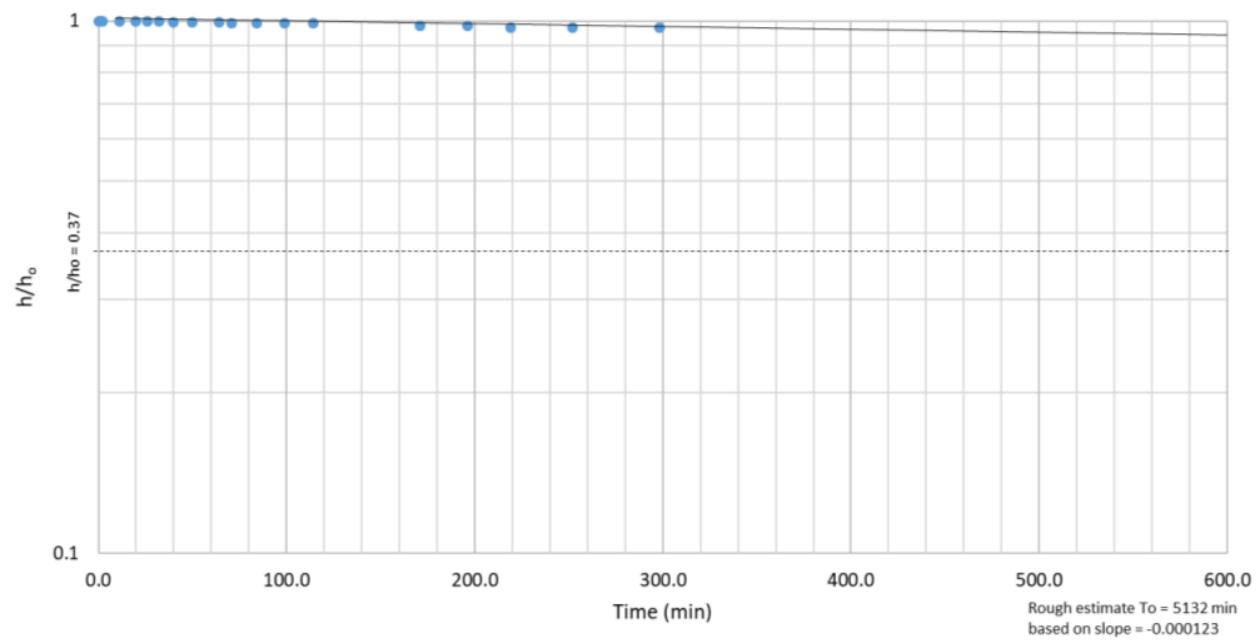

Figure A.20 h/ho vs time plot for EK-Bio MW2A

$k_{M W 2 A}=\frac{(0.051 \mathrm{~m})^{2} \ln \left(\frac{0.610 \mathrm{~m}}{0.114 \mathrm{~m}}\right)}{2(0.610 \mathrm{~m})(5132 \mathrm{~min})}=6.96 \times 10^{-7} \mathrm{~m} / \mathrm{min}=1.0 \times 10^{-3} \mathrm{~m} / \mathrm{day}$

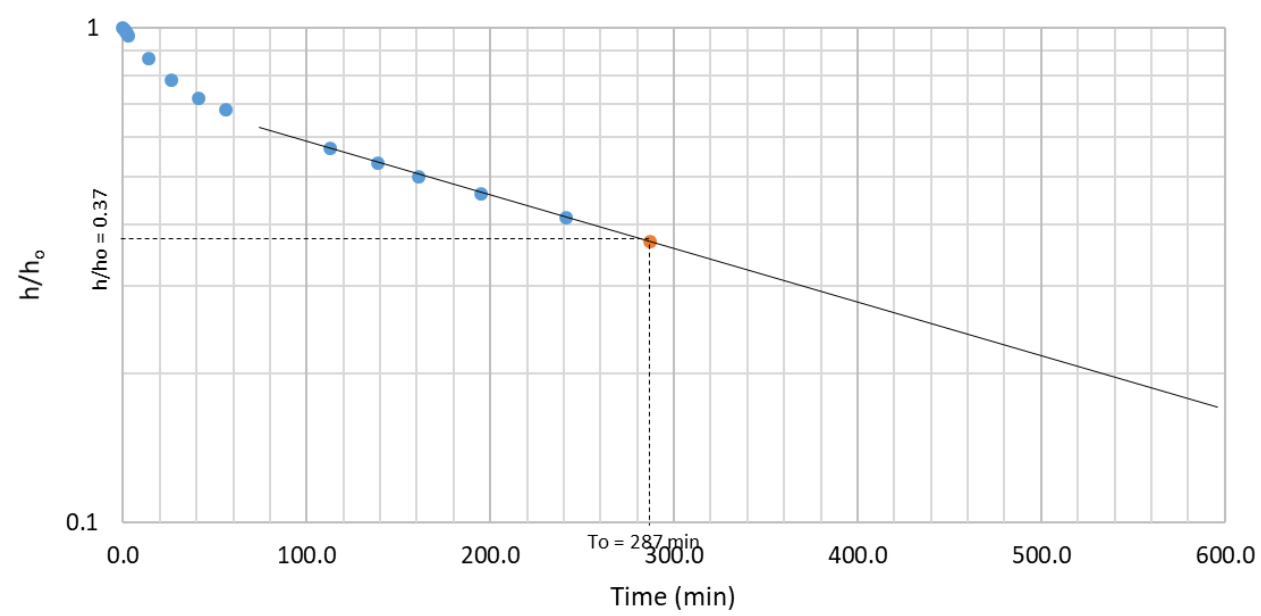

Figure A.21 h/ho vs time plot for EK-Bio MW2B

$$
k_{M W 2 B}=\frac{(0.051 \mathrm{~m})^{2} \ln \left(\frac{0.610 \mathrm{~m}}{0.114 \mathrm{~m}}\right)}{2(0.610 \mathrm{~m})(287 \mathrm{~min})}=1.24 \times 10^{-5} \mathrm{~m} / \mathrm{min}=1.8 \times 10^{-2} \mathrm{~m} / \text { day }
$$




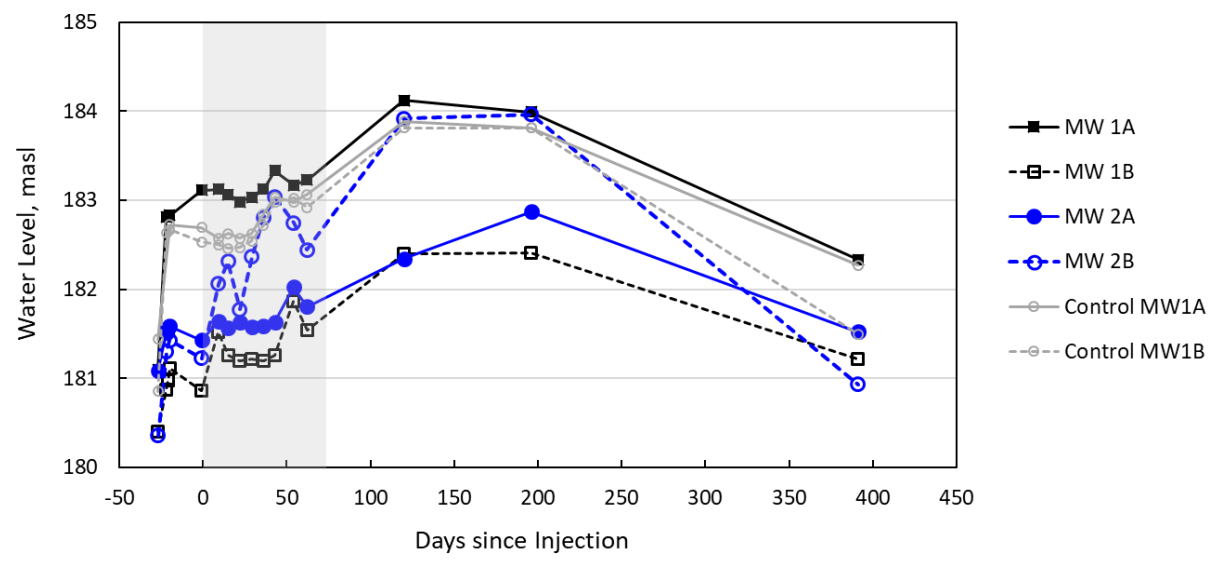

Figure A.22 Water levels in each EK-Bio well on sampling events. After day zero, wells were purged then given one week to recover before the water levels were taken in each well. Before day zero, wells were still being developed so measurements were not given consistent time frames in which to recover.

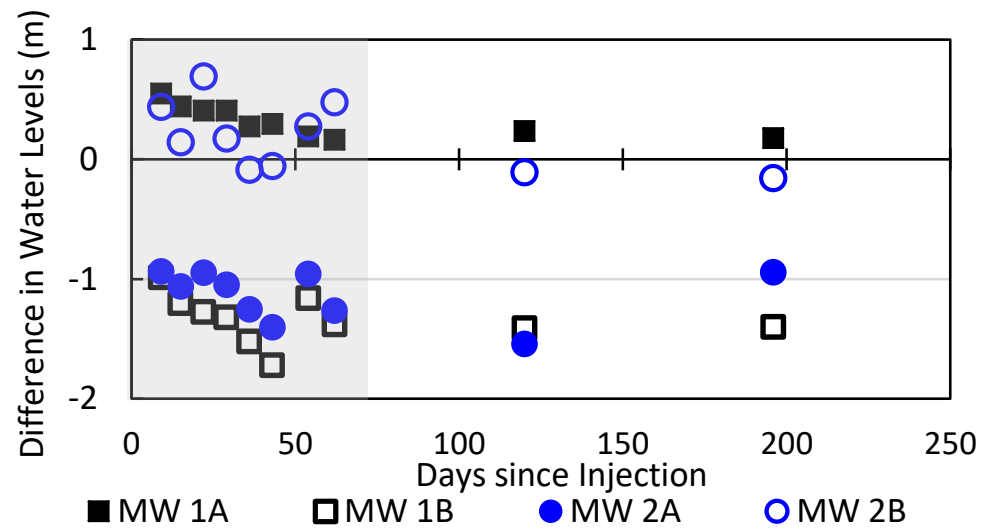

Figure A.23 Differences in water levels between EK-Bio and Control wells with 7 days recovery time. Grey interval indicates the application of EK and injection of lactate. Fastest water level recovery is observed in MW1A and MW2B which reach water levels comparable with the Control baseline water levels after only 7 days after pumping dry. MW1B and MW2A are consistently 1 to $2 \mathrm{~m}$ below the baseline water levels. Variations in the recovery rate of monitoring wells provides further evidence that there are heterogeneities that can result in increased advection at MW1A and MW2B. MW1B's slow recovery was not consistent with the comparable hydraulic conductivity to MW1A and MW2B estimated at this location during slug testing, however it is consistent with the lack of advection observed at this location. 


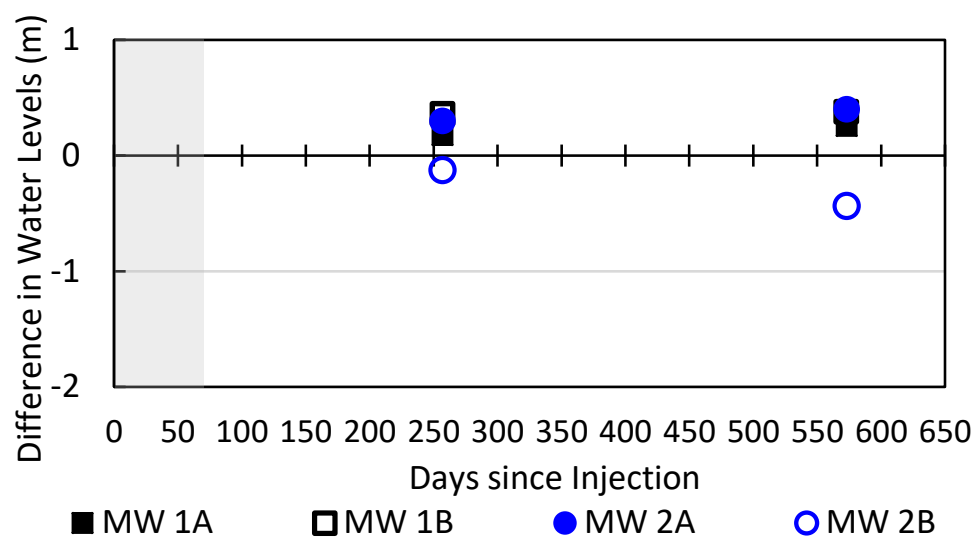

Figure A.24 Differences in water levels between EK-Bio and Control wells with greater than 30 days of recovery time. Grey interval indicated the application of EK and injection of lactate. All wells recover fully in this time.

Table A.4 General bacteria qPCR results for all DNA samples analyzed. DNA samples from each location and time are analyzed by qPCR in triplicates to determine the average gene copies $/ \mathrm{mL}$ of groundwater. The total gene copies were determined by multiplying the extracted DNA concentration (gene copies $/ \mu \mathrm{L}$ ) by the dilution factor and the volume extraction with which the DNA is eluded. Gene copies $/ \mathrm{mL}$ of groundwater was then determined by dividing total gene copies by the filtered groundwater volume. Red values either have Sq mean values (gene copies $/ \mu \mathrm{L}$ ) lower than lowest trusted standard or they have quantification cycle values $(\mathrm{Cq})$ greater than the blank with the lowest $\mathrm{Cq}$. Therefore red samples are below the limit of quantification. Since the Control and EK-Control samples had a different dilution factor than the EK-Bio samples, the limit of quantification for these 2 samples in gene copies $/ \mathrm{mL}$ of groundwater is different. Standard curves had efficiency and $\mathrm{R}^{2}$ value of $98.51 \%$ and 0.947 respectively for $-15,9$ and 54 days, $98.99 \%$ and 0.952 for 196 days, and $88.28 \%$ and 0.976 for 391 days.

\begin{tabular}{|c|c|c|c|c|c|c|c|c|c|}
\hline Days & Location & $\begin{array}{l}\text { Dilution } \\
\text { factor }\end{array}$ & $\begin{array}{c}\mathrm{Cq} \\
\text { mean }\end{array}$ & $\begin{array}{c}\text { Sq mean } \\
(\text { Gene } \\
\text { Copies/ } \mu \mathrm{L})\end{array}$ & $\begin{array}{c}\text { Eluded } \\
\text { Volume } \\
(\mu \mathrm{L})\end{array}$ & $\begin{array}{c}\text { Average } \\
\text { Total } \\
\text { Gene } \\
\text { Copies } \\
\end{array}$ & $\begin{array}{c}\text { Filtered } \\
\text { Volume } \\
(\mathrm{mL})\end{array}$ & $\begin{array}{c}\text { Average } \\
\text { Gene } \\
\text { Copies/mL of } \\
\text { Groundwater } \\
\end{array}$ & $\begin{array}{c}\text { Standard } \\
\text { Deviation } \\
\text { (Gene } \\
\text { Copies/mL) } \\
\end{array}$ \\
\hline \multirow{2}{*}{-15} & $\begin{array}{l}\text { Control } \\
\text { MW1B }\end{array}$ & 50 & 26.20 & $5.16 \mathrm{E}+04$ & 50 & $1.29 \mathrm{E}+08$ & 220 & $5.87 \mathrm{E}+05$ & $4.83 \mathrm{E}+04$ \\
\hline & $\begin{array}{l}\text { EK- } \\
\text { Control } \\
\text { MW1B }\end{array}$ & 50 & 27.71 & $1.83 \mathrm{E}+04$ & 50 & $4.57 \mathrm{E}+07$ & 210 & $2.18 \mathrm{E}+05$ & $2.51 \mathrm{E}+04$ \\
\hline
\end{tabular}




\begin{tabular}{|c|c|c|c|c|c|c|c|c|c|}
\hline & $\begin{array}{c}\text { EK- } \\
\text { Control } \\
\text { MW2B }\end{array}$ & 50 & 25.23 & $1.00 \mathrm{E}+05$ & 50 & $2.51 \mathrm{E}+08$ & 220 & $1.14 \mathrm{E}+06$ & $1.35 \mathrm{E}+05$ \\
\hline & $\begin{array}{l}\text { EK-Bio } \\
\text { MW1B }\end{array}$ & 10 & 34.68 & $1.53 \mathrm{E}+02$ & 50 & $7.67 \mathrm{E}+04$ & 210 & $3.65 \mathrm{E}+02$ & $2.24 \mathrm{E}+01$ \\
\hline & $\begin{array}{l}\text { EK-Bio } \\
\text { MW2B }\end{array}$ & 10 & 32.63 & $6.27 \mathrm{E}+02$ & 50 & $3.13 \mathrm{E}+05$ & 220 & $1.42 \mathrm{E}+03$ & $1.33 \mathrm{E}+02$ \\
\hline \multirow{10}{*}{9} & $\begin{array}{l}\text { Control } \\
\text { MW1A }\end{array}$ & 50 & 26.14 & $5.35 \mathrm{E}+04$ & 50 & $1.34 \mathrm{E}+08$ & 200 & $6.68 \mathrm{E}+05$ & $3.07 \mathrm{E}+04$ \\
\hline & $\begin{array}{l}\text { Control } \\
\text { MW1B }\end{array}$ & 50 & 26.28 & $4.88 \mathrm{E}+04$ & 50 & $1.22 \mathrm{E}+08$ & 200 & $6.10 \mathrm{E}+05$ & $4.68 \mathrm{E}+04$ \\
\hline & $\begin{array}{c}\text { EK- } \\
\text { Control } \\
\text { MW1A }\end{array}$ & 50 & 30.80 & $2.20 \mathrm{E}+03$ & 50 & $5.49 \mathrm{E}+06$ & 200 & $2.74 \mathrm{E}+04$ & $5.48 \mathrm{E}+02$ \\
\hline & $\begin{array}{c}\text { EK- } \\
\text { Control } \\
\text { MW1B }\end{array}$ & 50 & 32.63 & $6.25 \mathrm{E}+02$ & 50 & $1.56 \mathrm{E}+06$ & 200 & $7.82 \mathrm{E}+03$ & $1.04 \mathrm{E}+02$ \\
\hline & $\begin{array}{c}\text { EK- } \\
\text { Control } \\
\text { MW2A }\end{array}$ & 50 & 25.18 & $1.03 \mathrm{E}+05$ & 50 & $2.59 \mathrm{E}+08$ & 200 & $1.29 \mathrm{E}+06$ & $8.44 \mathrm{E}+04$ \\
\hline & $\begin{array}{c}\text { EK- } \\
\text { Control } \\
\text { MW2B }\end{array}$ & 50 & 25.92 & $6.23 \mathrm{E}+04$ & 50 & $1.56 \mathrm{E}+08$ & 200 & $7.79 \mathrm{E}+05$ & $5.57 \mathrm{E}+04$ \\
\hline & $\begin{array}{l}\text { EK-Bio } \\
\text { MW1A } \\
\end{array}$ & 10 & 33.49 & $3.49 \mathrm{E}+02$ & 50 & $1.75 \mathrm{E}+05$ & 200 & $8.73 \mathrm{E}+02$ & $1.24 \mathrm{E}+02$ \\
\hline & $\begin{array}{l}\text { EK-Bio } \\
\text { MW1B }\end{array}$ & 10 & 35.28 & $1.02 \mathrm{E}+02$ & 50 & $5.11 \mathrm{E}+04$ & 200 & $2.56 \mathrm{E}+02$ & $3.03 \mathrm{E}+01$ \\
\hline & $\begin{array}{l}\text { EK-Bio } \\
\text { MW2A }\end{array}$ & 10 & 33.56 & $3.32 \mathrm{E}+02$ & 50 & $1.66 \mathrm{E}+05$ & 200 & $8.30 \mathrm{E}+02$ & $6.02 \mathrm{E}+01$ \\
\hline & $\begin{array}{l}\text { EK-Bio } \\
\text { MW2B } \\
\end{array}$ & 10 & 34.52 & $1.73 \mathrm{E}+02$ & 50 & $8.63 \mathrm{E}+04$ & 200 & $4.31 \mathrm{E}+02$ & $5.25 \mathrm{E}+01$ \\
\hline \multirow{4}{*}{54} & $\begin{array}{l}\text { Control } \\
\text { MW1A }\end{array}$ & 50 & 25.90 & $6.33 \mathrm{E}+04$ & 50 & $1.58 \mathrm{E}+08$ & 200 & $7.92 \mathrm{E}+05$ & $7.88 \mathrm{E}+04$ \\
\hline & $\begin{array}{l}\text { Control } \\
\text { MW1B }\end{array}$ & 50 & 26.97 & $3.03 \mathrm{E}+04$ & 50 & $7.58 \mathrm{E}+07$ & 140 & $5.42 \mathrm{E}+05$ & $2.23 \mathrm{E}+04$ \\
\hline & $\begin{array}{c}\text { EK- } \\
\text { Control } \\
\text { MW1A }\end{array}$ & 50 & 26.16 & $5.28 \mathrm{E}+04$ & 50 & $1.32 \mathrm{E}+08$ & 200 & $6.59 \mathrm{E}+05$ & $4.41 \mathrm{E}+03$ \\
\hline & $\begin{array}{c}\text { EK- } \\
\text { Control } \\
\text { MW1B }\end{array}$ & 50 & 25.34 & $9.27 \mathrm{E}+04$ & 50 & $2.32 \mathrm{E}+08$ & 200 & $1.16 \mathrm{E}+06$ & $6.07 \mathrm{E}+04$ \\
\hline
\end{tabular}




\begin{tabular}{|c|c|c|c|c|c|c|c|c|c|}
\hline & $\begin{array}{c}\text { EK- } \\
\text { Control } \\
\text { MW2A }\end{array}$ & 50 & 25.40 & $8.90 \mathrm{E}+04$ & 50 & $2.23 \mathrm{E}+08$ & 200 & $1.11 \mathrm{E}+06$ & $6.02 \mathrm{E}+04$ \\
\hline & $\begin{array}{c}\text { EK- } \\
\text { Control } \\
\text { MW2B }\end{array}$ & 50 & 27.03 & $3.00 \mathrm{E}+04$ & 50 & $7.49 \mathrm{E}+07$ & 200 & $3.74 \mathrm{E}+05$ & $1.13 \mathrm{E}+05$ \\
\hline & $\begin{array}{l}\text { EK-Bio } \\
\text { MW1A } \\
\end{array}$ & 10 & 26.73 & $3.60 \mathrm{E}+04$ & 50 & $1.80 \mathrm{E}+07$ & 200 & $9.00 \mathrm{E}+04$ & $1.08 \mathrm{E}+04$ \\
\hline & $\begin{array}{l}\text { EK-Bio } \\
\text { MW1B }\end{array}$ & 10 & 32.93 & $5.10 \mathrm{E}+02$ & 50 & $2.55 \mathrm{E}+05$ & 200 & $1.28 \mathrm{E}+03$ & $6.09 \mathrm{E}+01$ \\
\hline & $\begin{array}{l}\text { EK-Bio } \\
\text { MW2A }\end{array}$ & 10 & 33.24 & $4.14 \mathrm{E}+02$ & 50 & $2.07 \mathrm{E}+05$ & 200 & $1.03 \mathrm{E}+03$ & $8.56 \mathrm{E}+01$ \\
\hline & $\begin{array}{l}\text { EK-Bio } \\
\text { MW2B }\end{array}$ & 10 & 22.70 & $5.68 \mathrm{E}+05$ & 50 & $2.84 \mathrm{E}+08$ & 160 & $1.78 \mathrm{E}+06$ & $7.43 \mathrm{E}+04$ \\
\hline \multirow{10}{*}{196} & $\begin{array}{l}\text { Control } \\
\text { MW1A }\end{array}$ & 50 & 23.72 & $1.69 \mathrm{E}+05$ & 50 & $4.22 \mathrm{E}+08$ & 200 & $2.11 \mathrm{E}+06$ & $1.18 \mathrm{E}+05$ \\
\hline & $\begin{array}{l}\text { Control } \\
\text { MW1B }\end{array}$ & 50 & 23.82 & $1.60 \mathrm{E}+05$ & 50 & $4.00 \mathrm{E}+08$ & 200 & $2.00 \mathrm{E}+06$ & $4.20 \mathrm{E}+05$ \\
\hline & $\begin{array}{c}\text { EK- } \\
\text { Control } \\
\text { MW1A }\end{array}$ & 50 & 27.66 & $1.15 \mathrm{E}+04$ & 50 & $2.86 \mathrm{E}+07$ & 200 & $1.43 \mathrm{E}+05$ & $3.40 \mathrm{E}+04$ \\
\hline & $\begin{array}{c}\text { EK- } \\
\text { Control } \\
\text { MW1B }\end{array}$ & 50 & 25.97 & $3.60 \mathrm{E}+04$ & 100 & $1.80 \mathrm{E}+08$ & 150 & $1.20 \mathrm{E}+06$ & $9.90 \mathrm{E}+04$ \\
\hline & $\begin{array}{c}\text { EK- } \\
\text { Control } \\
\text { MW2A }\end{array}$ & 50 & 25.74 & $4.21 \mathrm{E}+04$ & 50 & $1.05 \mathrm{E}+08$ & 200 & $5.26 \mathrm{E}+05$ & $3.10 \mathrm{E}+04$ \\
\hline & $\begin{array}{c}\text { EK- } \\
\text { Control } \\
\text { MW2B }\end{array}$ & 50 & 26.55 & $2.51 \mathrm{E}+04$ & 50 & $6.26 \mathrm{E}+07$ & 200 & $3.13 \mathrm{E}+05$ & $1.06 \mathrm{E}+05$ \\
\hline & $\begin{array}{l}\text { EK-Bio } \\
\text { MW1A }\end{array}$ & 10 & 24.38 & $1.08 \mathrm{E}+05$ & 50 & $5.38 \mathrm{E}+07$ & 200 & $2.69 \mathrm{E}+05$ & $3.72 \mathrm{E}+04$ \\
\hline & $\begin{array}{l}\text { EK-Bio } \\
\text { MW1B }\end{array}$ & 10 & 28.72 & $5.45 \mathrm{E}+03$ & 50 & $2.73 \mathrm{E}+06$ & 150 & $1.82 \mathrm{E}+04$ & $2.47 \mathrm{E}+03$ \\
\hline & $\begin{array}{l}\text { EK-Bio } \\
\text { MW2A }\end{array}$ & 10 & 26.90 & $1.90 \mathrm{E}+04$ & 50 & $9.49 \mathrm{E}+06$ & 200 & $4.75 \mathrm{E}+04$ & $6.06 \mathrm{E}+03$ \\
\hline & $\begin{array}{l}\text { EK-Bio } \\
\text { MW2B }\end{array}$ & 10 & 21.91 & $5.90 \mathrm{E}+05$ & 50 & $2.95 \mathrm{E}+08$ & 100 & $2.95 \mathrm{E}+06$ & $4.52 \mathrm{E}+05$ \\
\hline 391 & $\begin{array}{l}\text { Control } \\
\text { MW1A }\end{array}$ & 50 & 22.04 & $5.20 \mathrm{E}+05$ & 50 & $1.30 \mathrm{E}+09$ & 210 & $6.19 \mathrm{E}+06$ & $1.82 \mathrm{E}+04$ \\
\hline
\end{tabular}




\begin{tabular}{|c|c|c|c|c|c|c|c|c|}
\hline $\begin{array}{l}\text { Control } \\
\text { MW1B } \\
\end{array}$ & 50 & 25.11 & $7.91 \mathrm{E}+04$ & 50 & $1.98 \mathrm{E}+08$ & 135 & $1.47 \mathrm{E}+06$ & $1.79 E+04$ \\
\hline $\begin{array}{c}\text { EK- } \\
\text { Control } \\
\text { MW1A }\end{array}$ & 50 & 24.36 & $1.22 \mathrm{E}+05$ & 50 & $3.06 \mathrm{E}+08$ & 150 & $2.04 \mathrm{E}+06$ & $7.33 \mathrm{E}+03$ \\
\hline $\begin{array}{c}\text { EK- } \\
\text { Control } \\
\text { MW1B }\end{array}$ & 50 & 27.04 & $2.31 \mathrm{E}+04$ & 50 & $5.78 \mathrm{E}+07$ & 200 & $2.89 \mathrm{E}+05$ & $1.28 \mathrm{E}+03$ \\
\hline $\begin{array}{c}\text { EK- } \\
\text { Control } \\
\text { MW2A }\end{array}$ & 50 & 36.30 & $7.20 \mathrm{E}+01$ & 50 & $1.80 \mathrm{E}+05$ & 150 & $1.20 \mathrm{E}+03$ & $4.68 \mathrm{E}+00$ \\
\hline $\begin{array}{c}\text { EK- } \\
\text { Control } \\
\text { MW2B }\end{array}$ & 50 & 27.31 & $1.94 \mathrm{E}+04$ & 50 & $4.84 \mathrm{E}+07$ & 200 & $2.42 \mathrm{E}+05$ & $1.90 \mathrm{E}+02$ \\
\hline $\begin{array}{l}\text { EK-Bio } \\
\text { MW1A }\end{array}$ & 10 & 21.95 & $5.50 \mathrm{E}+05$ & 50 & $2.75 \mathrm{E}+08$ & 200 & $1.37 \mathrm{E}+06$ & $2.36 \mathrm{E}+04$ \\
\hline $\begin{array}{l}\text { EK-Bio } \\
\text { MW1B }\end{array}$ & 10 & 32.17 & $9.65 \mathrm{E}+02$ & 50 & $4.83 \mathrm{E}+05$ & 110 & $4.39 \mathrm{E}+03$ & $2.04 \mathrm{E}+02$ \\
\hline $\begin{array}{l}\text { EK-Bio } \\
\text { MW2A }\end{array}$ & 10 & 30.13 & $3.37 \mathrm{E}+03$ & 50 & $1.69 \mathrm{E}+06$ & 200 & $8.43 \mathrm{E}+03$ & $3.35 \mathrm{E}+02$ \\
\hline $\begin{array}{l}\text { EK-Bio } \\
\text { MW2B }\end{array}$ & 10 & 31.98 & $1.06 \mathrm{E}+03$ & 50 & $5.30 \mathrm{E}+05$ & 90 & $5.89 \mathrm{E}+03$ & $1.56 \mathrm{E}+01$ \\
\hline
\end{tabular}


Table A.5 Dehalococcoides qPCR data for all DNA samples analyzed. DNA samples from each location and time are analyzed by $\mathrm{qPCR}$ in triplicates to determine the average gene copies $/ \mathrm{mL}$ of groundwater. The total gene copies were determined by multiplying the extracted DNA concentration (gene copies $/ \mu \mathrm{L}$ ) by the dilution factor and the volume extraction with which the DNA is eluded. Gene copies $/ \mathrm{mL}$ of groundwater was then determined by dividing total gene copies by the filtered groundwater volume. Red values either have Sq mean values (gene copies $/ \mu \mathrm{L}$ ) lower than lowest trusted standard or they have quantification cycle values $(\mathrm{Cq})$ greater than the blank with the lowest Cq. Therefore red samples are below the limit of quantification. Since the Control and EK-Control samples had a different dilution factor than the EK-Bio samples, the limit of quantification for these 2 samples in gene copies $/ \mathrm{mL}$ of groundwater is different. Samples with no data (N/A) had no amplification. Standard curves had efficiency and $\mathrm{R}^{2}$ value of $93.77 \%$ and 0.989 respectively for $-15,9$ and 54 days, and $92.27 \%$ and 0.998 for 196 days.

\begin{tabular}{|c|c|c|c|c|c|c|c|c|}
\hline Days & Location & $\begin{array}{l}\text { Dilution } \\
\text { factor }\end{array}$ & $\begin{array}{c}\text { Cq } \\
\text { mean }\end{array}$ & $\begin{array}{c}\text { Sq mean } \\
(\text { Gene } \\
\text { Copies } / \mu \mathrm{L})\end{array}$ & $\begin{array}{c}\text { Eluded } \\
\text { Volume } \\
(\mu \mathrm{L})\end{array}$ & $\begin{array}{c}\text { Average } \\
\text { Total } \\
\text { Gene } \\
\text { Copies } \\
\end{array}$ & $\begin{array}{c}\text { Filtered } \\
\text { Volume } \\
(\mathrm{mL})\end{array}$ & $\begin{array}{c}\text { Average } \\
\text { Gene } \\
\text { Copies/mL of } \\
\text { Groundwater } \\
\end{array}$ \\
\hline \multirow{5}{*}{-15} & $\begin{array}{l}\text { Control } \\
\text { MW1B }\end{array}$ & 50 & 35.28 & $3.30 \mathrm{E}+01$ & 50 & $8.24 \mathrm{E}+04$ & 220 & $3.75 \mathrm{E}+02$ \\
\hline & $\begin{array}{c}\text { EK- } \\
\text { Control } \\
\text { MW1B }\end{array}$ & 50 & 38.93 & $2.98 \mathrm{E}+00$ & 50 & $7.44 \mathrm{E}+03$ & 210 & $3.54 \mathrm{E}+01$ \\
\hline & $\begin{array}{c}\text { EK- } \\
\text { Control } \\
\text { MW2B } \\
\end{array}$ & 50 & 36.80 & $8.34 \mathrm{E}+00$ & 50 & $2.09 \mathrm{E}+04$ & 220 & $9.48 \mathrm{E}+01$ \\
\hline & $\begin{array}{l}\text { EK-Bio } \\
\text { MW1B }\end{array}$ & 10 & N/A & N/A & 50 & N/A & 210 & N/A \\
\hline & $\begin{array}{l}\text { EK-Bio } \\
\text { MW2B }\end{array}$ & 10 & 38.07 & $5.12 \mathrm{E}+00$ & 50 & $2.56 \mathrm{E}+03$ & 220 & $1.16 \mathrm{E}+01$ \\
\hline \multirow{5}{*}{9} & $\begin{array}{l}\text { Control } \\
\text { MW1A }\end{array}$ & 50 & 32.53 & $2.01 \mathrm{E}+02$ & 50 & $5.03 \mathrm{E}+05$ & 200 & $2.52 \mathrm{E}+03$ \\
\hline & $\begin{array}{l}\text { Control } \\
\text { MW1B }\end{array}$ & 50 & 31.63 & $3.64 \mathrm{E}+02$ & 50 & $9.10 \mathrm{E}+05$ & 200 & $4.55 \mathrm{E}+03$ \\
\hline & $\begin{array}{c}\text { EK- } \\
\text { Control } \\
\text { MW1A } \\
\end{array}$ & 50 & 39.03 & $2.89 \mathrm{E}+00$ & 50 & $7.22 \mathrm{E}+03$ & 200 & $3.61 \mathrm{E}+01$ \\
\hline & $\begin{array}{c}\text { EK- } \\
\text { Control } \\
\text { MW1B } \\
\end{array}$ & 50 & 38.50 & $3.87 \mathrm{E}+00$ & 50 & $9.68 \mathrm{E}+03$ & 200 & $4.84 \mathrm{E}+01$ \\
\hline & $\begin{array}{c}\text { EK- } \\
\text { Control } \\
\text { MW2A }\end{array}$ & 50 & 28.37 & $3.14 \mathrm{E}+03$ & 50 & $7.86 \mathrm{E}+06$ & 200 & $3.93 \mathrm{E}+04$ \\
\hline
\end{tabular}




\begin{tabular}{|c|c|c|c|c|c|c|c|c|}
\hline & $\begin{array}{c}\text { EK- } \\
\text { Control } \\
\text { MW2B }\end{array}$ & 50 & 33.52 & $1.04 \mathrm{E}+02$ & 50 & $2.60 \mathrm{E}+05$ & 200 & $1.30 \mathrm{E}+03$ \\
\hline & $\begin{array}{l}\text { EK-Bio } \\
\text { MW1A }\end{array}$ & 10 & 33.07 & $1.40 \mathrm{E}+02$ & 50 & $7.01 \mathrm{E}+04$ & 200 & $3.50 \mathrm{E}+02$ \\
\hline & $\begin{array}{l}\text { EK-Bio } \\
\text { MW1B } \\
\end{array}$ & 10 & N/A & N/A & 50 & N/A & 200 & N/A \\
\hline & $\begin{array}{l}\text { EK-Bio } \\
\text { MW2A }\end{array}$ & 10 & 38.12 & $5.90 \mathrm{E}+00$ & 50 & $2.95 \mathrm{E}+03$ & 200 & $1.47 \mathrm{E}+01$ \\
\hline & $\begin{array}{l}\text { EK-Bio } \\
\text { MW2B }\end{array}$ & 10 & 37.23 & $1.03 \mathrm{E}+01$ & 50 & $5.13 \mathrm{E}+03$ & 200 & $2.56 \mathrm{E}+01$ \\
\hline \multirow{10}{*}{54} & $\begin{array}{l}\text { Control } \\
\text { MW1A }\end{array}$ & 50 & 33.42 & $1.14 \mathrm{E}+02$ & 50 & $2.84 \mathrm{E}+05$ & 200 & $1.42 \mathrm{E}+03$ \\
\hline & $\begin{array}{l}\text { Control } \\
\text { MW1B }\end{array}$ & 50 & 34.04 & $7.39 \mathrm{E}+01$ & 50 & $1.85 \mathrm{E}+05$ & 140 & $1.32 \mathrm{E}+03$ \\
\hline & $\begin{array}{c}\text { EK- } \\
\text { Control } \\
\text { MW1A }\end{array}$ & 50 & 32.28 & $2.38 \mathrm{E}+02$ & 50 & $5.94 \mathrm{E}+05$ & 200 & $2.97 \mathrm{E}+03$ \\
\hline & $\begin{array}{c}\text { EK- } \\
\text { Control } \\
\text { MW1B }\end{array}$ & 50 & 34.71 & $4.73 \mathrm{E}+01$ & 50 & $1.18 \mathrm{E}+05$ & 200 & $5.92 \mathrm{E}+02$ \\
\hline & $\begin{array}{c}\text { EK- } \\
\text { Control } \\
\text { MW2A }\end{array}$ & 50 & 28.56 & $2.76 \mathrm{E}+03$ & 50 & $6.91 \mathrm{E}+06$ & 200 & $3.45 \mathrm{E}+04$ \\
\hline & $\begin{array}{c}\text { EK- } \\
\text { Control } \\
\text { MW2B }\end{array}$ & 50 & 34.73 & $4.69 \mathrm{E}+01$ & 50 & $1.17 \mathrm{E}+05$ & 200 & $5.86 \mathrm{E}+02$ \\
\hline & $\begin{array}{l}\text { EK-Bio } \\
\text { MW1A }\end{array}$ & 10 & 35.03 & $3.84 \mathrm{E}+01$ & 50 & $1.92 \mathrm{E}+04$ & 200 & $9.59 \mathrm{E}+01$ \\
\hline & $\begin{array}{l}\text { EK-Bio } \\
\text { MW1B }\end{array}$ & 10 & 39.24 & $2.37 \mathrm{E}+00$ & 50 & $1.18 \mathrm{E}+03$ & 200 & $5.92 \mathrm{E}+00$ \\
\hline & $\begin{array}{l}\text { EK-Bio } \\
\text { MW2A }\end{array}$ & 10 & N/A & N/A & 50 & N/A & 200 & N/A \\
\hline & $\begin{array}{l}\text { EK-Bio } \\
\text { MW2B }\end{array}$ & 10 & 27.69 & $4.96 \mathrm{E}+03$ & 50 & $2.48 \mathrm{E}+06$ & 160 & $1.55 \mathrm{E}+04$ \\
\hline \multirow{3}{*}{196} & $\begin{array}{l}\text { Control } \\
\text { MW1A }\end{array}$ & 50 & 32.34 & $4.26 \mathrm{E}+02$ & 50 & $1.07 \mathrm{E}+06$ & 200 & $5.33 \mathrm{E}+03$ \\
\hline & $\begin{array}{l}\text { Control } \\
\text { MW1B }\end{array}$ & 50 & 30.26 & $1.66 \mathrm{E}+03$ & 50 & $4.16 \mathrm{E}+06$ & 200 & $2.08 \mathrm{E}+04$ \\
\hline & EK- & 50 & 31.10 & $9.53 \mathrm{E}+02$ & 50 & $2.38 \mathrm{E}+06$ & 200 & $1.19 \mathrm{E}+04$ \\
\hline
\end{tabular}




\begin{tabular}{|c|c|c|c|c|c|c|c|}
\hline $\begin{array}{c}\text { Control } \\
\text { MW1A }\end{array}$ & & & & & & & \\
\hline $\begin{array}{c}\text { EK- } \\
\text { Control } \\
\text { MW1B }\end{array}$ & 50 & 32.06 & $5.13 \mathrm{E}+02$ & 100 & $2.56 \mathrm{E}+06$ & 150 & $1.71 \mathrm{E}+04$ \\
\hline $\begin{array}{c}\text { EK- } \\
\text { Control } \\
\text { MW2A }\end{array}$ & 50 & 30.18 & $1.74 \mathrm{E}+03$ & 50 & $4.35 \mathrm{E}+06$ & 200 & $2.18 \mathrm{E}+04$ \\
\hline $\begin{array}{c}\text { EK- } \\
\text { Control } \\
\text { MW2B }\end{array}$ & 50 & 33.85 & $1.59 \mathrm{E}+02$ & 50 & $3.98 \mathrm{E}+05$ & 200 & $1.99 \mathrm{E}+03$ \\
\hline $\begin{array}{c}\text { EK-Bio } \\
\text { MW1A }\end{array}$ & 10 & 32.24 & $4.53 \mathrm{E}+02$ & 50 & $2.27 \mathrm{E}+05$ & 200 & $1.13 \mathrm{E}+03$ \\
\hline $\begin{array}{c}\text { EK-Bio } \\
\text { MW1B }\end{array}$ & 10 & 33.23 & $2.38 \mathrm{E}+02$ & 50 & $1.19 \mathrm{E}+05$ & 150 & $7.94 \mathrm{E}+02$ \\
\hline $\begin{array}{c}\text { EK-Bio } \\
\text { MW2A }\end{array}$ & 10 & 31.75 & $6.24 \mathrm{E}+02$ & 50 & $3.12 \mathrm{E}+05$ & 200 & $1.56 \mathrm{E}+03$ \\
\hline $\begin{array}{c}\text { EK-Bio } \\
\text { MW2B }\end{array}$ & 10 & 28.25 & $6.16 \mathrm{E}+03$ & 50 & $3.08 \mathrm{E}+06$ & 100 & $3.08 \mathrm{E}+04$ \\
\hline
\end{tabular}

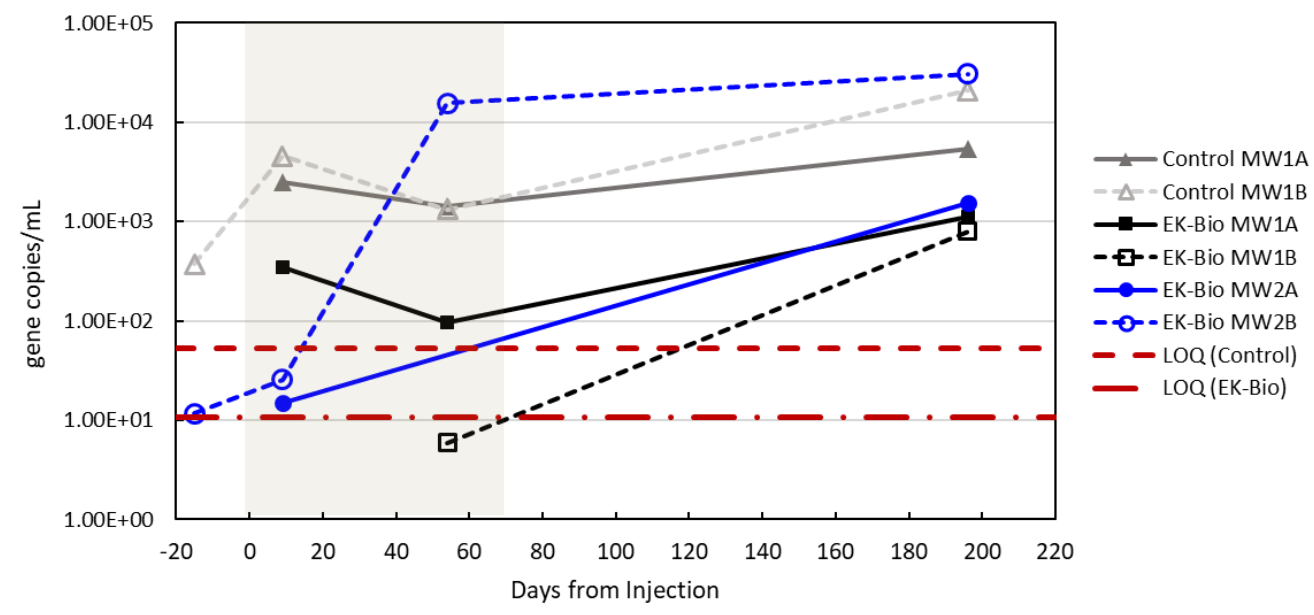

Figure A.25 Dehalococcoides concentrations in EK-Bio and Control cell determined through qPCR. The limit of quantification (LOQ) for Control and EK-Bio samples are shown with red dashed lines. All EK-Bio samples increased by 196 days. Grey region indicates duration of EK application and lactate injection. 
Table A.6 Percentages of bacterial population made up by each genus in Control samples over time.

Genera present at greater than $3 \%$ in at least 1 sample on site are given, but any genera less than $3 \%$ across all site samples are summed and given as a total.

\begin{tabular}{|c|c|c|c|c|c|c|c|c|c|}
\hline & \multirow[b]{2}{*}{ Days from Injection } & \multicolumn{4}{|c|}{ Control MW1A (\%) } & \multicolumn{4}{|c|}{ Control MW1B (\%) } \\
\hline & & \multirow[t]{2}{*}{9} & \multirow[t]{2}{*}{54} & \multirow[t]{2}{*}{196} & \multirow[t]{2}{*}{391} & \multirow[t]{2}{*}{9} & \multirow{2}{*}{54} & \multirow[t]{2}{*}{196} & \multirow[t]{2}{*}{391} \\
\hline Phylum & Genus & & & & & & & & \\
\hline \multirow{13}{*}{ Firmicutes } & Trichococcus & 0.0 & 0.0 & 0.0 & 0.1 & 0.0 & 0.0 & 0.0 & 0.0 \\
\hline & Proteiniclasticum & 0.0 & 0.0 & 0.0 & 0.2 & 0.0 & 0.0 & 0.0 & 0.1 \\
\hline & Bacillus & 0.1 & 0.1 & 0.1 & 0.0 & 0.0 & 0.0 & 0.0 & 0.0 \\
\hline & Sedimentibacter & 0.0 & 0.0 & 0.0 & 0.3 & 0.0 & 0.1 & 0.0 & 0.0 \\
\hline & Desulfitobacterium & 0.0 & 3.9 & 1.2 & 1.1 & 0.0 & 2.6 & 1.8 & 3.7 \\
\hline & Tyzzerella & 0.0 & 0.0 & 0.0 & 0.1 & 0.0 & 0.0 & 0.0 & 0.0 \\
\hline & Domibacillus & 0.0 & 0.0 & 0.0 & 0.0 & 0.0 & 0.0 & 0.0 & 0.0 \\
\hline & Fictibacillus & 0.0 & 0.0 & 0.0 & 0.0 & 0.0 & 0.0 & 0.0 & 0.0 \\
\hline & Clostridium & 0.0 & 0.0 & 0.0 & 0.3 & 0.1 & 0.1 & 0.0 & 0.0 \\
\hline & Lachnospiraceae & 0.0 & 0.0 & 0.0 & 0.0 & 0.0 & 0.0 & 0.0 & 0.0 \\
\hline & Desulfosporosinus & 0.0 & 0.0 & 0.0 & 0.0 & 0.0 & 0.1 & 0.4 & 0.0 \\
\hline & Enterococcus & 0.0 & 0.0 & 0.0 & 0.0 & 0.0 & 0.0 & 0.0 & 0.0 \\
\hline & Anaerosporobacter & 0.0 & 0.0 & 0.0 & 0.0 & 0.0 & 0.0 & 0.0 & 0.0 \\
\hline \multirow{10}{*}{ Proteobacteria } & Acidovorax & 7.9 & 12.0 & 16.9 & 6.9 & 4.9 & 8.9 & 8.0 & 7.7 \\
\hline & Methylotenera & 6.6 & 1.2 & 0.9 & 0.3 & 4.0 & 3.5 & 0.5 & 0.9 \\
\hline & Acinetobacter & 2.0 & 0.9 & 0.1 & 0.5 & 0.8 & 0.3 & 0.1 & 0.1 \\
\hline & Brevundimonas & 4.1 & 1.0 & 0.5 & 0.2 & 3.6 & 0.9 & 0.7 & 0.9 \\
\hline & Hydrogenophaga & 0.1 & 0.3 & 0.6 & 1.9 & 0.3 & 0.2 & 0.9 & 0.6 \\
\hline & Sphingomonas & 0.0 & 0.0 & 0.2 & 0.1 & 0.0 & 0.1 & 0.1 & 0.2 \\
\hline & Citrobacter & 0.0 & 0.0 & 0.0 & 0.3 & 0.0 & 0.0 & 0.0 & 0.0 \\
\hline & Sulfuricurvum & 3.3 & 0.5 & 0.4 & 0.0 & 7.3 & 0.0 & 0.2 & 0.0 \\
\hline & Polaromonas & 1.2 & 0.3 & 0.4 & 0.2 & 4.6 & 1.2 & 0.2 & 0.5 \\
\hline & Aquabacterium & 2.2 & 0.1 & 0.1 & 0.4 & 3.9 & 0.1 & 0.1 & 0.1 \\
\hline
\end{tabular}




\begin{tabular}{|c|c|c|c|c|c|c|c|c|c|}
\hline \multirow{5}{*}{ Lutibacter } & 4.0 & 4.9 & 8.2 & 0.6 & 2.4 & 4.7 & 25.4 & 6.5 \\
\cline { 2 - 10 } & Proteiniphilum & 1.6 & 4.1 & 2.3 & 1.5 & 2.0 & 2.1 & 2.4 & 1.8 \\
\cline { 2 - 10 } & Pedobacter & 9.2 & 5.7 & 2.0 & 0.6 & 4.4 & 1.7 & 1.5 & 1.3 \\
\cline { 2 - 10 } & Macellibacteroides & 0.0 & 0.0 & 0.0 & 2.7 & 0.0 & 0.0 & 0.0 & 0.0 \\
\cline { 2 - 10 } & Bacteroides & 0.0 & 0.1 & 0.0 & 1.3 & 0.0 & 0.0 & 0.0 & 0.0 \\
\cline { 2 - 10 } & Algoriphagus & 8.2 & 1.2 & 0.5 & 0.2 & 8.7 & 0.8 & 0.3 & 0.4 \\
\cline { 2 - 10 } & Sediminibacterium & 8.5 & 3.3 & 2.0 & 0.3 & 1.0 & 0.3 & 0.4 & 0.6 \\
\hline \multirow{3}{*}{ Chloroflexi } & Dehalogenimonas & 0.7 & 1.7 & 1.2 & 0.2 & 1.1 & 1.8 & 0.7 & 3.1 \\
\hline \multirow{3}{*}{ Actinobacteria } & Arthrobacter & 0.4 & 0.1 & 0.1 & 0.1 & 0.8 & 0.2 & 0.0 & 0.0 \\
\hline \multicolumn{2}{|c|}{ Sum of minor genera (<3\%) } & 11.8 & 9.9 & 9.1 & 21.1 & 12.8 & 10.8 & 8.0 & 12.3 \\
\hline
\end{tabular}

Table A.7 Percentages of bacterial population made up by each genus in EK-Bio MW1 samples over time. Genera present at greater than 3\% in at least 1 sample on site are given, but any genera less than $3 \%$ across all site samples are summed and given as a total.

\begin{tabular}{|c|c|c|c|c|c|c|c|c|c|}
\hline & \multirow[b]{2}{*}{ Days from Injection } & \multicolumn{4}{|c|}{ EK-Bio MW1A (\%) } & \multicolumn{4}{|c|}{ EK-Bio MW1B (\%) } \\
\hline & & \multirow[t]{2}{*}{9} & \multirow[t]{2}{*}{54} & \multirow[t]{2}{*}{196} & \multirow[t]{2}{*}{391} & \multirow[t]{2}{*}{9} & \multirow[t]{2}{*}{54} & \multirow[t]{2}{*}{196} & \multirow[t]{2}{*}{391} \\
\hline Phylum & Genus & & & & & & & & \\
\hline \multirow{9}{*}{ Firmicutes } & Trichococcus & 2.6 & 15.7 & 19.8 & 30.4 & 0.0 & 1.2 & 1.0 & 9.0 \\
\hline & Proteiniclasticum & 0.0 & 2.8 & 15.8 & 8.6 & 0.0 & 0.1 & 0.1 & 0.8 \\
\hline & Bacillus & 4.3 & 0.3 & 0.0 & 0.2 & 7.2 & 6.2 & 1.2 & 5.4 \\
\hline & Sedimentibacter & 0.1 & 3.0 & 9.7 & 2.9 & 0.0 & 0.1 & 0.0 & 1.8 \\
\hline & Desulfitobacterium & 0.0 & 0.3 & 1.3 & 5.0 & 0.0 & 0.1 & 0.0 & 0.7 \\
\hline & Tyzzerella & 0.0 & 11.5 & 2.9 & 11.3 & 0.0 & 0.1 & 0.0 & 0.0 \\
\hline & Domibacillus & 1.8 & 0.1 & 0.0 & 0.0 & 5.5 & 3.3 & 0.4 & 1.8 \\
\hline & Fictibacillus & 2.1 & 0.1 & 0.0 & 0.0 & 6.0 & 2.8 & 0.2 & 1.6 \\
\hline & Clostridium & 0.4 & 6.3 & 1.7 & 0.3 & 0.6 & 0.8 & 0.4 & 0.3 \\
\hline
\end{tabular}




\begin{tabular}{|c|c|c|c|c|c|c|c|c|c|}
\hline & Lachnospiraceae & 0.0 & 6.4 & 3.0 & 0.5 & 0.0 & 0.0 & 0.0 & 0.0 \\
\hline & Desulfosporosinus & 0.0 & 1.5 & 0.3 & 0.0 & 0.0 & 0.0 & 0.0 & 0.0 \\
\hline & Enterococcus & 0.0 & 5.6 & 0.0 & 0.0 & 0.0 & 0.0 & 0.0 & 0.0 \\
\hline & Anaerosporobacter & 0.0 & 0.1 & 0.2 & 0.0 & 0.0 & 0.0 & 0.0 & 0.0 \\
\hline \multirow{10}{*}{ Proteobacteria } & Acidovorax & 0.9 & 0.0 & 0.0 & 6.3 & 0.5 & 0.3 & 0.2 & 1.9 \\
\hline & Methylotenera & 3.4 & 0.2 & 0.0 & 0.0 & 3.2 & 3.8 & 0.3 & 2.6 \\
\hline & Acinetobacter & 3.7 & 0.2 & 0.1 & 1.2 & 0.8 & 4.5 & 0.3 & 0.8 \\
\hline & Brevundimonas & 0.5 & 0.2 & 0.4 & 0.6 & 0.0 & 0.5 & 2.4 & 1.3 \\
\hline & Hydrogenophaga & 0.5 & 0.0 & 0.0 & 0.0 & 0.7 & 0.6 & 0.3 & 0.6 \\
\hline & Sphingomonas & 0.1 & 0.0 & 0.2 & 0.1 & 0.0 & 0.2 & 3.7 & 1.3 \\
\hline & Citrobacter & 0.5 & 5.8 & 3.8 & 0.5 & 0.0 & 0.2 & 0.0 & 0.0 \\
\hline & Sulfuricurvum & 0.0 & 0.0 & 0.0 & 0.0 & 0.0 & 0.3 & 0.0 & 0.0 \\
\hline & Polaromonas & 0.4 & 0.1 & 0.0 & 0.0 & 0.0 & 0.0 & 0.8 & 0.1 \\
\hline & Aquabacterium & 2.5 & 0.0 & 0.0 & 0.6 & 0.0 & 0.5 & 0.0 & 0.3 \\
\hline \multirow{7}{*}{ Bacteroidetes } & Lutibacter & 0.1 & 0.0 & 0.0 & 0.0 & 0.0 & 0.0 & 8.0 & 0.1 \\
\hline & Proteiniphilum & 2.4 & 0.6 & 1.2 & 5.2 & 0.4 & 0.0 & 0.0 & 1.0 \\
\hline & Pedobacter & 8.0 & 0.1 & 0.2 & 0.9 & 0.2 & 0.3 & 3.7 & 2.9 \\
\hline & Macellibacteroides & 0.0 & 15.1 & 8.0 & 3.8 & 0.0 & 0.0 & 0.0 & 2.3 \\
\hline & Bacteroides & 0.0 & 9.4 & 5.1 & 0.4 & 0.0 & 0.0 & 0.0 & 0.0 \\
\hline & Algoriphagus & 0.2 & 0.0 & 0.0 & 0.0 & 0.0 & 0.0 & 0.4 & 0.0 \\
\hline & Sediminibacterium & 0.1 & 0.0 & 0.0 & 0.4 & 0.2 & 0.0 & 0.1 & 0.3 \\
\hline Chloroflexi & Dehalogenimonas & 0.6 & 0.1 & 0.1 & 0.0 & 0.0 & 0.0 & 0.0 & 0.0 \\
\hline Actinobacteria & Arthrobacter & 2.4 & 0.4 & 3.3 & 0.6 & 0.7 & 3.5 & 8.6 & 0.9 \\
\hline \multicolumn{2}{|c|}{ Sum of minor genera $(<3 \%)$} & 21.7 & 6.5 & 12.9 & 6.7 & 25.8 & 23.8 & 29.3 & 21.3 \\
\hline
\end{tabular}


Table A.8 Percentages of bacterial population made up by each genus in EK-Bio MW2 samples over time. Genera present at greater than $3 \%$ in at least 1 sample on site are given, but any genera less than $3 \%$ across all site samples are summed and given as a total.

\begin{tabular}{|c|c|c|c|c|c|c|c|c|c|}
\hline & \multirow[b]{2}{*}{ Days from Injection } & \multicolumn{4}{|c|}{ EK-Bio MW2A (\%) } & \multicolumn{4}{|c|}{ EK-Bio MW2B (\%) } \\
\hline & & 9 & 54 & 196 & 391 & 9 & 54 & 196 & 391 \\
\hline Phylum & Genus & & & & & & & & \\
\hline \multirow{13}{*}{ Firmicutes } & Trichococcus & 0.4 & 8.9 & 2.8 & 29.8 & 0.1 & 5.4 & 20.6 & 14.2 \\
\hline & Proteiniclasticum & 0.0 & 0.5 & 16.5 & 3.1 & 0.0 & 6.4 & 6.0 & 14.5 \\
\hline & Bacillus & 2.8 & 5.2 & 0.2 & 3.6 & 5.9 & 4.0 & 0.6 & 2.5 \\
\hline & Sedimentibacter & 0.1 & 1.2 & 0.9 & 0.7 & 1.4 & 2.1 & 5.5 & 5.8 \\
\hline & Desulfitobacterium & 0.2 & 0.0 & 0.1 & 4.6 & 0.2 & 1.3 & 4.6 & 2.4 \\
\hline & Tyzzerella & 0.0 & 1.3 & 0.0 & 2.2 & 0.0 & 0.1 & 0.6 & 1.3 \\
\hline & Domibacillus & 1.0 & 3.4 & 0.1 & 1.6 & 1.9 & 0.2 & 0.0 & 1.8 \\
\hline & Fictibacillus & 1.3 & 3.1 & 0.1 & 1.8 & 1.5 & 0.0 & 0.0 & 1.8 \\
\hline & Clostridium & 0.4 & 1.5 & 0.1 & 0.6 & 0.4 & 0.9 & 1.2 & 0.5 \\
\hline & Lachnospiraceae & 0.0 & 0.3 & 0.1 & 0.0 & 0.0 & 0.1 & 0.4 & 0.1 \\
\hline & Desulfosporosinus & 0.1 & 0.1 & 0.0 & 0.0 & 0.0 & 1.2 & 3.4 & 0.4 \\
\hline & Enterococcus & 0.0 & 0.8 & 0.0 & 0.0 & 0.0 & 0.0 & 0.0 & 0.0 \\
\hline & Anaerosporobacter & 0.0 & 0.0 & 0.1 & 0.0 & 0.0 & 0.0 & 0.4 & 3.8 \\
\hline \multirow{10}{*}{ Proteobacteria } & Acidovorax & 6.3 & 0.4 & 0.0 & 4.4 & 0.9 & 1.4 & 0.0 & 0.4 \\
\hline & Methylotenera & 9.6 & 3.8 & 0.2 & 2.0 & 2.2 & 0.9 & 0.0 & 1.2 \\
\hline & Acinetobacter & 2.3 & 6.6 & 1.0 & 0.2 & 1.1 & 0.0 & 0.0 & 0.2 \\
\hline & Brevundimonas & 0.4 & 0.2 & 3.3 & 0.7 & 0.0 & 0.5 & 0.1 & 0.0 \\
\hline & Hydrogenophaga & 1.3 & 0.6 & 0.1 & 0.3 & 0.2 & 5.1 & 0.7 & 0.5 \\
\hline & Sphingomonas & 0.1 & 0.1 & 5.7 & 0.5 & 0.2 & 1.7 & 0.1 & 0.2 \\
\hline & Citrobacter & 0.0 & 0.4 & 0.9 & 0.1 & 0.0 & 0.6 & 1.4 & 0.1 \\
\hline & Sulfuricurvum & 0.4 & 0.2 & 0.0 & 0.0 & 0.0 & 0.0 & 0.0 & 0.0 \\
\hline & Polaromonas & 1.8 & 0.0 & 0.2 & 0.1 & 0.1 & 0.0 & 0.0 & 0.2 \\
\hline & Aquabacterium & 0.3 & 0.0 & 0.0 & 0.5 & 0.2 & 0.4 & 0.0 & 0.0 \\
\hline
\end{tabular}




\begin{tabular}{|c|c|c|c|c|c|c|c|c|c|}
\hline \multirow{7}{*}{ Bacteroidetes } & Lutibacter & 2.0 & 0.1 & 0.0 & 0.0 & 0.6 & 4.5 & 1.6 & 0.2 \\
\hline & Proteiniphilum & 0.7 & 0.1 & 0.9 & 4.1 & 4.1 & 2.7 & 4.3 & 6.0 \\
\hline & Pedobacter & 0.7 & 0.1 & 3.5 & 1.0 & 0.3 & 1.5 & 0.7 & 0.5 \\
\hline & Macellibacteroides & 0.0 & 3.1 & 3.2 & 1.5 & 0.0 & 2.5 & 7.3 & 0.5 \\
\hline & Bacteroides & 0.0 & 0.5 & 2.9 & 0.1 & 0.0 & 2.0 & 8.6 & 0.0 \\
\hline & Algoriphagus & 0.3 & 0.0 & 0.0 & 0.0 & 0.0 & 0.2 & 0.1 & 0.0 \\
\hline & Sediminibacterium & 0.0 & 0.1 & 0.0 & 0.1 & 0.0 & 0.0 & 0.0 & 0.0 \\
\hline Chloroflexi & Dehalogenimonas & 0.1 & 0.0 & 0.2 & 0.0 & 0.8 & 0.1 & 0.0 & 0.0 \\
\hline Actinobacteria & Arthrobacter & 1.3 & 3.9 & 6.1 & 0.9 & 1.2 & 4.7 & 1.5 & 2.1 \\
\hline Sum of & $\mathrm{ra}(<3 \%)$ & 0.0 & 13.0 & 19.5 & 30.6 & 13.6 & 14.7 & 16.1 & 8.9 \\
\hline
\end{tabular}

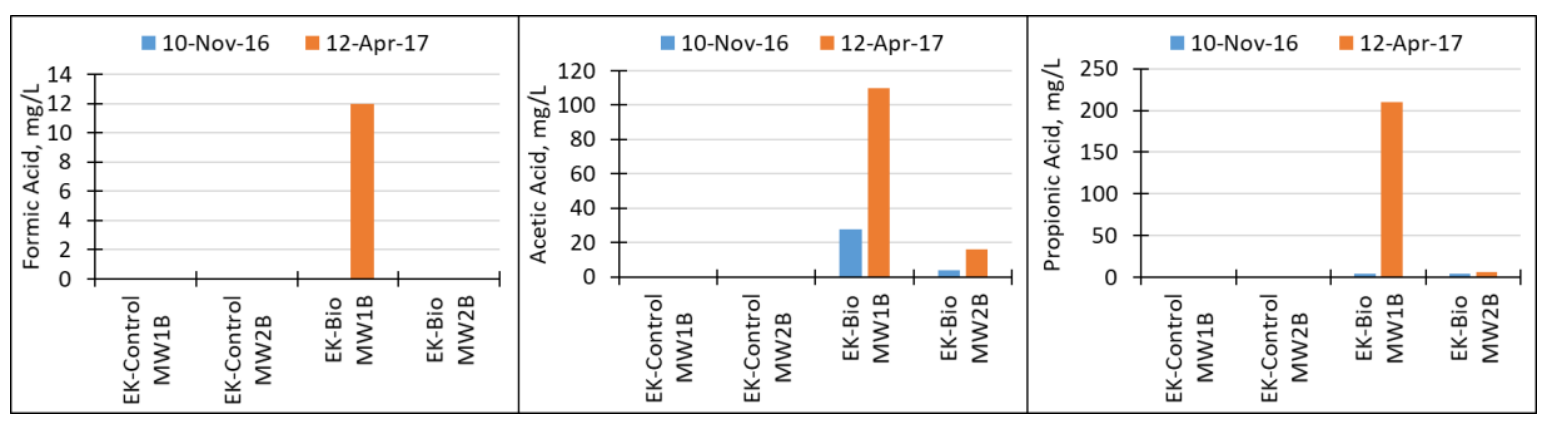

Figure A.26 Changes in volatile fatty acids (VFA) from EK and lactate injection phase to postinjection period in EK-Bio B depth wells. Increases in these VFAs provides evidence for fermentation of lactate. 

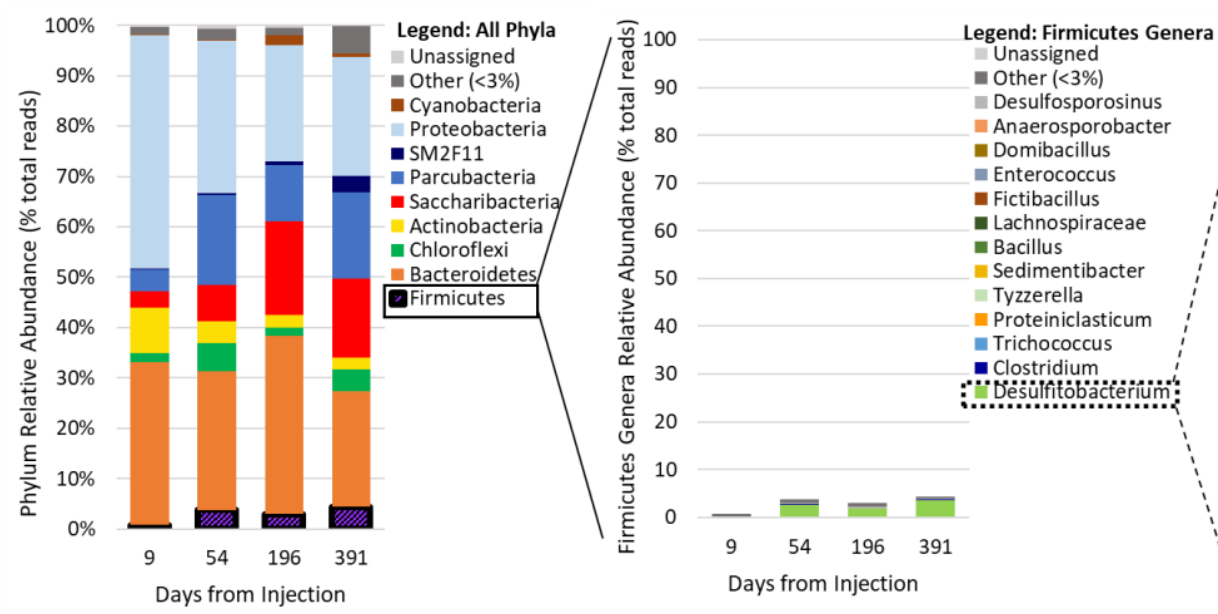

a)
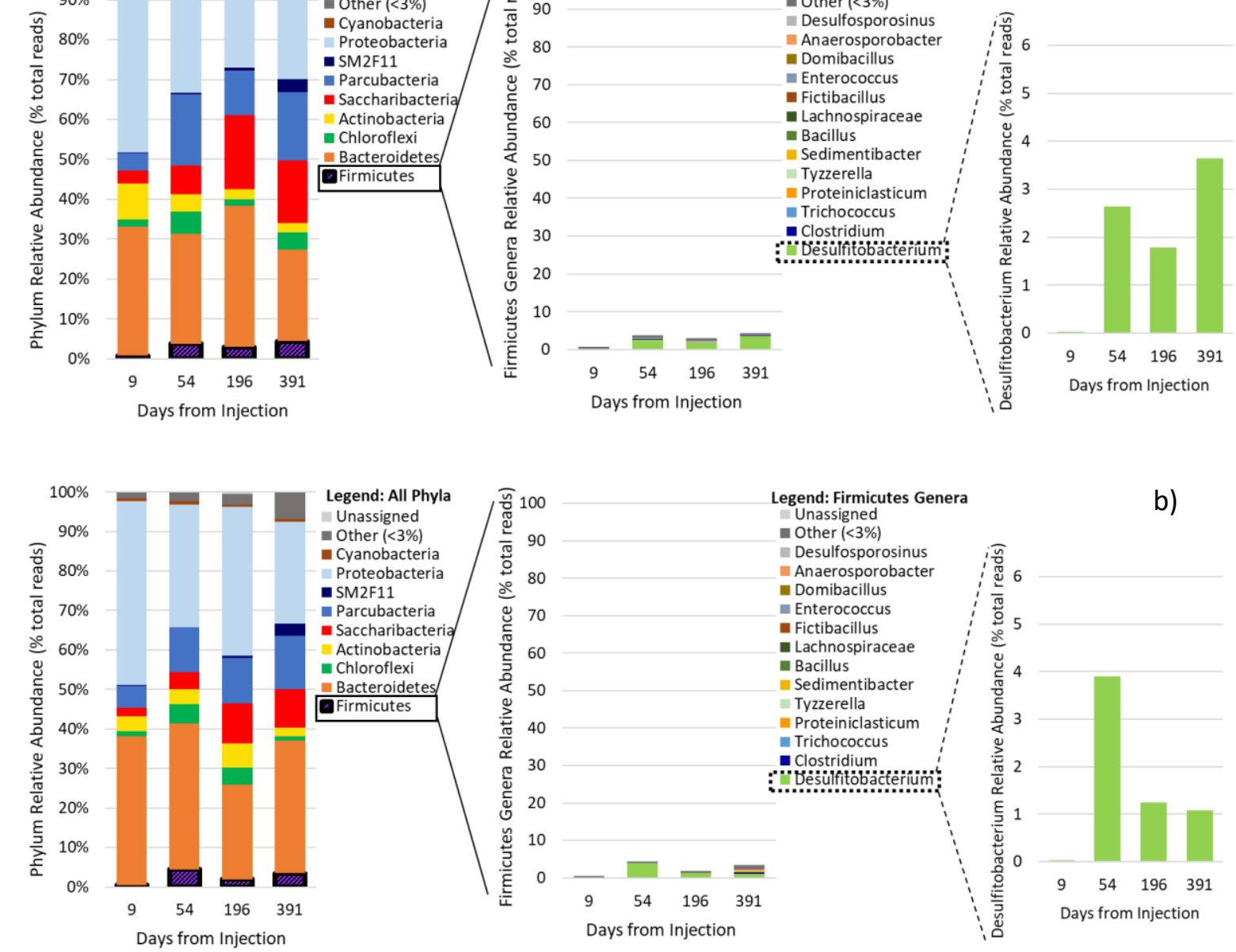

b)

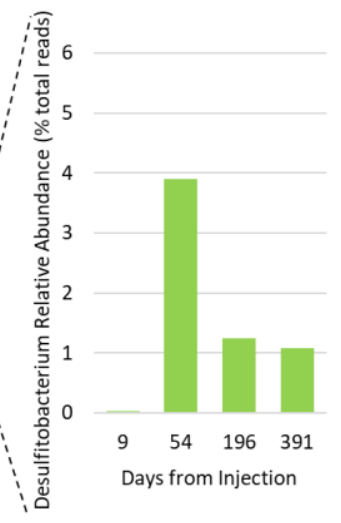

Figure A.27 Relative Abundance of Phyla and Firmicutes Genera in Control Cell determined from Illumina Sequencing and MetaAmp Analysis: a) MW1A b) MW1B. 


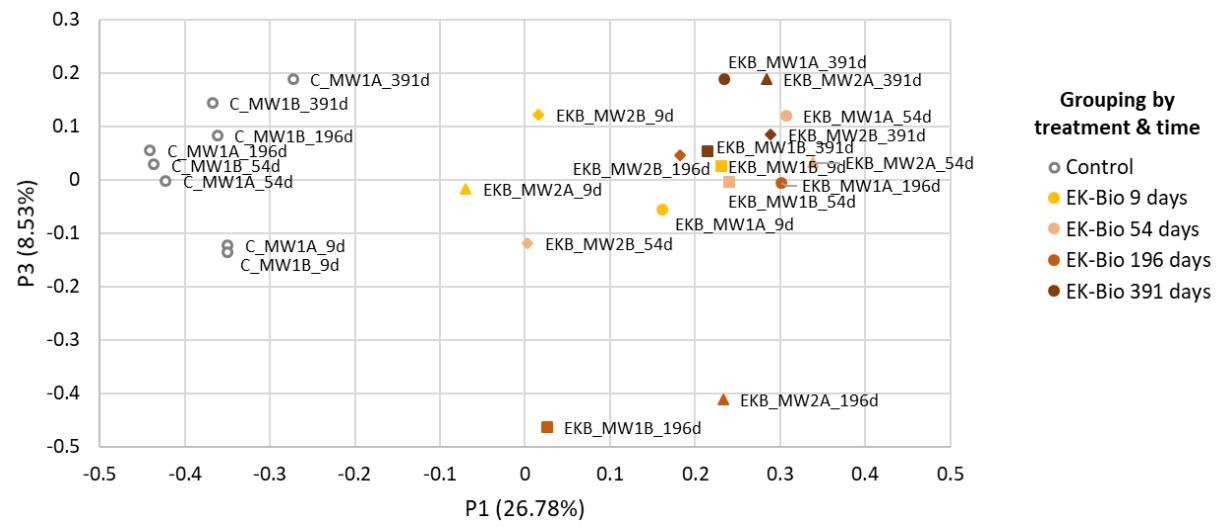

Figure A.28 Principle Coordinates Analysis of axes 1 and axes 3 showing dissimilarities between Control and EK-Bio samples, created through Illumina sequencing and MetaAmp analysis. $26.78 \%$ of the variation is captured in axis 1 and $8.53 \%$ of the variation is captured in axes 3 . The further the distance between the samples, the more dissimilar the samples are.

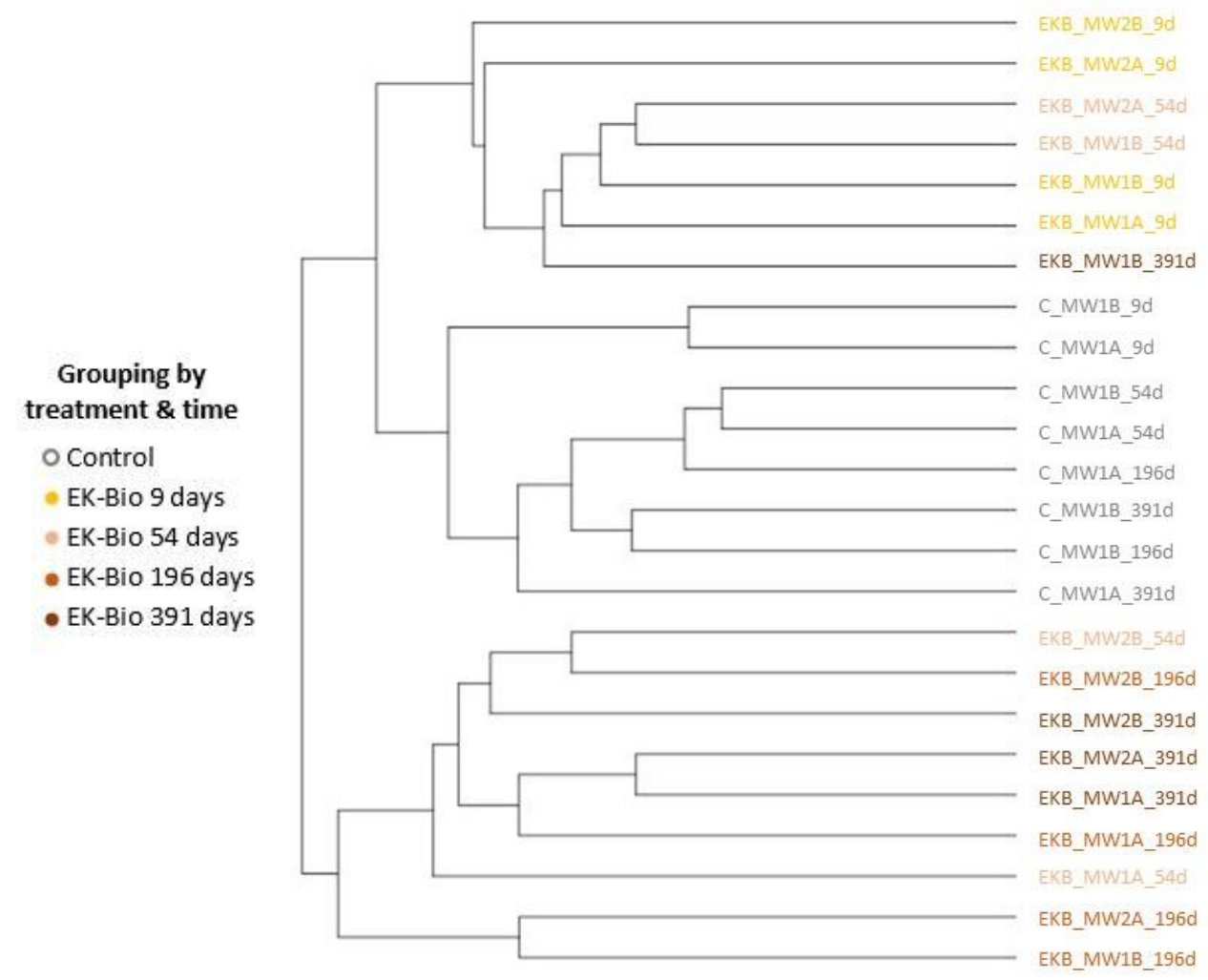

Figure A.29 Hierarchical clustering of Control and EK-Bio samples in a Dendrogram from Illumina Sequencing and performing MetaAmp analysis. 


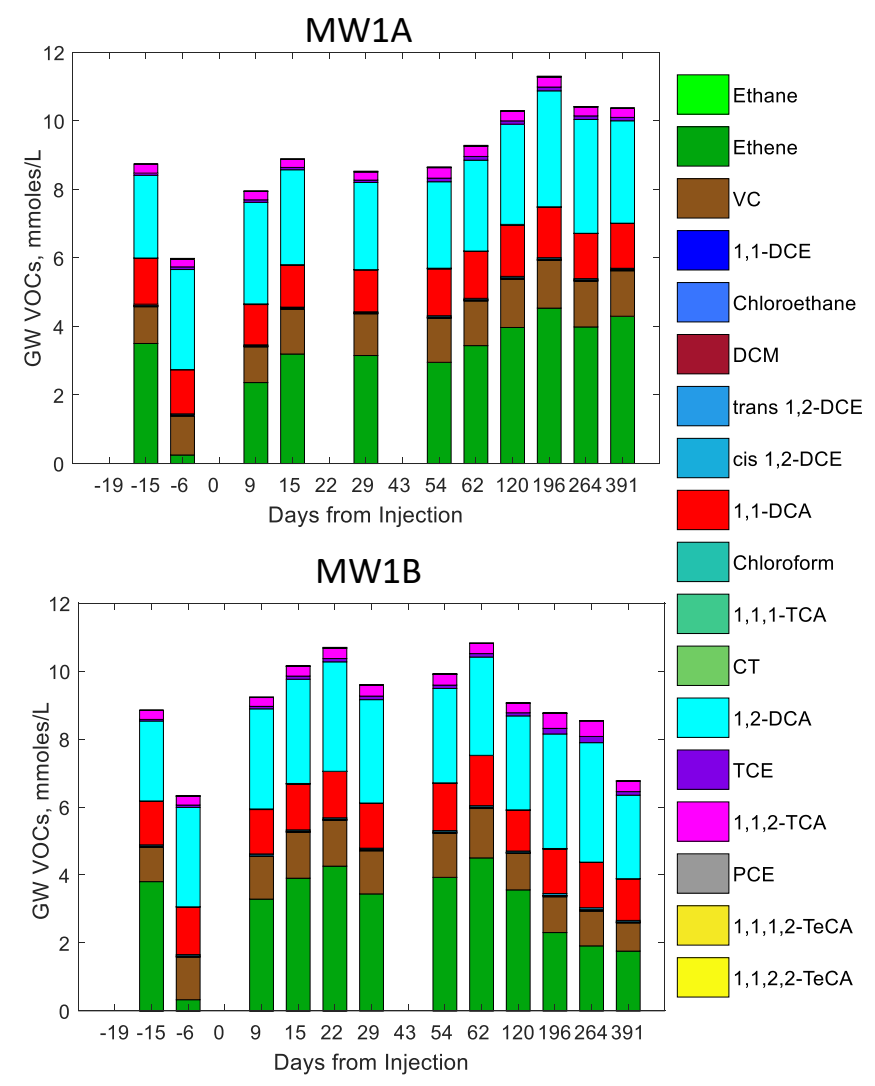

Figure A.30 Control cell aqueous cVOC concentrations over time showing no trend.

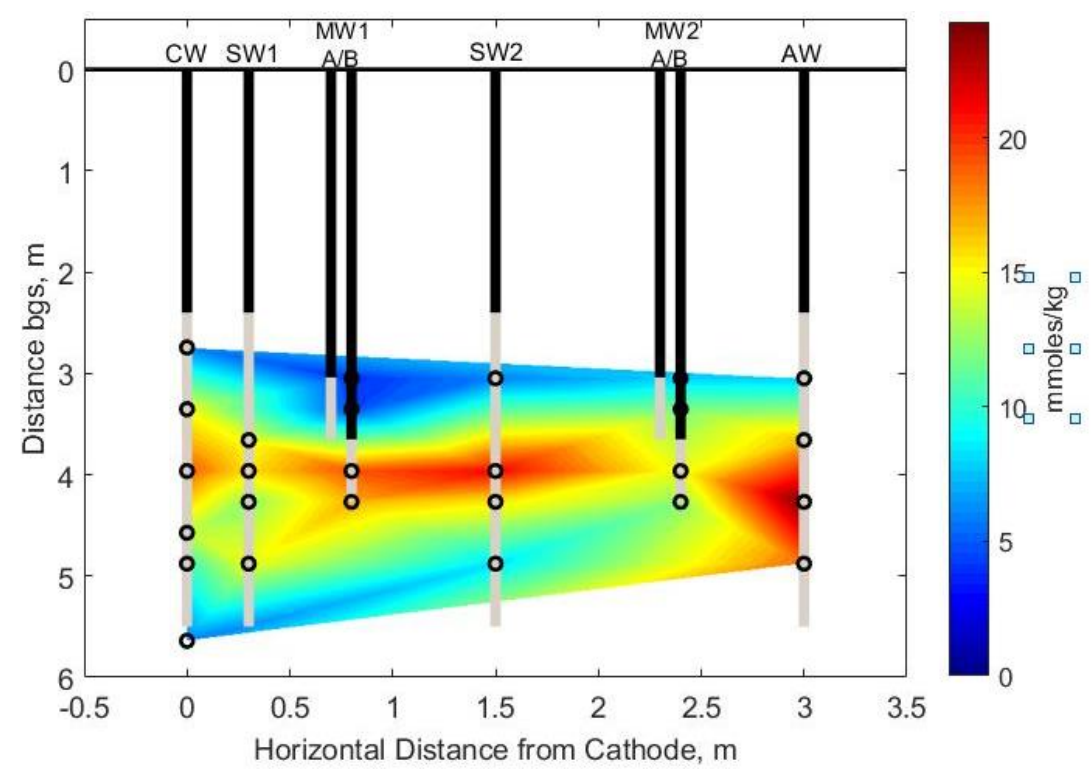

Figure A.31 Total soil cVOC concentration cross section in the EK-Bio cell before treatment showing heterogeneities in background contaminant distribution. 


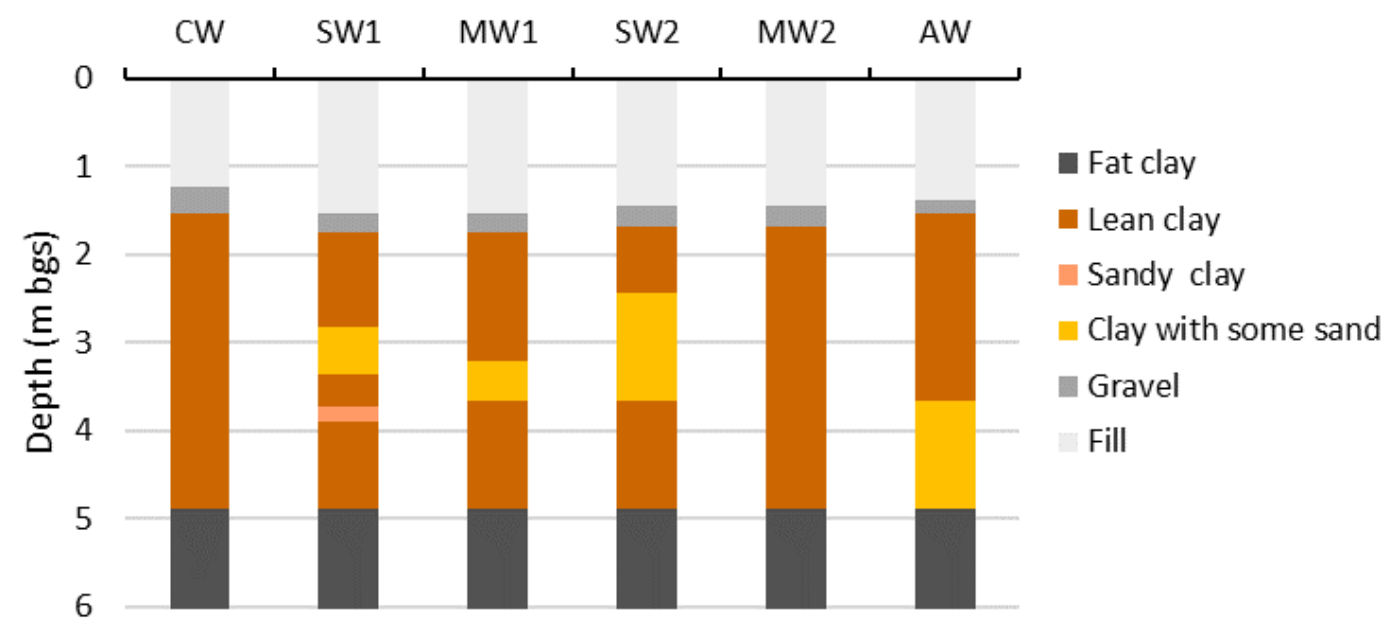

Figure A.32 Cross section of EK-Bio soil layers at each well location roughly inferred from borehole logs and soil core photographs.

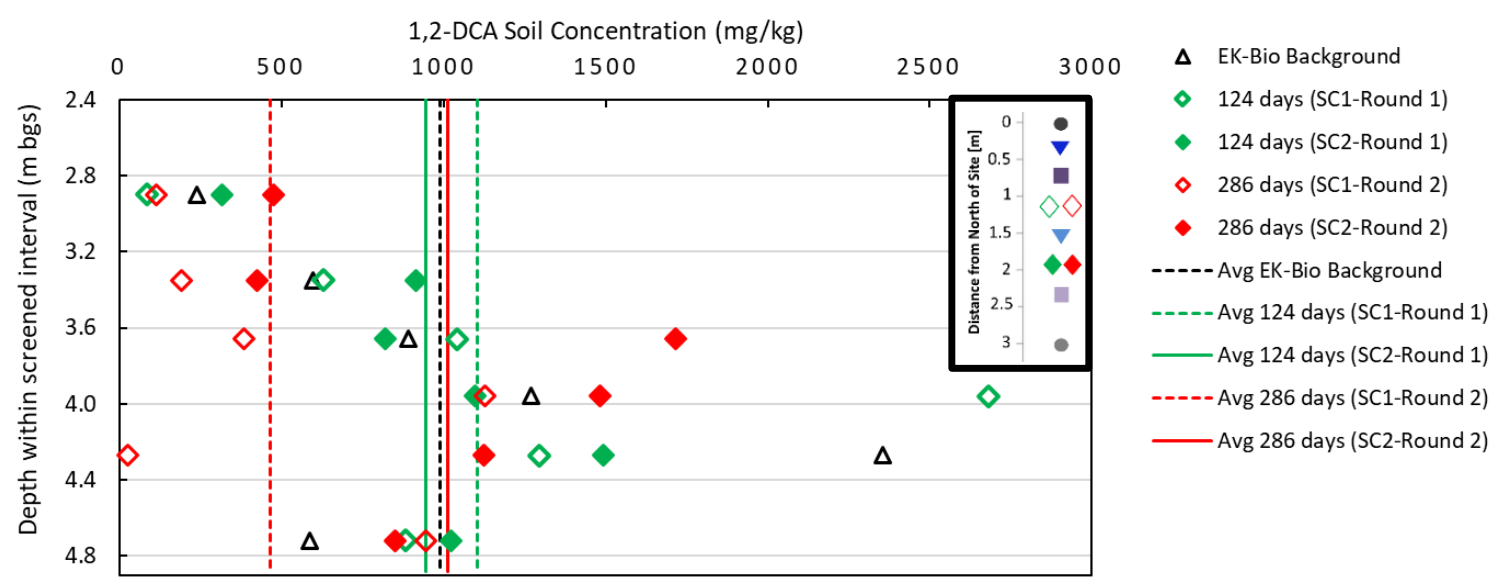

Figure A.33 EK-Bio 1,2-DCA soil concentration profile for each sampling time and location within the supply well screened interval. Vertical lines indicate the average concentration of the 6 sampling depths at each location and time. 


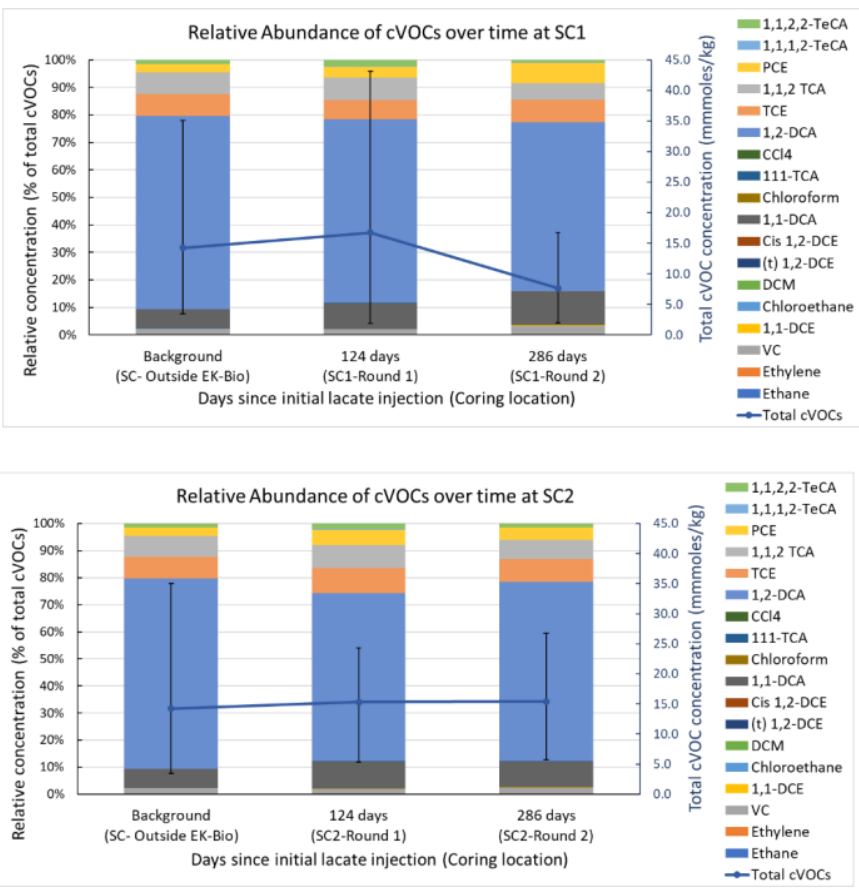

Figure A.34 Relative abundance of various cVOCs from each soil coring round as a fraction of total cVOCs. Concentrations are an average over 6 consistent depth intervals taken between $2.9 \mathrm{~m}$ and $4.72 \mathrm{~m}$. Line indicates average total cVOCs at each sampling event given on secondary axis. Vertical range bars indicate the range of total cVOCs for all depths at that location. The range gets smaller and the average decreases at $\mathrm{SC1}$ at 286 days supporting decreases in soil cVOCs.
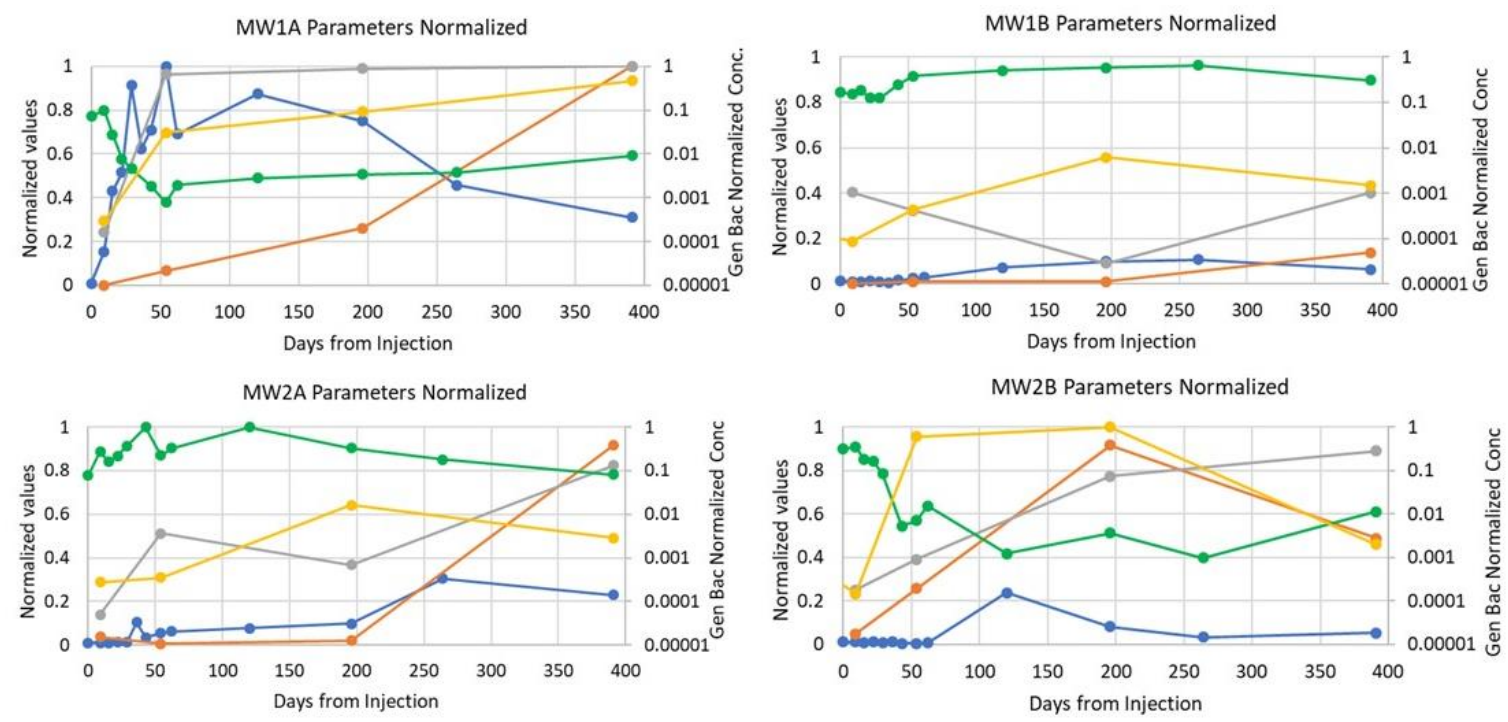

$\multimap$ Dissolved Organic Carbon $\rightarrow-$ Relative Abundance Desulfitobacterium $\rightarrow$ Relative Abundance Firmicutes $\rightarrow-G W$ total cVOCs $\rightarrow$ Conc of gen bac

Figure A.35 Monitored parameters for all wells normalized to the maximum value measured on site so each well is directly comparable. 


\section{B. Appendix B: Additional Methodology Details}

\section{Method B.1 cVOC analysis using gas chromatography}

For heavily chlorinated compounds (1,1,1-TCA, CCl4, 1,2-DCA, TCE, 1,1,2-TCA, PCE, 1,1,1,2-TeCA, 1,1,2,2-TeCA) a modified EPA Method 8021 was followed. GC vials were filled with $1 \mathrm{~mL}$ of hexane for the extraction of cVOCs. With a gastight syringe, $250 \mu \mathrm{L}$ aliquots of the collected field samples were added to the vials. Between every sample, the gastight syringe is cleaned thoroughly with isopropyl alcohol and air dried. After being vortex-mixed and allowed to equilibrate for 2 hours, the hexane containing the extracted cVOCs was separated into a secondary $2 \mathrm{~mL}$ GC vial. $1 \mu \mathrm{L}$ of extracted cVOCs in hexane was injected by the autosampler into an Agilent 7890 gas chromatograph (GC) with an electron capture detector and a DB-624 capillary column $(75 \mathrm{~m} \times 0.45 \mathrm{~mm} \times 2.55 \mu \mathrm{m})$ to analyze for chlorinated ethenes and ethanes. The conditions for GC analysis using the ECD (Modified EPA Method 8021) are as follows: A flow rate of $10 \mathrm{ml} / \mathrm{min}$ of $\mathrm{N}_{2}$ carrier gas. The oven temperature is held at $35{ }^{\circ} \mathrm{C}$ for 12 min, then a temperature ramp of $5^{\circ} \mathrm{C} / \mathrm{min}$ until it reaches $60{ }^{\circ} \mathrm{C}$ and is held for $1 \mathrm{~min}$. That is followed by another temperature ramp of $17^{\circ} \mathrm{C} / \mathrm{min}$ until it reached $200{ }^{\circ} \mathrm{C}$ and it held there for $5 \mathrm{~min}$.

Lesser chlorinated compounds (ethene, ethane, VC, 1,1-DCE, chloroethane, DCM, (t) 1,2- DCE, cis 1,2-DCE, 1,1-DCA) were analyzed in headspace samples. With a gastight syringe, $1 \mathrm{~mL}$ of collected field samples were added to $2 \mathrm{~mL} \mathrm{GC}$ vials. Vials are mixed with a vortex and let equilibrate for at least $30 \mathrm{~min}$ before $0.25 \mathrm{~mL}$ headspace samples are manually injected in the Agilent 7890 GC. Chlorinated compounds are separated using a GS-Gaspro column (30 m x $320 \mu \mathrm{m}$ I.D.) and measured with a flame ionization detector on the Agilent 7890 GC. The conditions set up on the GC with use of the FID are as follows: A flow rate of $2 \mathrm{~mL} / \mathrm{min}$ of $\mathrm{He}$ carrier gas. The oven is held at a temperature of $35{ }^{\circ} \mathrm{C}$ for $5 \mathrm{~min}$, followed by a temperature ramp of $10^{\circ} \mathrm{C} / \mathrm{min}$ until it reaches $220^{\circ} \mathrm{C}$ and is held there for $7 \mathrm{~min}$. 


\section{Method B.2 Additional details for MetaAmp analysis of Illumina Sequences}

MetaAmp (http://ebg.ucalgary.ca/metaamp) takes an input of fastq format sequence files and assembles the paired-end reads using USEARCH software package. A minimum overlap of $20 \mathrm{bp}$ and max mismatches of $4 \mathrm{bp}$ was defined. Read pairs that cannot be aligned or do not meet user-defined quality are discarded. The forward and reverse primers are then trimmed off the ends of the assembled read using Mothur. Quality filtering is performed using USEARCH to remove low-quality reads and reduce the influence of sequencing errors. The reads are then trimmed to a user-defined length of $400 \mathrm{bp}$. This length was chosen after evaluating the median sequence length after taking off technical sequences as reported in the QC of an analysis with 6 representative samples. The pooled reads are then clustered into operational taxonomic units (OTUs) using USPARSE. Using the OTU list file in Mothur, the dissimilarities among samples based on community structure and membership are calculated and ordination methods including principle coordinate analysis (PCoA) are performed to provide a simplified visualization of the differences in microbial communities between samples (Dong et al., 2017).

\section{References}

Acar, Y. B., \& Alshawabkeh, A. N. (1993). Principles of Electrokinetic Remediation. Environmental Science and Technology, 27(13), 2638-2647.

Bear, J. (1972). Dynamics of Fluids in Porous Media. New York: American Elsevier.

Dong, X., Kleiner, M., Sharp, C. E., Thorson, E., Li, C., Liu, D., \& Strous, M. (2017). Fast and simple analysis of MiSeq amplicon sequencing data with MetaAmp. Frontiers in Microbiology, 8, 1-8.

Lide, D. R. (1990). CRC Handbook of Chemistry and Physics. CRC Press, 2324.

Ola, S. A., Fadugba, O. ., \& Uduebor, M. A. (2016). Slug Tests for Determination of Hydraulic Conductivity of Contaminated Wells. Environment and Natural Resources Research, 6(2), 156.

Shackelford, C. D., \& Daniel, D. E. (1991). Diffusion in Saturated Soil . I: Background. Journal of Geotechnical Engineering, 117(3), 467-484. 
Wu, X., Alshawabkeh, A. N., Gent, D. B., Larson, S. L., \& Davis, J. L. (2007). Lactate Transport in Soil by DC Fields. Journal of Geotechnical and Geoenvironmental Engineering, 133(12), 1587-1596. 


\section{Curriculum Vitae}

Name:

Post-secondary Education and Degrees:

Honours and Awards:

Teaching

Experience

Industry

Experience
Ainsley Inglis

University of Guelph

Guelph, Ontario, Canada

2012-2016 B.Eng.

University of Western Ontario

London, Ontario, Canada

2016-2018 MESc

Geosyntec Student Paper Competition - Second Place

2018

Eric and Ruby Chung Graduate Award

Western Geotechnical Research Centre

2017

Ontario Graduate Scholarship

Western University

2017-2018

Haessler Family Engineering Scholarship

University of Guelph

2015

Professional Engineers Ontario Grand River Chapter Scholarship 2013

Linamar Engineering Entrance Scholarship

University of Guelph

2012

Teaching Assistant

Engineering Fluid Mechanics \& Engineering Statics

The University of Western Ontario

2016-2017

Master's Thesis, University of Western Ontario

Electrokinetically-enhanced emplacement of lactate in a chlorinated solvent contaminated clay site to promote

bioremediation

Remediation Education Network Internship

Field trial in partnership with Jacobs and Geosyntec Consultants 2016-2018 
Presentations and Treatment of chlorinated solvents in clay:

Publications

Pilot test of Electrokinetically-enhanced Bioremediation

Platform Presentation

RENEW Annual Meeting, Kingston ON, November 2017

Electrokinetically-Emplaced Amendments for Enhanced

Bioremediation of Chlorinated Solvents in Clay: A Pilot Field Test Poster Presentation

AGU Fall Meeting, New Orleans LA, December 2017

Electrokinetically-enhanced bioremediation of chlorinated solvents in clay: A pilot field test

Platform Presentation

Envirocon Western University, London ON, March 2018

Electrokinetically-Emplaced Amendments for Enhanced

Bioremediation of Chlorinated Solvents in Clay: A Pilot Field Test

Poster Presentation

Battelle Chlorinated Conference, Palm Springs CA, April 2018 